DUCE, Mauricio. "Reconocimientos oculares: una aproximación empírica a su funcionamiento y algunas recomendaciones para su mejora".

Polít. crim. Vol. 12, № 23 (Julio 2017), Art. 9, pp. 291-379.

[http://www.politicacriminal.cl/Vol_12/n_23/Vol12N23A9.pdf]

\title{
Los reconocimientos oculares: una aproximación empírica a su funcionamiento y algunas recomendaciones para su mejora
}

\section{Eyewitness identifications: an empirical approach to their operation and some recommendations for their improvement}

\author{
Mauricio Duce J. ${ }^{1}$ \\ Magíster en Ciencias Jurídicas Universidad de Stanford \\ Profesor Titular Facultad de Derecho Universidad Diego Portales \\ mauricio.duce@udp.cl
}

\section{Resumen}

El trabajo tiene por objeto ofrecer una imagen empírica exploratoria acerca de las prácticas de los reconocimientos oculares en el proceso penal chileno (con foco en la Región Metropolitana), teniendo como marco de fondo la incidencia de éstos podrían en la producción de decisiones erradas por parte de fiscales y jueces. Se realiza una descripción detallada de cómo son llevados adelante los procedimientos de reconocimientos y las prácticas asociadas a su uso en el sistema judicial, identificando una serie de problemas y proponiendo recomendaciones de mejora. El trabajo se basa en una investigación de corte empírico cualitativo y exploratorio basado en dos fuentes principales. La primera corresponde a una entrevista semi estructurada que fue efectuada a un total de 51 actores de la justicia penal de la Región Metropolitana. La segunda en el análisis de casos paradigmáticos de errores graves del sistema, seleccionados de la base de datos de recursos de revisión decididos por la Corte Suprema en el período 2007-2015 y por los casos del Proyecto Inocentes de la Defensoría Penal Pública.

Palabras clave: Reconocimientos oculares, condenas erróneas, sistema de justicia criminal

\begin{abstract}
The objective of this work is to offer an exploratory empirically based image about practices regarding eyewitness identification evidence in the Chilean criminal procedure (with focus on the Metropolitan Region), considering as a background the incidence of this evidence in the production of miscarriages of justice by wrong decisions from prosecutors and judges. The paper contains a detailed description about how eyewitness procedures are handled as well of the practices related to its use in the judicial system, identifying serious

\footnotetext{
${ }^{1}$ Este trabajo ha sido elaborado en el marco del proyecto Fondecyt Regular No 1150073 "Errores de la justicia penal: investigación empírica y dogmática sobre sus causas en nuestro país y recomendaciones para evitarlos"; Investigador Responsable: Mauricio Duce. El autor agradece el valioso apoyo realizado por los de los alumnos de la Facultad de Derecho de la Universidad Diego Portales que colaboraron con la transcripción de entrevistas.
} ayudantes del proyecto en distintas etapas: Eduardo Alcaíno y Ricardo Lillo. También se agradece el trabajo
\end{abstract}


DUCE, Mauricio. "Reconocimientos oculares: una aproximación empírica a su funcionamiento y algunas recomendaciones para su mejora".

problems and proposing recommendations to improve the system. The research is based on a qualitative and exploratory empirical method based in two main sources. The first one is based on semi-structured interviews made to 51 actors of the criminal justice system in the Metropolitan Region. The second, in the analysis of cases of miscarriages of justice taken from the data base of Habeas Corpus decided during years 2007-2015 by the Supreme Court and the data base of the Innocents Project from the Public Defender's Office.

Key words: Eyewitness identification, wrongful convictions, criminal justice system.

\section{Introducción.}

Los reconocimientos oculares que realizan víctimas o testigos de las personas que han participado en la comisión de un delito constituyen una evidencia de importancia en el funcionamiento concreto de los sistemas de justicia criminal contemporáneos. Esto ya que, por una parte, se trata de una herramienta investigativa de enorme valor para vincular o descartar la participación de alguien frente a la comisión de un delito ${ }^{2}$. Por la otra, una vez presentados en juicio, constituyen una evidencia que posee un enorme poder de convicción de los jueces encargados de decidir. En esta última dirección, por ejemplo, se encuentra la ya clásica afirmación del juez de la Corte Suprema de los Estados Unidos William Brennan quien señala "No hay nada más convincente que un ser vivo que sube al estrado, señala al acusado con el dedo y dice 'Es él!’"3. En forma más reciente, esta idea es expresada por un fiscal de España al ser preguntado por el diario El País acerca de si la identificación del sospechoso por parte de la víctima es suficiente para lograr una condena. Su respuesta es “Sin ninguna duda. Es la prueba reina! Se trata de lograr indicios para realizar una acusación lógica" ". Si uno revisa con detención la información disponible en la materia se encontrará con que ideas similares a estas se repiten en otros lugares y contextos ${ }^{5}$.

\footnotetext{
${ }^{2}$ No existen estadísticas claras acerca de la cantidad y frecuencia con la que se practican reconocimientos en los distintos sistemas de justicia penal a nivel comparado. Con todo, por su enorme utilidad parecieran ser una diligencia frecuente. Por ejemplo, en los Estados Unidos una encuesta realizada a organismos policiales en el año 1989 permitió estimar que en dicho año se realizaron al menos 80.000 procedimientos de reconocimientos. NATIONAL RESEARCH COUNCIL, Identifying the Culprit: Assessing Eyewitness Identification, Washington D.C.: The National Academies of Sciences, Engineering, and Medicine, 2014, p.7. ${ }^{3}$ Voto disidente William Brennan en Watkins vs. Sowders, 449 U.S. 341, 1981. Citado por LIPTAK, Adam, "34 Years Later Supreme Court Will Revisit Eyewitnesses IDs", New York Times, 22 de agosto de 2011, en: http://www.nytimes.com/2011/08/23/us/23bar.html?scp=1\&sq=\%22Perry\%20v.\%20New\%20Hampshire\%22 \&st=cse [visitado el 01.07.2016].

${ }^{4}$ El artículo de El País de España (uno de los medios escritos periodísticos de mayor reconocimiento en dicho país y a nivel internacional en idioma castellano) continúa señalando "La rutina judicial hace que los magistrados acepten como definitivos los reconocimientos visuales de las víctimas, que a veces cuentan con pruebas que los corroboran, y a veces no. "Siempre que no haya enemistad manifiesta, se aceptan porque los resultados de ADN suelen retrasarse entre un año y año y medio. Si esperáramos, la justicia se paralizaría", alegan fuentes judiciales". Véase, LUCAS, Ángeles; MARTíN-ARROYO, Javier, "El ADN llega tarde”, El País, 29 de marzo de 2014, en: http://politica.elpais.com/politica/2014/03/29/actualidad/1396115994_898988.html [visitado el 01.07.2016].

${ }^{5}$ Los ejemplos son innumerables, aquí sólo menciono uno. Se trata de un informe elaborado por las cabezas de los órganos de persecución penal de Canadá a nivel federal y local el año 2011 destinado a la prevención de condenas erróneas. Allí se afirma: "Los reconocimientos oculares de testigos son una herramienta crítica para la investigación y persecución de los criminales. Este tipo de evidencia está dentro de los testimonios más persuasivos que pueden ser ocupados en una corte". FPT HEADS OF PROSECUTIONS COMMITTEE,
} 
Polít. crim. Vol. 12, № 23 (Julio 2017), Art. 9, pp. 291-379.

[http://www.politicacriminal.cl/Vol_12/n_23/Vol12N23A9.pdf]

Estas ideas no son ajenas a nuestra realidad. En el Protocolo Interinstitucional de Reconocimiento de Imputados (en adelante "El Protocolo") desarrollado por el Ministerio Público y publicado en julio del año 2013, el Fiscal Nacional de la época afirma en la introducción del texto que, desde el punto de vista investigativo, se trata de una de las diligencias "más habituales" y de "la mayor importancia"6. En su desarrollo, el Protocolo enfatiza la idea de la importancia de esta diligencia al señalar que ella "...permite obtener información valiosa para orientar la investigación hacia un sujeto determinado."7. Junto con esto, la doctrina nacional ha reconocido la importancia de esta diligencia ${ }^{8}$, y la incipiente evidencia empírica disponible sobre el impacto de los reconocimientos en las decisiones de tribunales de juicio oral, dan cuenta de que se trata de una prueba de relevancia en la resolución de los casos ${ }^{9}$.

La habitualidad e importancia de las diligencias de reconocimiento en los sistemas de justicia criminal se explica, en definitiva, debido a que en una cantidad importante de

The Path to Justice: Preventing Wrongful Convictions, Canadá: FPT HEADS OF PROSECUTIONS COMMITTEE, 2011, p. 55.

6 MINISTERIO PÚBLICO, Protocolo Interinstitucional de Reconocimiento de Imputados, Santiago: Ministerio Público, 2013, p.3.

${ }^{7}$ MINISTERIO PÚBLICO, Protocolo Interinstitucional de Reconocimiento de Imputado, cit. nota $\mathrm{n}^{\circ}$ 6, p. 9.

${ }^{8}$ MORALES, Ana María; WELSCH, Gherman, El Reconocimiento de Imputados en Chile y a Nivel Comparado, Santiago: Fundación Paz Ciudadana, 2011, p. 5; CASTILLO, Ignacio, "Enjuiciando al Proceso Penal Chileno desde el Inocentrismo (algunos apuntes sobre la necesidad de tomarse en serio a los inocentes)", Polít. crim. Vol. 8, № 15 (2013), pp. 249-313, p. 273, SEPÚLVEDA, Verónica, "Identificación de Imputados. Condiciones de Legitimidad", Revista Razonamiento Penal, $\mathrm{N}^{\circ} 1$ (2012), pp. 9-18, p. 9, MORENO, Leonardo, "Algunas Consideraciones sobre el Funcionamiento de la Reforma Procesal Penal", en: DECAP, Mauricio; DUCE, Mauricio; MORENO, Leonardo; SÁEZ, Jorge, El Modelo Adversarial en Chile. Ponencias sobre su Implementación en la Reforma Procesal Penal, Santiago: Thomson Reuters, 2013, pp. 67-218, p. 84.

${ }^{9}$ Existen tres estudios con base empírica en el país que abordan esta materia, aún cuando todos lo hacen con un número muy acotado de casos. El primero, y más extenso de ellos, es uno que fue llevado a cabo el año 2005 que dedica una sección al análisis de 17 casos de tribunales orales en lo penal y juzgados de garantías producidos entre los años 2002 y 2005 en distintas regiones. En dicho análisis puede apreciarse la incidencia que esta actividad tiene tanto en las absoluciones como condenas de los respectivos casos. Véase: UNIVERSIDAD DE CONCEPCIÓN, Estudio reconocimiento visual errado en el proceso penal oral, Concepción: Programa de Responsabilidad Social de la Universidad de Concepción, 2005, pp. 285 (estudio en formato electrónico en poder del autor). Ver especialmente sección pp. 53-150; Un segundo estudio publicado hace un análisis de dos sentencias dictadas por tribunales de juicio oral en lo penal de la Región Metropolitana en los años 2008 y 2012 en los que se absolvió a los acusados como consecuencia de procedimientos de reconocimiento producidos por debajo de estándares mínimos de razonabilidad. Véase: SEPÚLVEDA, "Identificación de imputados", cit. nota ${ }^{\circ}$ 8; El estudio más reciente analiza en profundidad dos casos de condenas erróneas exonerados gracias a recursos de revisión acogidos por la Corte Suprema (Caso Lobos y Caso Robles) en donde un factor importante de las sentencias condenatorias se vinculó la valoración de los reconocimientos. Véase: DUCE, Mauricio, "Algunas Lecciones A Partir de Cuatro Casos de Condena de Inocentes en Chile", Revista de Derecho Universidad Católica del Norte, Año 22 n 1 (2015), pp. 149-208, especialmente 170-181; Existe un cuarto estudio de corte empírico en donde se citan cinco sentencias como fuentes de información utilizadas. Con todo, ellas no son luego objeto de análisis ya que el trabajo pone acento en la identificación de los procedimientos policiales. Véase: MERINO, Alberto; REUSE, Marcelo, "Testigos presenciales y reconocimiento de imputados en Chile. Aproximación a los procedimientos utilizados y propuestas para una mejora de prácticas", Revista de Derecho y Ciencias Penales, $\mathrm{n}^{\circ} 15$ (2010), pp. 55-83. 
DUCE, Mauricio. "Reconocimientos oculares: una aproximación empírica a su funcionamiento y algunas recomendaciones para su mejora".

delitos la forma más directa, a veces la única, de establecer responsabilidad de un autor es por medio de la identificación que realiza la víctima o el testigo que presenció el hecho. Por lo mismo, no es de esperar que en el corto plazo se trate de una diligencia que pierda relevancia a menos que operen cambios muy profundos a la dinámica de cómo se cometen e investigan los delitos en nuestras sociedades contemporáneas.

Por otra parte, la literatura comparada ha llegado a un fuerte consenso respecto a que los reconocimientos visuales son menos confiables de lo que se estima y, por lo mismo, constituyen el principal factor que explica la condena de inocentes. De esta manera, se da cuenta de los importantes riesgos que tiene para el funcionamiento del sistema de justicia criminal el uso de este tipo de diligencias ${ }^{10}$. Esta misma preocupación ha sido también manifestada por la escasa doctrina nacional que ha abordado el tema ${ }^{11}$. Es más, el propio Protocolo elaborado por el Ministerio Público ha sido justificado por la necesidad de estandarizar prácticas $^{12}$ y mejorar la calidad de los reconocimientos ${ }^{13}$. La visión crítica sobre los riesgos que representa el uso incorrecto de esta prueba ha dado lugar también a algunas iniciativas de cambio legal en Chile. Así, en enero de 2013, el Poder Ejecutivo presentó a tramitación legislativa un proyecto de ley conocido como "la reforma a la reforma" que propuso introducir un nuevo artículo 196 bis al CPP con el objeto de establecer parámetros básicos para la realización de estas diligencias frente a la percepción de problemas de legitimidad que presentaban los procedimientos a la época ${ }^{14}$. A esto se sumó la propuesta contenida en el Plan Nacional de Seguridad Pública y Prevención de la Violencia y el Delito 2014-2018 (en adelante "Plan de seguridad pública") de perfeccionar a los procedimientos de reconocimientos en diversas áreas a través de la regulación de una norma que debiera cubrir diversas áreas señaladas en el texto ${ }^{15}$.

\footnotetext{
${ }^{10}$ Estas ideas serán objeto de desarrollo más pormenorizado en la sección I de este trabajo.

${ }^{11}$ Junto con los trabajos ya citados se pueden agregar los siguientes textos: CASTILLO, "Enjuiciando al Proceso Penal Chileno desde el Inocentrismo", cit. nota n 8; MORENO, "Algunas Consideraciones Sobre el Funcionamiento de la Reforma Procesal Penal", cit. nota n ${ }^{\circ}$ 8; ALCAÍNO, Eduardo, "La Confiabilidad como Estándar para Evaluar la Calidad de los Reconocimientos de Imputados", Polít. crim. Vol. 9, № 18 (2014), pp. 564-613; DUCE, "Algunas Lecciones A Partir de Cuatro Casos", cit. nota n 9; DUCE, Mauricio, "La Condena de Inocentes en Chile: Una Aproximación Empírica a partir de los Resultados de los Recursos de Revisión Acogidos por la Corte Suprema en el período 2007-2013”. Polít. crim. Vol. 10, № 19 (2015), pp. 159-191.

${ }^{12}$ MINISTERIO PÚBLICO, Protocolo Interinstitucional de Reconocimiento de Imputados, cit. nota ${ }^{\circ}$ 6, p. 3 (esta parte corresponde a la introducción realizada por el Fiscal Nacional al documento).

${ }^{13}$ MINISTERIO PÚBLICO, Protocolo Interinstitucional de Reconocimiento de Imputados, cit. nota ${ }^{\circ}$ 6, p. 9.

${ }^{14}$ Mensaje No 502-360, Mensaje de S.E El Presidente de la República, con el que Inicia un Proyecto de Ley que Perfecciona el Sistema de Justicia Penal, 29 de enero de 2013. Dicha propuesta fue luego modificada por un conjunto de indicaciones presentadas por el propio Poder Ejecutivo al Senado el día 4 de septiembre de 2013. Véase: Mensaje no 200-361, Formula Indicación al Proyecto de Ley que Perfecciona al Sistema de Justicia Penal.

${ }^{15}$ MINISTERIO DEL INTERIOR Y SEGURIDAD PÚBLICA, Plan Nacional de Seguridad Pública y Prevención de la Violencia y el Delito: Seguridad para Todos, Santiago: Gobierno de Chile, p. 67. Disponible en http://www.seguridadpublica.gov.cl/filesapp/Libro\%20final\%20final.pdf [visitado el 01.07.2016].

El texto del Plan de seguridad pública menciona, de manera general, diversas áreas que debiera cubrir la regla en materia de reconocimientos, pero sin especificar los alcances de dichos parámetros. En su justificación también se destaca el carácter fundamental y la importancia de esta diligencia en la investigación de los delitos.
} 
Polít. crim. Vol. 12, No 23 (Julio 2017), Art. 9, pp. 291-379.

[http://www.politicacriminal.cl/Vol_12/n_23/Vol12N23A9.pdf]

En el contexto descrito, el presente trabajo tiene por objeto ofrecer una aproximación empírica actualizada y más completa que la que hoy se encuentra disponible en la literatura nacional acerca de las prácticas y usos de los reconocimientos oculares en el proceso penal nacional con foco en las prácticas de la Región Metropolitana, teniendo como marco de fondo la incidencia que éstos podrían tener en la producción de decisiones erradas por parte de nuestros fiscales y tribunales penales. Se pretende ofrecer entonces, de manera exploratoria, una descripción de cómo son llevados adelantes los procedimientos de reconocimientos y las prácticas asociadas a su uso en el sistema judicial en dicha jurisdicción, de manera de identificar problemas que permitan elaborar recomendaciones de mejora para el futuro.

Para estos efectos, el trabajo se basa en una investigación de corte empírico cualitativo y exploratorio basado en dos fuentes de información principales. La primera de ellas corresponde a una entrevista semi estructurada que fue efectuada a un total de 51 actores del sistema de justicia penal de la Región Metropolitana, incluyendo a abogados privados (4), defensores penales públicos (8), fiscales del Ministerio Público (13), jueces de garantía (8), jueces de tribunales orales en lo penal (8) y policías (Carabineros: 2 y Policías de Investigaciones de Chile: 8$)^{16}$. Junto con lo anterior, la segunda fuente estuvo constituida por el análisis en profundidad de casos paradigmáticos de condenas erróneas o de errores graves del sistema seleccionados de la base de datos de recursos de revisión decididos por la Corte Suprema en el período 2007-2015 y por los casos registrados en la página web del Proyecto Inocentes de la Defensoría Penal Pública hasta el mes de marzo de 2016.

A estas fuentes se agrega como un insumo adicional los resultados provenientes de un estudio empírico exploratorio realizado sobre la base de revisión de sentencias dictadas en el año 2015 por tres Tribunales Orales en lo Penal de la ciudad de Santiago (en adelante TOP), que fue realizado por un tesista de magíster dirigido por el autor del presente trabajo y que contó con el apoyo de este proyecto Fondecyt en su realización ${ }^{17}$. Cabe aclarar que este estudio aporta insumos complementarios que permiten fortalecer los hallazgos de la investigación principal sobre la que se sustenta este trabajo, pero no constituye la investigación misma.

Como se puede apreciar, dado el carácter exploratorio de este estudio no se pretende entregar una visión acabada y estadísticamente representativa de lo que ocurre en todo el país y ni siquiera de la Región Metropolitana. Los datos, por el contrario, me permiten construir una imagen, a modo de hipótesis de trabajo, de las prácticas en la materia. $\mathrm{Su}$

\footnotetext{
${ }^{16}$ En el anexo de este trabajo se aportarán mayores detalles acerca de las características del universo entrevistado y contenidos de la entrevista.

${ }^{17}$ Se trata de un trabajo concluido y que ya se encuentra aprobado (nota final 6,2), pero que no ha sido publicado. Véase: CATALÁN, Mario, Aproximación Empírica sobre la Realización y Valoración de la Prueba del Reconocimiento Ocular en Chile, Santiago: Trabajo final para titulación del Magíster en Derecho Penal y Procesal Penal, Universidad Diego Portales, septiembre de 2016, 124 pp., no publicado (documento electrónico en poder del autor). Este estudio revisó las primeras 200 sentencias dictadas por cada uno los TOP $\mathrm{n}^{\circ} 1, \mathrm{n}^{\circ} 2$ y n $^{\circ} 3$ de Santiago durante el año 2015. Estas representan el $47 \%$ del total de sentencias dictadas el año 2015 en dichos tribunales (600 de 1.275). Las sentencias seleccionadas para el análisis, ya que en ellas se constató que en el juicio hubo algún tipo de reconocimiento ocular, fueron finalmente 67 ( 20 del TOP n ${ }^{\circ} 1,23$ del TOP $n^{\circ} 2$ y 24 del TOP n ${ }^{\circ} 3$ ).
} 
DUCE, Mauricio. "Reconocimientos oculares: una aproximación empírica a su funcionamiento y algunas recomendaciones para su mejora".

fortaleza metodológica se sustenta en los consensos provenientes de las opiniones de informantes expertos que trabajan en el sistema desde distintos roles (testigos privilegiados de su propia realidad) y en la consistencia de dichos hallazgos con otras fuentes revisadas como lo son los casos paradigmáticos obtenidos de dos bases de datos diversas y del estudio de sentencias TOP considerado como un insumo adicional. En este contexto, el propósito de esta investigación es mejorar la calidad del conocimiento disponible a la fecha en la materia con el objeto de aproximarnos de manera sucesiva a una mejor comprensión de la realidad nacional. Con sus limitaciones metodológicas, se trata no obstante de la investigación empírica de mayor alcance disponible en el país sobre la materia. También espero contribuir a sensibilizar a nuestra comunidad jurídica sobre los problemas que el trabajo identifica y así generar el interés por desarrollar nuevas investigaciones en el área. Finalmente, espero aportar algunos elementos preliminares para la formulación de propuestas de mejoramiento en aquellas materias que he detectado el sistema presenta mayor debilidad o vulnerabilidad.

Para el cumplimiento de sus objetivos, el trabajo se organiza en tres capítulos además de esta introducción y las conclusiones. El capítulo 2 estará destinado a revisar de manera breve algunas cuestiones generales sobre los reconocimientos, tanto desde el punto de vista de la literatura legal como desde las ciencias, que permitan al lector tener una visión del "estado del arte en la materia" que permitirá comprender mejor los problemas de las prácticas identificadas en la investigación. El capítulo 3 se abocará a describir la situación chilena tanto desde el punto de vista de regulación normativa existente y del impacto que los reconocimientos tendrían en los errores del sistema. El capítulo 4 constituye el núcleo central de la investigación y presenta los principales hallazgos en materia del desarrollo de la práctica del sistema en la materia. En la sección de conclusiones (5) se formularán algunas recomendaciones destinadas a mejorar la realización de los reconocimientos en nuestro país con el propósito de disminuir los riesgos de decisiones erradas inspiradas en los mismos. Se agrega al final un breve anexo metodológico con mayores datos sobre el diseño y ejecución de las entrevistas a informantes expertos.

\section{Aspectos generales sobre los reconocimientos oculares desde el derecho y las ciencias.}

Como señalaba en la introducción, el objetivo de este capítulo será abordar algunas cuestiones preliminares con el propósito que el lector cuente con toda la información relevante a considerar para evaluar mejor la situación de nuestro país a la que me referiré en capítulos posteriores. En esta lógica, me abocaré brevemente a tres cuestiones. La primera de ella tiene que ver con aclarar bien los alcances de lo que son los procedimientos de reconocimientos. A partir de ello resumiré los principales hallazgos que se han realizado en la investigación científica acerca de la confiabilidad de los mismos. En tercer término, me referiré a la evidencia que indica que estos serían el principal factor productor de condenas erróneas en el ámbito comparado. 
Polít. crim. Vol. 12, № 23 (Julio 2017), Art. 9, pp. 291-379.

[http://www.politicacriminal.cl/Vol_12/n_23/Vol12N23A9.pdf]

\subsection{Algunas aclaraciones sobre la diversidad de procedimientos de reconocimientos.}

De manera preliminar, es necesario clarificar que cuando se hace referencia a los reconocimientos oculares se está hablando potencialmente de diversas técnicas o procedimientos a través de los cuáles quien ha sido víctima o testigo de un delito identifica a quien o quienes intervinieron en su comisión ${ }^{18}$. Se suele reconocer que existen tres procedimientos principales por medio de los cuales se realizan identificaciones de sospechosos en los sistemas de justicia criminal ${ }^{19}$, aún cuando a veces sus nombres varían un poco $^{20}$ : (1) los reconocimientos en rueda de imputados (lineup en inglés), es decir, aquellos en donde se le pide a la víctima o el testigo que observe a un número de personas presentes (por ejemplo 5 ó 6) con el objeto de identificar a o no al partícipe del delito, debiendo al menos haber un sospechoso en el conjunto de personas exhibidas; (2) los reconocimientos en ruedas o set fotográficos (photo array en inglés), es decir, aquellos en que se le exhiben a la víctima o testigo un número acotado de fotografías (por ejemplo entre 5 a 10) dentro de las cuáles al menos una corresponde a un sospechoso; y (3) las exhibiciones (showup en inglés), es decir, casos en que la policía u otra institución exhibe a la víctima o testigo a una sola persona en forma directa con el propósito de ser identificada, normalmente en contexto de una detención ${ }^{21}$.

A estos tres formatos podría agregarse un cuarto procedimiento que se asocia a los reconocimientos, pero me parece es algo distinto. Se trata de la exhibición de fotografías sin sospechoso o lo que se denomina en nuestro país como un kardex fotográfico ${ }^{22}$. Lo que caracteriza esta cuarta forma y lo diferencia de las restantes son dos elementos. El primero, es que normalmente se trata de una exhibición de una cantidad muy superior de fotografías (decenas o centenas dependiendo la base de datos disponible) en comparación con los otros procedimientos que trabajan en la lógica de exhibir un número acotado de personas. Lo segundo, probablemente lo central, es que este procedimiento se realiza sin que exista dentro de las fotografías exhibidas un sospechoso específico previamente identificado. De

\footnotetext{
${ }^{18}$ El Plan de Seguridad Pública la describe como “....aquella herramienta investigativa mediante la cual una persona que ha sido víctima o testigo de un delito identifica al autor en una rueda de personas o en un set fotográfico". Véase: MINISTERIO DEL INTERIOR Y SEGURIDAD PÚBLICA, Plan Nacional de Seguridad Pública, cit. nota ${ }^{\circ} 15$, p. 67.

${ }^{19}$ En el caso chileno véase: ALCAIINO, "La Confiabilidad como Estándar", cit. nota no 11, p. 565.

${ }^{20}$ El Protocolo del Ministerio Público también identifica estos tres tipos de procedimientos denominándolos como "Reconocimientos en rueda o línea de personas", "Reconocimientos en rueda o línea de fotografías" e "identificación o exhibición en contexto de flagrancia". Con todo, tratándose de este último se sostiene que merece un tratamiento diferenciado según tendré oportunidad de revisar más adelante. Véase, MINISTERIO PÚBLICO, Protocolo Interinstitucional de Reconocimiento de Imputados, cit. nota n ${ }^{\circ}$ 6, pp. 9, 21.

${ }^{21}$ Una encuesta realizada el año 2013 a agencias policiales en los Estados Unidos permite tener una imagen del impacto de cada uno de estos procedimientos en términos de su uso práctico. Así, los resultados muestran que un $94,1 \%$ de las agencias que respondieron utilizan los reconocimientos en ruedas fotográficas, un $61,8 \%$ las exhibiciones y un $21,4 \%$ los reconocimientos en rueda de imputados. POLICE EXECUTIVE RESEARCH FORUM, A National Survey Eyewitness Identification Procedures in Law Enforcement Agencies, Washington D.C.: National Institute of Justice, 2013, p. viii.

${ }^{22}$ También se trata de una diligencia reconocida en el Protocolo e identificada como "Reconocimiento fotográfico sin sospechoso". MINISTERIO PÚBLICO, Protocolo Interinstitucional de Reconocimiento de Imputados, cit. nota $\mathrm{n}^{\circ}$ 6, p. 23. En la encuesta que ya he citado de agencias policiales en los Estados Unidos, un $28,8 \%$ reconoce ocupar este tipo de procedimientos. POLICE EXECUTIVE RESEARCH FORUM, $A$ National Survey, cit. nota ${ }^{\circ} 21$, p. viii.
} 
DUCE, Mauricio. "Reconocimientos oculares: una aproximación empírica a su funcionamiento y algunas recomendaciones para su mejora".

esta forma, la exhibición de kardex fotográficos tiene por objetivo desplegar una línea de investigación destinada a identificar a un posible sospechoso, en tanto que los otros tres están más bien orientados a confirmar sospechas específicas que ya existen sobre una persona concreta ${ }^{23}$.

Estos procedimientos son complementados con dos tipos de acciones adicionales que suelen realizar los sistemas de justicia penal y que tienen incidencia en las diligencias de reconocimiento. La primera es la confección de los denominados "retratos hablados", es decir, una caricatura o dibujo que representa a la persona sospechosa y que se construye a partir de la descripción de la víctima o testigo. Estos retratos hablados pueden confeccionarse por un dibujante especialista o por distintos tipos de sistemas técnicos y programas computacionales ${ }^{24}$. Su uso se asimila a la exhibición de kardex sin sospechoso más que el de los procedimientos con rueda ya que permite ir a la búsqueda de personas no identificadas todavía.

La segunda acción se genera a partir de la actividad de realizar reconocimientos en las audiencias de juicio. Como lo reconocen el Protocolo y el Plan de Seguridad Pública, los reconocimientos son diligencias investigativas que per se no constituyen prueba en la medida que no sean introducidos a juicio por alguna fuente de información diversa que se presente a juicio (por ejemplo, la declaración de un testigo del procedimiento o del funcionario policial que intervino en su realización o de la propia víctima ${ }^{25}$. Esto lleva a que con alguna frecuencia en las audiencias de juicio se realice un procedimiento de reconocimiento complementario que consiste en solicitarle a la víctima o al testigo identifique en la sala de audiencia al autor o partícipe del delito. Como se puede observar, este procedimiento se asemeja más a la exhibición o showup que a las ruedas de personas o fotográficas.

Esta investigación se centra en los tres procedimientos descritos. No obstante lo anterior, también aportaré elementos de análisis sobre las otras actividades complementarias o asociadas de manera de construir un cuadro lo más completo posible de las prácticas que existen en el país en la materia.

\footnotetext{
${ }^{23}$ Cabe señalar que en las entrevistas efectuadas me pude percatar que entre los actores del sistema de justicia penal en nuestro país es frecuente utilizar la nomenclatura de "kardex" para referirse a las ruedas o set fotográficos. Para efectos de este trabajo seré estricto en el uso de la terminología que estoy proponiendo para evitar confusiones del lector.

${ }^{24}$ El Protocolo no se hace cargo de manera específica de los retratos hablados, pero a propósito de la regulación de las descripciones previas que víctimas y testigos deben realizar antes de ejecutar los procedimientos de reconocimientos, se señala que se permite la confección de uno siempre que "la descripción lo permita y exista personal calificado para ello". MINISTERIO PÚBLICO, Protocolo Interinstitucional de Reconocimiento de Imputados, cit. $\mathrm{n}^{\circ}$ 6, p. 21. En la encuesta realizada el año 2013 a las agencias policiales de los Estados Unidos, un 35,5\% señaló confeccionar retratos hablados en usando distintos tipos de formatos y tecnologías. POLICE EXECUTIVE RESEARCH FORUM, A National Survey, cit. $\mathrm{n}^{\circ} 21$, p. viii.

${ }^{25}$ MINISTERIO PÚBLICO, Protocolo Interinstitucional de Reconocimiento de Imputados, cit. $\mathrm{n}^{\circ}$ 6, p. 15 en donde se hace referencia que ésta es la forma en que ha sido concebido también por la jurisprudencia nacional, aún cuando no existen referencias específicas a ningún caso.
} 
Polít. crim. Vol. 12, № 23 (Julio 2017), Art. 9, pp. 291-379.

[http://www.politicacriminal.cl/Vol_12/n_23/Vol12N23A9.pdf]

\subsection{La confiabilidad y precisión de los reconocimientos: lo que hoy sabemos gracias a la investigación científica.}

Los reconocimientos oculares han sido objeto de estudio desde diversas disciplinas científicas con el propósito de determinar su confiabilidad ${ }^{26}$. Así, según reporta Epstein, en los últimos 30 años es posible identificar al menos 2.000 estudios publicados en revistas académicas con revisión de pares sobre la materia ${ }^{27}$. En su conjunto, estos estudios han consolidado un conocimiento que, si bien está siempre en evolución, da cuenta de un importante consenso en términos de que la confiabilidad y precisión de los reconocimientos es mucho más limitado que lo que intuitivamente se pudiera pensar, tanto en las ruedas de personas, fotografías y en las exhibiciones.

La investigación empírica disponible da cuenta que un porcentaje importante de identificaciones que se realizan son erróneas y, por lo mismo, eso lleva tanto a los órganos de persecución penal como a los tribunales a tomar decisiones equivocadas. Así, un análisis de los estudios realizados en Estados Unidos e Inglaterra, sobre la base de revisión de una cantidad significativa de procedimientos de rueda en casos reales, da cuenta de resultados muy consistentes donde en promedio en un $21 \%$ de los casos se escoge a una persona que integra la rueda en calidad de "cebo" o "relleno", es decir, que se sabe es inocente (lo que se denomina como un "falso positivo") ${ }^{28}$. Datos similares arrojan estudios que incluyen no sólo reconocimientos reales sino que también meta análisis de estudios experimentales ${ }^{29}$ En este último contexto se ha podido experimentar con la composición de ruedas donde el autor no se encuentra presente, de manera de simular lo que ocurre con muchos procedimientos en el funcionamiento real del sistema de justicia criminal. Los resultados en este escenario arrojan que en un $48 \%$ de los casos las víctimas o testigos igualmente escogen a alguien que por definición se sabe es una persona inocente ${ }^{30}$. En consecuencia, considerando que en la práctica un porcentaje de las ruedas se estructuran sin los

\footnotetext{
${ }^{26}$ Una disciplina que ha prestado especial atención a la investigación científica en esta materia es la psicología a través de diversas ramas tales como la psicología experimental, la psicología del testimonio y la piscología forense. Un resumen de los principales métodos utilizados en este tipo de investigaciones desde el punto de vista de la psicología puede revisarse en LOFTUS, Elizabeth F.; DOYLE, James M.; DYSART, Jennifer E., Eyewitness Testimony: Civil and Criminal, United States: LexisNexis, 2013, pp. 4-12. No obstante, la investigación en la materia excede al área de la psicología e incluye, entre otras disciplinas, a la investigación médica y en neurociencia.

${ }^{27}$ EPSTEIN, Jules, "Eyewitness and Erroneous Convictions: An American Conundrum", en: LUCY, Sarah, Controversies in Innocence Cases in America, England: Ashgate, 2014, p. 45, nota ${ }^{\circ} 30$.

${ }^{28}$ En estas mismas investigaciones un porcentaje promedio de $33 \%$ no escoge a un sospechoso de la rueda. Dicho comportamiento no puede estimarse como error ya que no es posible determinar si no se escogió a alguien porque el verdadero autor no estaba en la rueda o simplemente debido a que estando ahí no lo reconoció. Eliminados de la muestra los casos en donde no se escoge a nadie, el porcentaje de elección de personas inocentes (cebos o rellenos) se eleva a 33\%, es decir, uno de cada tres casos. El porcentaje promedio de elección de la persona sospechosa en estos mismos estudios es de 47\%, aún cuando eso no significa que la persona identificada sea necesariamente el verdadero autor. WELLS, Gary L.; GREATHOUSE, Sarah M.; SMALARZ, Laura, Why do motions to suppress suggestive eyewitness identifications fail?, Washington D.C.: American Psychological Association, 2012, p. 174-175.

${ }^{29}$ SIMON, Dan, In Doubt: The Psychology of the Criminal Justice Process, Cambridge: Harvard University Press, 2012, p. 53.

${ }^{30}$ SIMON, In Doubt, cit. nota n ${ }^{\circ} 29$, p. 53.
} 
DUCE, Mauricio. "Reconocimientos oculares: una aproximación empírica a su funcionamiento y algunas recomendaciones para su mejora".

verdaderos autores del delito, el margen de falsos positivos (escoger a un inocente) es aún superior al porcentaje que señalaba en forma previa.

Si bien existe algún debate respecto a los alcances de los resultados de diversos estudios científicos que analizan la confiabilidad de los procedimientos de exhibiciones (showup), el mínimo común denominador sería que éstos no presentan mejores tasas de acierto que los procedimientos en ruedas y potencialmente mayores tasas de error tratándose la identificación de inocentes ${ }^{31}$.

Un dato interesante que las investigaciones arrojan es que la precisión de los reconocimientos está correlacionada sólo de manera moderada o tenue con el grado de confianza o certeza que manifieste la persona al momento de reconocer. Incluso, en algunos tipos de casos, la correlación puede llegar a ser sumamente débil o inexistente ${ }^{32}$. Es decir, aún cuando las personas señalen poseer niveles de seguridad del $100 \%$ o cercanos a tal porcentaje, se pueden igualmente cometer errores en la identificación ${ }^{33}$. Desde la otra perspectiva, la certeza manifestada por la persona que reconoce no asegura la precisión del reconocimiento.

Las razones que explican la confiabilidad limitada de los reconocimientos, en sus diversos formatos, han sido objeto también de una importante cantidad de estudios científicos. En esta dirección, las investigaciones en el área muestran que las dificultades de se producen en diversos niveles. En lo que constituye el nivel central, el corazón de un proceso de identificación descansa en la forma que trabaja nuestro cerebro, particularmente respecto a cómo opera el sistema de percepción visual y la memoria de los seres humanos. La evidencia científica disponible da cuenta de que todos los seres humanos tenemos limitaciones relevantes, tanto en los procesos de percepción visual como de ejercicio de nuestra memoria, que impactan en nuestra capacidad para efectuar reconocimientos con

${ }^{31}$ En esta dirección, haciendo un llamado al desarrollo de mayor investigación en el punto, GOODSELL, Charles A.; WETMORE, Stacy A.; NEUSCHATZ, Jeffrey S.; GRONLUND, Scott D., "Showups", en: CUTLER, Brian L. (Ed.), Reform of Eyewitness Identification Procedures, Washington D.C.: American Psychological Association, 2013, pp. 45-63, especialmente pp. 51-54. En una visión más crítica Loftus, Doyle y Dysart, quienes sostienen que los showup hacen más probable la identificación errada de inocentes sospechosos. LOFTUS/DOYLE/DYSART, Eyewitness Testimony, cit. nota n 26, p. 87.

32 Citando diversos meta estudios sobre la material, SMALARZ, Laura; WELLS, Gary L., "Eyewitness Certainty as System Variable", en: CUTLER, Brian L. (Ed.), Reform of Eyewitness Identification Procedures, Washington D.C.: American Psychological Association, 2013, pp. 161-177, p. 165. En el mismo sentido, HARRIS, David, Failed Evidence, New York: New York University Press, 2012, pp. 53-55. Diges y PérezMata, hablan de correlación casi inexistente en la generalidad de los casos, aún cuando mejora de manera positiva cuando las condiciones de visión de la cara fueron óptimas. DIGES, Margarita; PÉREZ-MATA, Nieves, "La Prueba de Identificación desde la Psicología del Testimonio", en: DIGES, Margarita et al., Identificaciones fotográficas y en rueda de reconocimientos, Madrid: Marcial Pons, 2014, pp. 33-85, p.73.

${ }^{33}$ Una de las razones que explica este fenómeno es que la confianza o certeza de los reconocimientos puede ser influida por la presencia de un conjunto de factores externos que se no se relacionan con la precisión del mismo. Estos factores pueden originarse tanto en aspectos que están fuera del control del sistema de justicia criminal como provenir del propio trabajo del sistema. SMALARZ/WELLS, "Eyewitness Certainty", cit. nota $\mathrm{n}^{\circ}$ 32, p. 173-174. Un análisis en detalle sobre la evidencia existente respecto a la influencia sobre la confianza puede verse en: BRADFIELD, Amy; PAVLETIC, Afton, "Eyewitness Confidence Malleability", en: CUTLER, Brian L. (Ed.), Conviction of the Innocent: Lessons from Psychological Research, Washington D.C.: American Psychological Association, 2012, pp. 149-165. 
Polít. crim. Vol. 12, № 23 (Julio 2017), Art. 9, pp. 291-379.

[http://www.politicacriminal.cl/Vol_12/n_23/Vol12N23A9.pdf]

precisión $^{34}$. Por lo mismo, los problemas de confiabilidad de los reconocimientos se producen aún en contextos en los que se está en presencia de víctimas y testigos honestos y de buena fe que pretenden colaborar de la mejor forma que pueden con una investigación criminal.

La información científica disponible contradice nociones intuitivas que le asignan mucha mayor confiabilidad y precisión al funcionamiento de nuestro cerebro que la que tiene en realidad, especialmente cuando estamos en presencia de los procesos mentales requeridos por los reconocimientos. No puedo detenerme en el detalle de los distintos aspectos que están involucradas en estos procesos y que han sido descritos por la literatura, por lo que sólo menciono algunas cuestiones específicas que me parece son esclarecedoras para el lector menos informado. Por ejemplo, en materia de funcionamiento de la memoria, una creencia fuertemente instalada es que ella opera como una "máquina fotográfica" o una "cámara de video" que registra de manera precisa los eventos que percibimos y que luego puede ser revisada en el futuro ${ }^{35}$. Comprendido así el trabajo de la memoria, es fácil considerar que los reconocimientos son el producto de un ejercicio relativamente sencillo de comparación entre imágenes precisas almacenadas e imágenes actualmente percibidas y, por lo mismo, que debiera ser bastante confiable respecto a sus resultados ${ }^{36}$. Lamentablemente, nuestra memoria no funciona de esta forma y eso se refleja en las estadísticas de error que ya he citado en forma precedente. La ciencia ha esclarecido que la memoria opera más bien como un trabajo de reconstrucción de imágenes a partir de información normalmente limitada, en muchos casos imprecisa y que es complementada con nuestras propias creencias y conjeturas. En este sentido, como afirma un experto en neurociencia, este trabajo "Se parece más a pintar que a fotografiar" "37. Agregaría que se trata de una pintura que se realiza sobre la base de un recuerdo del objeto retratado y no su percepción actual $^{38}$.

En concreto, la literatura científica ha descrito que el trabajo de la memoria para los efectos de llevar a cabo reconocimientos se desarrolla en tres procesos diversos: la codificación (que corresponde al registro y retención inicial de los datos de un rostro percibido), el almacenamiento (en el que se guardan o almacenan a más largo aliento los datos codificados), y la recuperación (proceso en que se accede a la información almacenada de

\footnotetext{
${ }^{34}$ La literatura que desarrolla estos temas es extensa y su revisión en detalle me aleja de los objetivos de este trabajo. En esta dirección recomiendo la revisión de dos trabajos que contienen en mi opinión un excelente resumen del estado del arte en la materia desde el punto de vista de la ciencia: NATIONAL RESEARCH COUNCIL, Identifying the Culprit, cit. nota $\mathrm{n}^{\circ}$ 2, pp. 31-48. En castellano recomiendo MAZZONI, Giuliana, ¿Se Puede Creer a un Testigo? El Testimonio y las Trampas de la Memoria, Madrid: Editorial Trotta, 2010, especialmente pp. 15-61.

${ }^{35}$ Los resultados de un estudio realizados en los Estados Unidos el año 2011 arroja que el 63\% de las personas concuerdan con esta noción. Estudio citado en: EPSTEIN, "Eyewitness and Erroneous Convictions", cit. nota $\mathrm{n}^{\circ} 27$, p. 47.

${ }^{36}$ Un fiscal entrevistado refleja con claridad esta forma de comprender el funcionamiento de la memoria al señalar "Las víctimas son capaces de reconocer porque las caras siempre quedan grabadas en su memoria". Entrevista Fiscal $n^{\circ} 11,7$ de enero de 2016.

${ }^{37}$ SIGMAN, Mariano, La Vida Secreta de la Mente, Buenos Aires: Debate, 2016, p. 98.

${ }^{38}$ Una analogía similar es realizada por Simon quien señala que la memoria se parece a "un mecanismo de grabación defectuoso que gradualmente hace decaer y confunde imágenes, mezcla imágenes de distintas fuentes y altera imágenes bajo presión." SIMON, In Doubt, cit. nota n ${ }^{\circ} 29$, p. 80.
} 
DUCE, Mauricio. "Reconocimientos oculares: una aproximación empírica a su funcionamiento y algunas recomendaciones para su mejora".

manera consciente y ella es usada para tomar decisiones y guiar comportamientos) ${ }^{39}$. Esta misma literatura ha descrito que la memoria puede verse afectada o distorsionada en cada uno de los procesos por diversos factores que tienen un impacto directo en la precisión de un reconocimiento posterior. Se trata de un listado complejo de variables que suelen agruparse bajo dos categorías: variables o indicadores de estimación (o del incidente); y, variables o indicadores del sistema ${ }^{40}$. Las primeras incluyen factores asociados a las circunstancias bajo las que se produjo la observación de la persona a identificar (por ejemplo, la distancia y luminosidad que había al momento de la percepción, el tiempo de duración de la percepción, la presencia o no de un arma, el nivel de estrés de la persona, entre otras). Se trata de factores "dados" en el caso, respecto de los cuáles el sistema de justicia criminal no tiene mucha injerencia salvo identificarlos al momento de valorar la confiabilidad y precisión del reconocimiento respectivo.

Las variables del sistema, en cambio, se refieren al conjunto de factores asociados a la manera en que se llevan adelante los procesos de reconocimiento que habitualmente practican las agencias de persecución penal (por ejemplo, el lenguaje usado por los funcionarios que administran el procedimiento; la entrega de información previa o posterior a la persona que realiza el reconocimiento por parte de los funcionarios; la forma en que se diseñan y componen las ruedas; entre otras) ${ }^{41}$. Se trata en este caso de factores que sí dependen del sistema de justicia criminal y que, por lo mismo, pueden ser controlados a través de regulaciones y prácticas que minimicen su interferencia con los procesos de memoria de la persona que debe practicar el reconocimiento ${ }^{42}$.

39 NATIONAL RESEARCH COUNCIL, Identifying the Culprit, cit. nota $\mathrm{n}^{\circ} 2$, pp. 40-45, LOFTUS/DOYLE/DYSART, Eyewitness Testimony, cit. nota n² 26, pp. 14-15; SIMON, In Doubt, cit. nota ${ }^{\circ}$ 29 pp. 55-58.

40 Se trata de una categorización propuesta en el año 1978 por Gary Wells, uno de los principales investigadores en el área, y que luego ha sido adoptada por la mayoría de los especialistas en consideración a su utilidad para ordenar el estudio, análisis y desarrollo de políticas públicas en la materia. LOFTUS/DOYLE/DYSART, Eyewitness Testimony, cit. nota ${ }^{\circ} 26$, p. 16; EPSTEIN, "Eyewitness and Erroneous Convictions", cit. nota n 27, p. 46; SIMON, In Doubt, cit. nota n 29, p. 265, nota 22.

${ }^{41}$ La literatura que desarrolla con detalle estas categorías es bastante extensa en el ámbito comparado. Un texto que recomiendo revisar que da cuenta del estado actual del debate en materia científica de manera clara y acotada en el tema es: SIMON, In Doubt, cit. nota $\mathrm{n}^{\circ}$ 29, pp. 50-89; LOFTUS/DOYLE/DYSART, Eyewitness Testimony, cit. nota $\mathrm{n}^{\circ}$ 26, pp. 66-110. En castellano puede verse: MANZANERO, Antonio; GONZÁLEZ, José Luis, Avances en Psicología del Testimonio, Santiago: Ediciones Jurídicas de Santiago, 2013, pp. 83-131; DIGES/PÉREZ-MATA, "La Prueba de Identificación”, cit. nota n 32, pp. 33-85. A nivel nacional se trata de uno de los pocos temas en donde existen diversos textos que explican los problemas que tienen los procesos de reconocimientos. Especialmente recomiendo revisar: MERINO/REUSE, "Testigos Presenciales y Reconocimiento de Imputados en Chile", cit. nota ${ }^{\circ}$ 9; SEPÚLVEDA, "Identificación de Imputados", cit. nota n ${ }^{\circ}$, pp. 9 y 13; MORALES/WELSH, "El Reconocimiento de Imputados en Chile y a Nivel Comparado", cit. nota n 8, pp. 11-12; CASTILLO, "Enjuiciando al Proceso Penal Chileno desde el Inocentrismo”, cit. nota n 8, pp. 272-287; DUCE, Mauricio, “¿Debiéramos Preocuparnos de la Condena de Inocentes en Chile? Antecedentes Comparados y Locales para el Debate", Revista Ius et Praxis, Año 19 n $^{\circ} 1$ (2013), pp. 77 - 138, pp. 91-98; MORENO, "Algunas Consideraciones Sobre el Funcionamiento de la Reforma Procesal Penal", cit. nota n 8, pp. 84-99. ALCAÍNO, "La Confiabilidad como Estándar", cit. nota $\mathrm{n}^{\circ} 11$.

42 Debido a esto, en el análisis que realizaré en los capítulos posteriores volveré sobre algunos de estos factores para analizar la corrección de las prácticas nacionales identificadas en esta investigación. 
Polít. crim. Vol. 12, No 23 (Julio 2017), Art. 9, pp. 291-379.

[http://www.politicacriminal.cl/Vol_12/n_23/Vol12N23A9.pdf]

Como se puede apreciar, hoy existe un cuerpo de información proveniente desde la ciencia que ha consolidado un conocimiento bastante preciso y valioso sobre el funcionamiento de nuestro cerebro (percepción visual y memoria) que es central para comprender y valorar a los reconocimientos. Como veremos más adelante, un problema en nuestro país ha sido que el sistema legal ha prestado bastante poca atención a estos desarrollos, de manera que muchas de sus decisiones están informadas más por la comprensión intuitiva de cómo se producen los reconocimientos que el acervo de conocimiento consensuado en la ciencia sobre la materia.

\subsection{El impacto de los reconocimientos en la condena de inocentes en el ámbito comparado: algunos casos paradigmáticos.}

Uno de los impactos básicos que tendría la inadecuada valoración que se hace de la confiabilidad y precisión de los reconocimientos en los sistemas de justicia criminal es aumentar la posibilidad de errores en sus decisiones. En este sentido, el error más obvio sería el condenar a un inocente como consecuencia de un reconocimiento equivocado pero valorado por el tribunal como confiable (un falso positivo como he señalado anteriormente). Desafortunadamente, no todos los países tienen registros de la frecuencia con la que ocurren condenas erróneas y menos sobre los factores o causas que las explican, lo que imposibilita tener una visión comparada completa y exhaustiva del problema. No obstante, me parece ilustrativo revisar de manera breve la evidencia disponible en los Estados Unidos en donde existe información de calidad en la materia.

Estados Unidos es por lejos el país que cuenta con mayor información empírica acerca de la condena de inocentes y de los factores que explican dichos casos. Registros elaborados por diferentes instituciones en dicho país dan cuenta de manera consistente que la errada identificación ocular de los acusados es el principal o, al menos, uno de los principales factores que explican las condenas de inocentes. Así, en la base de datos que dispone el Innocence Project al mes de marzo de 2016, de un total de 325 exoneraciones obtenidas por la institución a partir del año 1989, en un 72\% de los casos (235) hubo un problema con el reconocimiento del condenado, siendo por lejos el factor de mayor incidencia (el segundo es el uso inadecuado de pericias con un $47 \%)^{43}$. Por su parte, en la base de datos del National Registry of Exonerations (NRE), el cual -a diferencia del Innocence Projectregistra todos los casos en los que se ha producido una exoneración en los Estados Unidos desde el año 1989 (1753 a marzo de 2016) en el 32\% de ellos (556) hubo un problema con la identificación, constituyendo la tercera causal en importancia ${ }^{44}$.

\footnotetext{
${ }^{43}$ Véase: http://www.innocenceproject.org/causes-wrongful-conviction [visitado el 01.07.2016].

44 Véase: http://www.law.umich.edu/special/exoneration/Pages/ExonerationsContribFactorsByCrime.aspx [visitado el 01.07.2016]. El factor con mayor incidencia en esos casos son la acusación o declaración falsa de testigos $(56 \%)$ y el mal comportamiento de autoridades estatales $(47 \%)$. Las diferencias porcentuales con la base del Innocent Project se explica por los distintos tipos de casos cubiertos por ellas. Dado a que esta última contabiliza los casos de exoneración fundamentalmente obtenida gracias al uso de evidencia de ADN exculpatoria, tiende a presentar una mayor concentración de delitos sexuales en donde es posible encontrar esa evidencia y en los que aparentemente es más frecuente el error de identificación ocular. Si en la base de datos del NRE se estudian los factores sólo en los delitos de asalto sexual (284) los problemas de identificación ocular están presentes en el $70 \%$ de los casos.
} 
DUCE, Mauricio. "Reconocimientos oculares: una aproximación empírica a su funcionamiento y algunas recomendaciones para su mejora".

Investigaciones más recientes en los Estados Unidos han llamado la atención acerca de los sesgos que produce identificar los factores que contribuyen a los errores del sistema a partir de bases de datos que solo contienen los casos de exoneraciones. Es por eso que se han diseñado nuevas metodologías que consultan bases de datos más amplias que incluyen también otros denominados "near misses" (que podría ser traducido como casos cerca de o casi de errores). Estos estudios dan cuenta que no existen diferencias significativas entre ambos tipos de casos respecto a la incidencia de los reconocimientos errados, lo que da cuenta que efectivamente se trata de un problema de magnitud en dicho país ${ }^{45}$.

Un estudio realizado por Brandon Garret a los primeros 250 casos que forman parte de la base de datos del Innocence Project da cuenta de dos datos que me parecen de interés mencionar para comprender la dinámica de cómo los reconocimientos contribuyen a condenas de inocentes. El primero, es que se identifica que un $36 \%$ de los casos hubo múltiples identificaciones erradas del mismo condenado, llegando en muchos casos a tres, cuatro y cinco identificaciones ${ }^{46}$. Se trata de un dato que muestra lo delicado que es el uso de esta evidencia ya que incluso en casos en los que intuitivamente uno pensaría la posibilidad de error es baja debido a la multiplicidad de identificaciones, igualmente se pueden cometer errores. El segundo dato, es que un 33\% del total de casos de condenas de inocentes que contaron con reconocimientos errados, ellos fueron producto de un procedimiento de showup o exhibición, lo que da cuenta de la relevancia e impacto que tiene esta modalidad en el funcionamiento del sistema ${ }^{47}$.

En varios otros países el uso de los reconocimientos es objeto de una preocupación importante por el impacto que ellos tienen en la condena de inocentes, aún cuando no cuentan con investigación de corte empírico de la calidad disponible en los de Estados Unidos, por lo mismo no me detengo en ellos con el afán de no extender en demasía esta sección $^{48}$.

${ }^{45}$ GOULD, Jon, et al., "Predicting Erroneous Convictions", Iowa Law Review, Vol. 99 (2014), pp.471-522. De acuerdo a este estudio, en la muestra de casos de inocentes condenados los errores de identificación ocular se presentaron en un $82 \%$ en tanto que en los "near misses" en un $75 \%$. Los autores concluyen que no se trata de una diferencia estadísticamente significativa. La diferencia relevante que sí identifican es que en los casos de condenas erróneas hay mayor presencia de errores honestos o genuinos (no intencionales) y, en cambio, en los "near misses" hay mucho mayor presencia de errores intencionales. La explicación que otorgan a este fenómeno es que los errores intencionales son más susceptibles de ser descubiertos por el sistema y, por lo mismo, existe la posibilidad que se puedan descubrir y evitarse la condena como ocurre en los casos estudiados en esta categoría.

${ }^{46}$ GARRETT, Brandon L., Convicting the Innocent: Where Criminal Prosecutions Go Wrong, United States: Harvard University Press, 2011, p. 50.

${ }^{47}$ GARRETT, Convicting the Innocent, cit. nota ${ }^{\circ} 46$, p. 55.

${ }^{48}$ Por ejemplo, en Reino Unido, véase: NAUGHTON, Michael, The Innocent and the Criminal Justice System. A Sociological Analysis of Miscarriages of Justice, United Kingdom: Palgrave Macmillan, 2013, pp. 82-91. En Canadá, véase: FPT HEADS OF PROSECUTIONS COMMITTEE, The Path to Justice, cit. nota $\mathrm{n}^{\circ} 5$ y FPT HEADS OF PROSECUTIONS COMMITTEE WORKING GROUP, Report on the Prevention of Miscarriages of Justice, Canadá: Department of Justice, 2004. En España la doctrina también ha manifestado su preocupación e incluso ha sistematizado algunos de los casos de condenas erróneas. Véase: SOLETO, Helena, La Identificación del Imputado, Valencia: Tirant lo Blanch, 2009, pp. 191-193. Con todo, esto no se ha traducido en una respuesta legislativa o jurisprudencial clara. Sobre la creciente consideración de los problemas derivados de reconocimiento pero la falta de consistencia en la respuesta jurisprudencial de los diversos tribunales, véase: OBACH, Jorge; GARCÍA, María Carmen, "Praxis Judicial sobre los 
Polít. crim. Vol. 12, № 23 (Julio 2017), Art. 9, pp. 291-379.

[http://www.politicacriminal.cl/Vol_12/n_23/Vol12N23A9.pdf]

\section{Los reconocimientos en Chile: aspectos normativos y su impacto en los errores del sistema.}

Como adelanté en la introducción, el objetivo de este capítulo es entregar información básica sobre los reconocimientos en Chile que permiten luego comprender los alcances de las prácticas que describiré en el siguiente. Para ello, dedicaré una primera sección para revisar de manera crítica la situación normativa de los reconocimientos en nustro país. Luego, en una segunda sección, me referiré a la información empírica disponible acerca del impacto que tendría los reconocimientos en los errores del sistema de justicia penal en nuestro país.

\subsection{Aspectos normativos.}

A diferencia de lo que ocurría con el antiguo Código de Procedimiento Penal de $1906^{49}$, nuestra actual legislación no contempla reglas que de manera explícita regulen la práctica de las diligencias de reconocimiento. Esto obedece a la idea de nuestro legislador de desformalizar la etapa de investigación y evitar la excesiva regulación y, en consecuencia, la rigidez de las actividades de investigación que contenía el Código que se derogaba. En esta lógica, el Código Procesal Penal (en adelante el CPP) le entrega espacios importantes de discrecionalidad y flexibilidad a los fiscales para decidir el tipo de diligencias que son necesarias para llevar adelante una investigación exitosa ${ }^{50}$. Por lo mismo, la inexistencia de reglas específicas no es sinónimo de que el Ministerio Público y las policías no cuenten con facultades legales para llevar adelante procedimientos de reconocimientos, sino simplemente que la ley no fija parámetros específicos para su realización.

En este contexto, las facultades legales para realizar reconocimientos han sido construidas a partir de la interpretación de normas generales que regulan la etapa de investigación. En particular, el artículo 180 del CPP que permite a los fiscales realizar por sí mismos o encomendar a las policías cualquier diligencia de investigación "que consideraren conducentes al esclarecimiento de los hechos." ${ }^{.51}$.

No obstante lo anterior, con el tiempo se ha ido avanzando en una regulación de estos procedimientos a nivel de protocolos, inicialmente desarrollados por las policías y hoy a nivel interinstitucional.

Reconocimientos de Identidad", en: DIGES, Margarita et al., Identificaciones Fotográficas y en Rueda de Reconocimientos, Buenos Aires: Marcial Pons, 2014, pp. 87-115. Otro ejemplo se da en Alemania. En dicho país la preocupación por el impacto de los reconocimientos en la condena de inocentes es de antigua data y puede verse recogida en la doctrina hace más de cincuenta años. En esta dirección, Hirschberg analiza varios casos de connotación en el ámbito comparado y otros producidos en Alemania. Véase: HIRSCHBERG, Max, La Sentencia Errónea en el Proceso Penal, Trad. BANZHAF, Tomas A., Buenos Aires: Ediciones Jurídicas Europa-América, 1969, pp. 44-61, (publicación original en alemán en el año 1960).

${ }^{49}$ Este cuerpo legal contenía un conjunto de disposiciones referidas a los reconocimientos a propósito de las reglas del sumario o etapa de investigación, entendiéndola como una diligencia judicial destinada a esclarecer la “identificación del delincuente". Véase Libro II, Primera parte, Título VII, artículos 342 a 346.

${ }^{50}$ Sobre el carácter desformalizado y flexible de la etapa de investigación en el CPP puede verse: DUCE, Mauricio; RIEGO, Cristián, Proceso Penal, Santiago: Editorial Jurídica de Chile, 2007, pp. 121-125.

${ }^{51}$ En esta dirección: SEPÚLVEDA, "Identificación de imputados", cit. nota $n^{\circ}$ 8, p. 13. 
DUCE, Mauricio. "Reconocimientos oculares: una aproximación empírica a su funcionamiento y algunas recomendaciones para su mejora".

\subsubsection{El desarrollo de una normativa a nivel de protocolos.}

La inexistencia de reglas uniformes en materia de reconocimientos oculares generó una práctica que comenzó a ser objeto de críticas y debates a propósito de caso en los que quedó en evidencia los procedimientos habían sido llevados adelante en forma problemática. Merino y Reuse dan cuenta de un conjunto diverso de de publicaciones aparecidas en diversos medios de prensa entre los años 2008 y 2009 que instalan una crítica importante acerca de los procedimientos realizados y los resultados obtenidos. ${ }^{52}$ Especialmente ilustradora es una noticia aparecida en El Mercurio a fines del año 2009 (no citada por Merino y Reuse) en la que se señala "La falta de un protocolo que regule la forma en que las policías y/o los fiscales realicen rondas de reconocimientos, a través de rueda de presos o examen fotográfico de supuestos autores de delitos, provoca graves errores en la identificación de los supuestos culpables." $" 53$.

Esta crítica se vio respaldada por la escasa investigación empírica disponible a la época en la materia. Así, el Estudio Universidad de Concepción del año 2005, identifica serios problemas de estandarización en la realización de estas diligencias ${ }^{54}$. El estudio de Merino y Reuse, por su parte, concluye sobre la extrema variabilidad de los procedimientos utilizados, incluso al interior de una misma unidad policial ${ }^{55}$. Esto lleva a concluir a sus autores que, tratándose de reconocimiento en Chile (al menos en la zona sur del país), "No existen procedimientos estandarizados, ni tampoco métodos claramente definidos a partir de sus objetivos y etapas" $"$.

Este escenario motivó a la adopción de diversos protocolos al interior de nuestras agencias de persecución penal destinados a ofrecer un marco más claro para la práctica de esta diligencia. La primera institución en avanzar fue Carabineros, a través de un instrumento elaborado por el Departamento OS-9 denominado "Manual sobre Normas Básicas para la Identificación de Imputados de Delitos a Través del reconocimiento Fotográfico y en Rueda de Personas" $" 57$. En dicho documento se reconoce la necesidad de contar con procedimientos que tengan pasos metodológicos claros y definidos para otorgarle validez y confiabilidad a

\footnotetext{
${ }^{52}$ Se trata de diez noticias aparecidas entre el mes de abril de 2008 y julio de 2009 en La Tercera, El Mercurio, El Mostrador, La Nación, The Clinic y Las Últimas Noticias, entre otros. MERINO/REUSE, "Testigos Presenciales y Reconocimiento de Imputados en Chile", cit. nota n 9, pp. 63-64.

53 "Falta de regulación provoca graves fallas en el reconocimiento de autores de delitos", El Mercurio, 22 de noviembre de 2009, C16, en: http://diario.elmercurio.com/detalle/index.asp?id=\{37a9ca9f-db1b-43f1-97ad31663c4ae368\} [visitado el 01.07.2016].

${ }^{54}$ Véase: UNIVERSIDAD DE CONCEPCIÓN, Estudio reconocimiento visual errado en el proceso penal oral, cit. nota $\mathrm{n}^{\circ}$ 9, pp. 50- 153. En la encuesta existen varios resultados de interés. Así, el 38,1\% estimó que la primera causal de los reconocimientos errados era la falta de rigurosidad de los procedimientos policiales (p. 199).

${ }^{55}$ MERINO/REUSE, “Testigos Presenciales y Reconocimiento de Imputados en Chile”, cit. nota n 9, pp. 5583. Ver especialmente páginas 65 a 69.

${ }^{56}$ MERINO/REUSE, "Testigos Presenciales y Reconocimiento de Imputados en Chile", cit. nota n ${ }^{\circ}$ 9, p. 70 .

${ }^{57}$ CARABINEROS DE CHILE, Manual sobre Normas Básicas para la Identificación de Imputados de Delitos a través del Reconocimiento Fotográfico y la Rueda de Personas, Santiago: Carabineros de Chile, 2009. pp. 18.
} 
Polít. crim. Vol. 12, № 23 (Julio 2017), Art. 9, pp. 291-379.

[http://www.politicacriminal.cl/Vol_12/n_23/Vol12N23A9.pdf]

los resultados ${ }^{58}$. La Policía de Investigaciones (PDI) también desarrolló un protocolo contenido en un documento denominado "Cartilla Instructiva sobre el Reconocimiento de Personas" en el mes de octubre de $2010^{59}$.

Desde el Ministerio Público también se dieron los primeros pasos por regular de manera algo más precisa las diligencias de reconocimientos. La Fiscalía Regional Metropolitana Oriente fue quien lideró dicho proceso al establecer a finales del año 2009 una mesa técnica destinada a regular un protocolo en la materia que finalmente fue adoptado, con acuerdo con las policías, en julio del año $2010^{60}$. En forma paralela, la Fiscalía Nacional encargó a la Fundación Paz Ciudadana un estudio sobre buenas prácticas a nivel internacional con el objetivo de desarrollar guías y protocolos de actuación, documento que fue dado a conocer en julio de $2011^{61}$.

No obstante estos avances, ellos al parecer no fueron suficientes para cambiar de manera significativa las prácticas instaladas. Se trata de un punto en el cual existe consenso entre los diversos autores que escribieron sobre el tema en la época ${ }^{62}$. Incluso alguno señaló que "la situación en Chile no podría ser peor" derivada de la falta de regulación legal, débil preocupación del Ministerio Público por regularla, y la forma en que eran llevados los reconocimientos en la práctica por las policías ${ }^{63}$.

En este contexto y asumiendo el diagnóstico existente en la materia, el Ministerio Público concluye el proceso de reglamentación de las diligencias de reconocimientos por medio de la dictación del Protocolo Interinstitucional el año 2013, que vino a reemplazar toda la regulación que se había elaborado a la fecha.

\footnotetext{
${ }^{58}$ También se identifica que en caso que no se sigan pasos metodológicamente fundados se corre el riesgo de incriminar a inocentes. Véase: CARABINEROS DE CHILE, Manual sobre Normas Básicas, cit. nota $\mathrm{n}^{\circ} 57$, p. 1.

59 POLICIA DE INVESTIGACIONES DE CHILE, Orden General $n^{o} 2287$ del Director General de la Policía de Investigaciones de Chile, Aprueba Cartilla Instructiva para el Reconocimiento de Personas, Santiago, Policía de Investigaciones de Chile, 2010.

${ }^{60}$ Véase: FISCALIA REGIONAL METROPOLITANA ORIENTE, Oficio 098-2010 del Fiscal Regional Xavier Armendáriz, Procedimiento de Reconocimiento de Imputados, Santiago: Fiscalía Regional Metropolitana Oriente, 2010. Contribuyó a que dicho instructivo viera la luz la ocurrencia en la zona oriente de Santiago de un caso grave de error en la identificación de un imputado inocente que generó bastante publicidad, debates y cuestionamientos en los medios de comunicación de la época. Este caso fue el conocido como el "violador de Ñuñoa" o "violador de la bicicleta". Véase, Caso Violador: El Juez Pide al Fiscal Nacional Revisar Procedimientos, El Mercurio, 23 de junio de 2010 en: http://diario.elmercurio.com/2010/06/23/nacional/_portada/noticias/0286FB04-1FC6-4D63-A82477CEC20E7244.htm?id=\%7b0286FB04-1FC6-4D63-A824-77CEC20E7244\%7d [visitado el 18.03.2016]. Se trata de un caso que ha tenido repercusión hasta la fecha, dada la presentación de una demanda civil en el año 2015 para obtener reparación por los perjuicios sufridos como consecuencia de la errónea imputación realizada en contra del demandante.

${ }^{61}$ Se trata del estudio ya citado de Morales y Welsh, véase: MORALES/WELSH, "El reconocimiento de imputados en Chile y a nivel comparado", cit. nota $\mathrm{n}^{\circ} 8$.

62 En este sentido, véase: LIBEDINSKY, Sofía, "Exigencias para un Adecuado Reconocimiento de Imputados", Revista 93, No 6 año 2 (2001), pp. 30-35, p. 34; DUCE, “¿Debiéramos Preocuparnos de la Condena de Inocentes en Chile? cit. nota $n^{\circ} 41$; SEPÚLVEDA, "Identificación de imputados", cit. nota $n^{\circ} 8$.

${ }^{63}$ CASTILLO, "Enjuiciando al Proceso Penal Chileno desde el Inocentrismo”, cit. nota n 8, pp. 275-276.
} 
DUCE, Mauricio. "Reconocimientos oculares: una aproximación empírica a su funcionamiento y algunas recomendaciones para su mejora".

3.1.2. El Protocolo Interinstitucional del año 2013: contenidos básicos y avances.

Como señala el Fiscal Nacional de la época en la introducción del Protocolo, éste constituye un esfuerzo de carácter interinstitucional destinado a "homogeneizar la forma de realizar la diligencia y fijar estándares mínimos de calidad" ${ }^{\text {, }}$. Para ello, se formó una mesa de trabajo en la que participaron policías de diversas unidades de Carabineros y la PDI, además de integrantes del Ministerio Público que coordinaron el trabajo. Dentro de los insumos utilizados, se consideró el informe elaborado por Fundación Paz Ciudadana el año 2011 y los protocolos existentes a la fecha en la materia ${ }^{65}$.

Es interesante acotar que el Protocolo se define como un conjunto de reglas que pretenden fijar un estándar mínimo de trabajo, por lo tanto, no impide el desarrollo de prácticas que superen los mínimos fijados ${ }^{66}$.

A la luz de estos objetivos y filosofía, el Protocolo se organiza en dos partes principales. El capítulo II se destina a lo que se denomina en el texto como "actuaciones previas a la realización de la diligencia" ${ }^{\text {}}$. Los puntos más relevantes contenidos en esta parte son tres en mi opinión. Lo primero es que el texto destaca que la realización de esta diligencia requiere previa instrucción del fiscal ya que se trata de una actividad que no forma parte de las facultades de actuación autónoma de las policías ${ }^{68}$. En segundo término, se establece la necesidad que antes de la diligencia se debe constar con una descripción previa de la víctima o testigo con el propósito de verificar si la persona está en condiciones de realizar un reconocimiento ${ }^{69}$. En tercer término, se excluye de la regulación las actividades de identificación realizadas en contextos de detención por flagrancia ya que se considera que su función es diferente a la de las diligencias de reconocimiento ${ }^{70}$. Junto con estas materias, se analizan cuestiones como los derechos de las víctimas, el origen de las fotografías a utilizar en las ruedas fotográficas, las reglas que rigen la participación del defensor en la diligencia y cuestiones vinculadas a la frecuencia, oportunidad y lugar de su realización.

El capítulo III está destinado a regular los estándares mínimos de realización de la diligencia y, por lo mismo, constituye la parte central del documento ${ }^{71}$. Su estructura se divide en tres secciones. La primera de ellas está destinada a fijar reglas comunes para todo tipo de procedimientos, incluyendo aspectos tales como la necesidad de contar con

\footnotetext{
${ }^{64}$ MINISTERIO PÚBLICO, Protocolo Interinstitucional de Reconocimiento de Imputados, cit. nota $n^{\circ}$ 6, p. 4

${ }^{65}$ Una descripción con más detalles de esto puede verse en: MINISTERIO PÚBLICO, Protocolo Interinstitucional de Reconocimiento de Imputados, cit. nota $\mathrm{n}^{\circ}$ 6, pp. 3-4.

${ }^{66}$ MINISTERIO PÚBLICO, Protocolo Interinstitucional de Reconocimiento de Imputados, cit. nota $\mathrm{n}^{\circ} 6, \mathrm{p}$. 10.

${ }^{67}$ MINISTERIO PÚBLICO, Protocolo Interinstitucional de Reconocimiento de Imputados, cit. nota $\mathrm{n}^{\circ} 6$, pp. 13-18.

${ }^{68}$ MINISTERIO PÚBLICO, Protocolo Interinstitucional de Reconocimiento de Imputados, cit. nota $\mathrm{n}^{\circ}$ 6, $\mathrm{p}$. 13.

${ }^{69}$ MINISTERIO PÚBLICO, Protocolo Interinstitucional de Reconocimiento de Imputados, cit. nota ${ }^{\circ}$ 6, $\mathrm{p}$. 14.

${ }^{70}$ MINISTERIO PÚBLICO, Protocolo Interinstitucional de Reconocimiento de Imputados, cit. nota $\mathrm{n}^{\circ}$ 6, pp. 17-18.

${ }^{71}$ MINISTERIO PÚBLICO, Protocolo Interinstitucional de Reconocimiento de Imputados, cit. nota ${ }^{\circ}$ 6, pp. 21-27.
} 
Polít. crim. Vol. 12, No 23 (Julio 2017), Art. 9, pp. 291-379.

[http://www.politicacriminal.cl/Vol_12/n_23/Vol12N23A9.pdf]

descripción previa; que sea una diligencia individual, es decir, de a una víctima o testigo a la vez; las obligaciones de los funcionarios a cargo de su realización; las instrucciones previas que deben darse a la víctima o testigo; su continuidad; y su registro ${ }^{72}$. La segunda parte está destinada a regular los reconocimientos fotográficos. En ella se distingue entre reconocimientos sin sospechoso (exhibición de kardex) y con sospechoso (rueda de

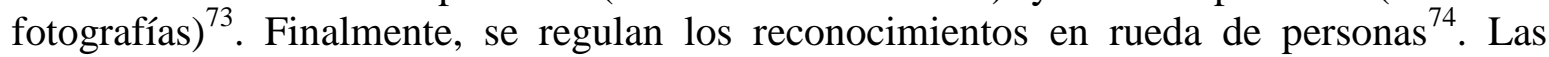
reglas principales en ambos tipos de reconocimientos están centradas en la manera de conformar las ruedas y exhibirlas, la participación de múltiples víctimas y de los defensores en su desarrollo, entre otras.

El documento concluye incorporando un acta tipo para procedimientos de reconocimientos. Se trata de formato que contiene los aspectos básicos regulados en las secciones previas. En todo caso, es un modelo para un acta escrita en consistencia con las reglas de registro especificadas en el desarrollo del Protocolo ${ }^{75}$.

Me parece que el Protocolo constituye un avance significativo en un contexto donde hasta ese momento la regulación de esta diligencia se encontraba dispersa en diversos instrumentos, elaborados por distintas instituciones, y que no eran del todo consistentes entre sí. Por otra parte, se valora que su elaboración se produzca en un momento en que la falta de homogeneidad de prácticas era identificada como un problema en nuestro país. El Protocolo, por lo tanto, parece apuntar a un objetivo correcto. Estimo también que la pretensión de instalar estándares mínimos de funcionamiento, pero sin clausurar la posibilidad del desarrollo de prácticas de mejor calidad a nivel local, es adecuada debido a la posibilidad de mejorar en forma continua procesos de trabajo a la luz de nuevos aportes desde la ciencia y la experiencia comparada.

En su contenido también aparecen algunas cuestiones positivas a destacar, especialmente aquellas que recogen las recomendaciones que provienen de la información científica para la construcción de procedimientos más confiables. Sin hacer una revisión exhaustiva de todos los componentes, destaco la importancia que se le asigna a la descripción previa la que resulta clave para luego configurar ruedas de fotografías o de personas que aseguren confiabilidad en el reconocimiento ${ }^{76}$. También destaco la regulación que realiza el

\footnotetext{
${ }^{72}$ MINISTERIO PÚBLICO, Protocolo Interinstitucional de Reconocimiento de Imputados, cit. nota $\mathrm{n}^{\circ} 6$, pp. 21-23.

${ }^{73}$ MINISTERIO PÚBLICO, Protocolo Interinstitucional de Reconocimiento de Imputados, cit. nota $\mathrm{n}^{\circ}$ 6, $\mathrm{pp}$. 23-25.

${ }^{74}$ MINISTERIO PÚBLICO, Protocolo Interinstitucional de Reconocimiento de Imputados, cit. nota $\mathrm{n}^{\circ}$ 6, pp. 26-27.

${ }^{75}$ MINISTERIO PÚBLICO, Protocolo Interinstitucional de Reconocimiento de Imputados, cit. nota $\mathrm{n}^{\circ}$ 6, pp. 31-34.

${ }^{76}$ Se trata de un tema abordado en el Protocolo en sus secciones II.3 y III.1.1. Un aspecto central de los reconocimientos en ruedas fotográficas o de personas es que sus integrantes deben tener un aspecto similar de manera de poder efectivamente verificar que la víctima o testigo está en condiciones de identificar al autor producto de un ejercicio de reconocimiento y no de descarte o conjeturas por parecido físico de una sola persona. Sin una descripción previa es imposible realizar la selección de "cebos" o "rellenos" adecuados a este objetivo. Evidencia reciente sugiere que a mayor similitud de los integrantes de una rueda se reduce el porcentaje de identificación errado, aún cuando también en forma algo menos marcada los porcentajes de acierto. Véase: CLARK, Steven, RUSH, Ryan A.; MORELAND, Molly B., "Constructing the Lineup: Law,
} 
DUCE, Mauricio. "Reconocimientos oculares: una aproximación empírica a su funcionamiento y algunas recomendaciones para su mejora".

documento sobre las instrucciones previas a las víctimas y testigos, especialmente aquella referida a la necesidad de advertir que el sospechoso podría o no estar en las fotografías o personas que se le exhibirán ${ }^{77}$. Otro aspecto positivo, que complementa al tema de las descripciones previas, es la regulación acerca de las características que deben tener los rellenos o cebos que las integran ${ }^{78}$. Finalmente, también valoro el énfasis que realiza el Protocolo de confeccionar un registro de la diligencia y sus resultados ${ }^{79}$.

\subsubsection{El Protocolo Interinstitucional del año 2013: aspectos problemáticos.}

No obstante los importantes avances que representa el Protocolo, es necesario referirse algunos límites y problemas en sus contenidos. A nivel de límites, resulta evidente que por su naturaleza y rango normativo, el Protocolo más que a una norma imperativa es una recomendación de buenas prácticas. Esto tiene dos consecuencias de importancia. La primera es que no es exigible el cumplimiento adecuado de todos los estándares fijados. La segunda, es que frente a casos de incumplimiento en principio no hay consecuencias claras. La suma de estos dos aspectos plantea dudas sobre las posibilidades de que un instrumento de esta naturaleza pueda incidir de manera significativa en el cambio de prácticas. Como se puede observar, esta no se trata de una crítica a los contenidos sino más bien a que el peso normativo que tiene este instrumento en principio no asegura el cumplimiento de los objetivos que se ha planteado ${ }^{80}$.

Más allá de esta cuestión general, varios de los contenidos del Protocolo son problemáticos. Nuevamente, no me detengo en detalle en todos los aspectos criticables sino que identifico aquellos que podrían generar mayores dificultades debido a que desconocen las recomendaciones que provienen de la investigación científica en la materia ${ }^{81}$.

Una primera cuestión problemática es que el Protocolo excluye de regulación a las exhibiciones en contexto de flagrancia (showup). En efecto, sobre este punto se señala que no se está en presencia de un reconocimiento propiamente tal y, por lo mismo, no se rige

Reform, Theory and Data, en: CUTLER, Brian L. (Ed.), Reform of Eyewitness Identification Procedures, Washington D.C.: American Psychological Association, 2013, pp. 87-112.

${ }^{77}$ Se trata de una material regulada en la sección III.1.4. El texto señala expresamente "Es imprescindible que la víctima y/o testigo sean advertidos previamente que él o los sospechosos del hecho investigado pueden estar o no incluidos en los cuadernillos de fotografías que se le presentan o en la rueda de personas que se le exhiba." MINISTERIO PÚBLICO, Protocolo Interinstitucional de Reconocimiento de Imputados, cit. nota $n^{\circ}$ 6, p. 22. Existe un acuerdo importante en la literatura científica sobre la materia que la inclusión de una advertencia de este tipo reduce de manera significativamente estadística los errores en la identificación. Entre otros, véase: STEBLAY, Nancy K., "Lineup Instructions", en: CUTLER, Brian L. (Ed.), Reform of Eyewitness Identification Procedures, Washington D.C.: American Psychological Association, 2013, pp. 6586; GARRETT, Convicting the Innocent, cit. nota $n^{\circ} 46$, p. 58-62.

${ }^{78}$ Véase secciones III.2.2.1 referidas a las ruedas fotográficas y III.3.2 tratándose de las ruedas de personas. MINISTERIO PÚBLICO, Protocolo Interinstitucional de Reconocimientos de Imputados, cit. nota $\mathrm{n}^{\circ} 6$.

${ }^{79}$ Véase secciones III.1.6 contenida en las reglas comunes; III.2.2.6 acerca de los reconocimientos en ruedas fotográficas; y pp. 31 a 33 en donde se contiene un acta tipo de registro. MINISTERIO PÚBLICO, Protocolo Interinstitucional de Reconocimientos de Imputados, cit. nota $n^{\circ} 6$.

${ }^{80}$ Alcaino se manifiesta en esta dirección al sostener la necesidad de regular legalmente los estándares básicos. Ver: ALCAÍNO, "La Confiabilidad como Estándar”, cit. nota n 11, p. 594.

${ }^{81}$ Algunas críticas, aún cuando con menor desarrollo, pueden ver en el texto de Duce: DUCE, "Algunas Lecciones A Partir de Cuatro Casos", cit. nota n 9, pp. 149-208. 
Polít. crim. Vol. 12, No 23 (Julio 2017), Art. 9, pp. 291-379.

[http://www.politicacriminal.cl/Vol_12/n_23/Vol12N23A9.pdf]

por estos estándares ${ }^{82}$. Como contrapartida, ya señalé que la evidencia científica disponible indica que este tipo de reconocimientos presenta serios problemas de confiabilidad y, además, la experiencia comparada muestra que se trata de un procedimiento utilizado de manera habitual. La consecuencia de ambas cuestiones es que las exhibiciones son una diligencia de investigación que aumenta la probabilidad de condena de inocentes si es que no se realizan con mucho cuidado y bajo ciertos parámetros estrictos que eviten al máximo los altos niveles de sugestividad inherentes a la misma ${ }^{83}$. Me parece se trata de un riesgo que se agrava en el caso chileno debido a la noción extendida de flagrancia regulada en nuestro CPP, la cual incorporaría algunas situaciones conocidas por la doctrina como de "cuasiflagrancia", "flagrancia ficta" o "flagrancia extendida",84. Por si esto fuera poco, el legislador ha ampliado en el tiempo el alcance de las causales por medio de diversas reformas al $\mathrm{CPP}^{85}$. La última de ellas, realizada el año 2008, estableció como marco temporal de inmediatez hasta doce horas después de cometido un delito ${ }^{86}$. Esto quiere decir que en el contexto del procedimiento de detención por flagrancia por algunas causales del artículo 130 del CPP (las letras d, e y f), las policías podrían, en principio, realizar exhibiciones y no reconocimientos en ruedas en procedimientos realizados muchas horas después de cometido un delito.

Un segundo aspecto problemático se refiere a la regulación de los funcionarios que intervienen en el desarrollo de la diligencia. La literatura científica en la materia señala que si el administrador del procedimiento conoce quien es el sospechoso del delito que integra la rueda de personas o fotografías, aumenta la probabilidad de que el reconocimiento no se base sólo en la memoria del testigo. El riesgo es que intencionadamente o -incluso más común y frecuente- sin intención, el administrador del procedimiento comunique al testigo pistas para la selección del sospechoso. Esto se traduce en que cuando el administrador conoce la identidad del sospechoso el testigo tiene mayor probabilidad de escogerlo independiente de su verdadera culpabilidad ${ }^{87}$. Por lo mismo, la recomendación básica formulada a nivel comparado es que para evitar este riesgo los procedimientos se deben realizar con sistemas de doble ciego, es decir, en donde el administrador desconozca al

\footnotetext{
${ }^{82}$ Sección II.9. MINISTERIO PÚBLICO, Protocolo Interinstitucional de Reconocimientos de Imputados, cit. nota ${ }^{\circ}$ 6, pp. 17-18. Con todo, el Protocolo entrega libertad al fiscal en estos casos de practicar diligencias de reconocimiento fotográfico o en rueda de personas.

${ }^{83}$ Una explicación del problema de sugestividad de las exhibiciones, manifestando su preocupación por el impacto de las mismas en la condena de inocentes por su uso contexto de flagrancia, véase en: ALCAÍNO, "La Confiabilidad como Estándar", cit. nota n 11, pp. 595-599.

${ }^{84}$ Se trata fundamentalmente de las causales reguladas en las letras c), d), e) y f) del artículo 130 del CPP, que van más allá de la situación natural de la persona que está cometiendo el delito o lo acabare de cometer. En esta dirección véase: DURÁN, Rodrigo, Medidas Cautelares Personales en el Proceso Penal, 3era Edición, Santiago: Librotecnia, 2011, pp. 177-181.

${ }^{85}$ Una visión crítica de este régimen amplio, aún antes de la reforma del 2008, puede verse en: CISTERNA, Adolfo, La Detención por Flagrancia en el Nuevo Código Procesal Penal, Santiago: Librotecnia, 2004, pp. 17-86. La última de estas reformas fue introducida por la ley $\mathrm{n}^{\circ} 20.931$ publicada en el Diario Oficial el 5 de julio de 2016 por la cual se reguló una nueva causal de flagrancia al artículo 130 agregando un literal f.

${ }^{86}$ Reforma introducida por la ley $n^{\circ} 20.253$ publicada en el Diario Oficial el 14 de marzo de 2008.

${ }^{87}$ En detalle sobre la investigación en este punto AUSTIN, Jacqueline et al., "Double-blind Lineup Administration: Effects of Administrator Knowledge on Eyewitness Decisions en: CUTLER, Brian L. (Ed.), Reform of Eyewitness Identification Procedures, Washington D.C.: American Psychological Association, 2013, pp. 139-160.
} 
DUCE, Mauricio. "Reconocimientos oculares: una aproximación empírica a su funcionamiento y algunas recomendaciones para su mejora".

sospechoso o a través de sistemas computacionales que reduzcan o eliminen el contacto entre los administradores y los testigos ${ }^{88}$. Este problema es reconocido por el Protocolo, pero el estándar establecido no es satisfactorio y abre un enorme espacio a prácticas problemáticas. En efecto, este establece un conjunto de reglas que están destinadas a evitar que los funcionarios sugieran o transmitan información a las víctimas o testigos que puedan afectar la confiabilidad de su reconocimiento, mostrando así que el problema descrito por la literatura científica es conocido y se considera como uno relevante ${ }^{89}$. Con todo, al momento de hacerse cargo de la recomendación de establecer un sistema de doble ciego, lo plantea como un procedimiento ideal, pero no obligatorio ${ }^{90}$.

Un tercer problema relevante en mi opinión se refiere al sistema de registro regulado en el Protocolo. Se trata de un tema en extremo sensible ya que para poder realizar un control mínimo a la calidad y confiabilidad de los reconocimientos se requiere contar con información bastante precisa y detallada acerca de cómo estos fueron llevados adelante. En esta dirección, una de las recomendaciones más fuertes a nivel comparado es precisamente la necesidad de mantener un registro completo del procedimiento, preferiblemente de carácter audiovisual, que permita contar con las imágenes utilizadas, las instrucciones dadas por el administrador, las elecciones y otras afirmaciones realizadas por el testigo, el tiempo de respuesta del testigo, y el medioambiente general en el que se desarrolló el procedimiento, entre otras ${ }^{91}$. El Protocolo nuevamente reconoce esta necesidad, pero desarrolla un sistema de registro que no parece satisfacer el estándar de información básico y, por lo mismo, arriesga que el control de calidad del mismo sea poco certero. En efecto, el documento exige la confección de un acta o registro pensado fundamentalmente en un formato escrito. Si bien la regulación del registro exige se consigne información relevante, se trata de aspectos parciales y limitados ${ }^{92}$. Por ejemplo, un acta de este tipo no recoge el

${ }^{88}$ GARRETT, Convicting the Innocent, cit. nota ${ }^{\circ} 46$, pp. 80-83; WELLS, Gary; QUINLIVAN, Deah, "Suggestive Eyewitness Identification Procedures and the Supreme Court's Reliability Test in Light of Eyewitness Science: 30 Years Later”, Law and Human Behavior, Vol. 33, N 1 (2009), pp 1-24, p. 8.

${ }^{89}$ En las reglas comunes a los reconocimientos en rueda se contemplan diversas recomendaciones en esta línea. Por ejemplo, la sección III.1.3 señala que los funcionarios deben actuar "respetando de manera irrestricta el principio de objetividad" (p. 22). Además, les exige ocupar un lenguaje (verbal o no verbal) que "elimine toda posibilidad de inducción" (p. 22) y "cualquier sesgo subjetivo cuyo fin sea orientar la diligencia en un sentido determinado" (p. 22). En la sección III.1.4 se señala que durante la diligencia los funcionarios deben permanecer en silencio y estarán impedidos de "realizar comentarios o cualquier otro tipo de gesto, a fin de evitar inducir, sugestionar o confundir."

${ }^{90}$ La sección II.1.3 señala sobre este punto que "Idealmente la diligencia de reconocimiento deberá ser realizada por un funcionario policial que no haya participado en las fases previas de investigación de los hechos". MINISTERIO PÚBLICO, Protocolo Interinstitucional de Reconocimiento de Imputados, cit. nota ${ }^{\circ}$ 6, p. 22.

${ }^{91}$ SIMON, In Doubt, cit. nota ${ }^{\circ} 29$, pp. 84-85.

${ }^{92}$ La sección III.1.6 señala que "Una vez concluida la diligencia se levantará acta o registro de la misma, que deberá ser firmada por la víctima y/o testigo que concurrió." Agrega más adelante que "El registro deberá contener la identidad de todos los sujetos que formaron parte de la rueda o el set fotográfico y el orden en que fueron presentados a la víctima y/o testigo. Además, deberá dejarse constancia de las consideraciones que se tuvieron en cuenta para incorporar al sospechoso a la rueda o set fotográfico respectivo" (p. 23). En sus anexos, se contempla un acta de reconocimiento tipo para ser llenada (pp. 31-34) que da cuenta que se está pensando fundamentalmente en un sistema de registro escrito y con información más limitada en relación a la considerada como óptima. MINISTERIO PÚBLICO, Protocolo Interinstitucional de Reconocimiento de Imputados, cit. nota $\mathrm{n}^{\circ} 6$. 
Polít. crim. Vol. 12, No 23 (Julio 2017), Art. 9, pp. 291-379.

[http://www.politicacriminal.cl/Vol_12/n_23/Vol12N23A9.pdf]

lenguaje detallado utilizado por los funcionarios o los testigos y víctimas que reconocen, el que puede arrojar pistas claves para evaluar la calidad del procedimiento. Tampoco registra el tipo de interacciones que se produjeron durante y con posterioridad al procedimiento que, por ejemplo, descarten la sugestividad del mismo o el reforzamiento a una elección realizada con dudas. No permite, por otra parte, registrar los tiempos de respuestas del testigo o víctima que son fundamentales para evaluar la confiabilidad del reconocimiento, entre otros elementos. En definitiva, la falta de exigencia de un registro de mayor calidad y completitud deja abierta la puerta que prácticas inadecuadas de reconocimiento sobrevivan frente a la imposibilidad de controlarlas.

Junto con estos tres problemas, que me parecen estructurales de la regulación contenida en el Protocolo, hay un conjunto de otras cuestiones de menor alcance que podrían ser criticadas desde el punto de vista del conocimiento científico acumulado. Dentro de ellas, el Protocolo permite que una misma persona sea exhibida en varias ocasiones (potencialmente en formatos distintos) a la víctima o testigo ${ }^{93}$, con lo cual se genera un riesgo que los reconocimientos posteriores no sean de la persona que originalmente cometió el delito sino de una que sino producto de la familiaridad adquirida con ese rostro exhibido en forma previa, tal como lo describe la literatura especializada ${ }^{94}$. Esta misma literatura enseña que para medir la confiabilidad del reconocimiento lo relevante es indagar la calidad del primero de éstos ya que ello puede determinar completamente los procedimientos posteriores $^{95}$.

El Protocolo también establece que, como parte de los procedimientos de reconocimientos, el fiscal ordene la confección de retratos hablados ${ }^{96}$, a pesar que la evidencia científica indica se trata de una diligencia que arroja resultados de baja calidad y que incluso podría

\footnotetext{
${ }^{93}$ En la sección II.8 se establece que "no existe obstáculo para que en relación a una misma víctima y/o un mismo testigo, esta diligencia investigativa sea realizada más de una vez..." (p.17). Esto se complementa cuando en la sección III.2.2.5 sobre exhibiciones fotográficas se permite que al finalizar la diligencia "se pueda mostrar más de una fotografía simultáneamente" (p. 25) Esta segunda regla agrega un problema adicional como lo es el permitir que la identificación se realice por comparación y conjeturas y no como un ejercicio de memoria propio de las actividades de reconocimiento visual. MINISTERIO PÚBLICO, Protocolo Interinstitucional de Reconocimiento de Imputados, cit. $\mathrm{n}^{\circ} 6$.

${ }^{94} \mathrm{La}$ investigación demuestra, además, que presentaciones múltiples de una persona inocente aumentan la probabilidad que el testigo lo identifique erróneamente. ZIMMERMAN, David M.; AUSTIN, Jacqueline L.; KOVERA, Margaret Bull, "Suggestive Eyewitness Identification Procedures", en: CUTLER, Brian L. (Ed.), Conviction of the Innocent: Lessons from Psychological Research, Washington D.C.: American Psychological Association, 2012, pp. 125-148, pp.140-141; LAMPINEN, James et al., The Psychology of Eyewitness Identification (Essays in Cognitive Psychology), New York: Taylor and Francis Group, 2012, pp. 159-161.

95 Los reconocimientos sucesivos en el tiempo producen serios problemas de confiabilidad en reconocimientos posteriores, los que pueden obedecer a que la persona identifica a quien ya reconoció y no al autor del delito. En detalle sobre los problemas de procedimientos sucesivos véase: SIMON, In Doubt, cit. nota $\mathrm{n}^{\circ} 29$, pp. 66-68. En la misma dirección y refiriéndose específicamente al impacto del reconocimiento fotográfico inicial Manzanero y González señalan "Las investigaciones sobre Memoria de los Testigos nos indican que mostrar las fotografías al testigo podría estar viciando todo el procedimiento de identificación, ya que en la rueda en vivo podría estar señalando a la persona de la fotografía y no al autor del delito". MANZANERO/GONZÁLEZ, Avances en Psicología del Testimonio, cit. nota n 41, p. 94.

${ }^{96}$ La sección III.1.1 permite que el fiscal orden su confección "siempre que la descripción lo permita y exista personal calificado para ello" (p. 21).
} 
DUCE, Mauricio. "Reconocimientos oculares: una aproximación empírica a su funcionamiento y algunas recomendaciones para su mejora".

afectar la confiabilidad de identificaciones posteriores en rueda de fotografías o personas ${ }^{97}$. Por lo mismo, la recomendación básica es evitar su uso ${ }^{98}$. Finalmente, el Protocolo contempla la posibilidad de agregar un reconocimiento de voz en las ruedas de personas a petición de la víctima o testigo, tema que no aparece regulado con claridad en otras partes $^{99}$. Junto con la falta de regulación clara de las hipótesis en que debiera utilizarse este procedimiento y de la forma en que debiera ejecutarse, la evidencia también indica que se trata de procedimientos de baja confiabilidad. En efecto, la investigación demuestra que la capacidad de reconocer una voz escuchada por una única vez y por un período breve no excede del $50 \%$ de acierto ${ }^{100}$.

Como se puede apreciar, a pesar de los evidentes avances que ha supuesto la dictación del Protocolo, todavía hay mucho que mejorar a nivel de diseño de procedimientos para asegurar la confiabilidad de esta diligencia, objetivo explícitamente perseguido por esta regulación. En esta dirección este instrumento recoge sólo en parte las recomendaciones que provienen de la literatura científica, abriendo un campo enorme a prácticas que podrían deteriorar completamente la calidad y confiabilidad de estas diligencias.

\subsection{Los reconocimientos y su impacto en errores del sistema en Chile.}

Antes de abocarme a la descripción de las prácticas existentes me parece necesario referirme, en forma breve, a la evidencia disponible en Chile sobre el impacto que tendrían los reconocimientos en la producción de errores del sistema de justicia penal. Como se puede intuir, se trata de una materia que no ha sido objeto de investigación empírica sistemática, por lo que la evidencia es escasa. No obstante, existen dos fuentes que permiten construir una primera imagen con base empírica sobre el tema.

En primer lugar, se puede recurrir a la base de sentencias dictadas por la Corte Suprema acogiendo recursos o acciones de revisión ${ }^{101}$. Se trata de casos en que el máximo tribunal se ha pronunciado específicamente sobre la inocencia de personas que habían sido condenadas en forma previa, de manera tal que si en dichas condenas se fundaron, al menos en parte, en reconocimientos oculares de las víctimas o testigos, se está frente a un impacto significativo. Un trabajo publicado el año 2015 realizó un análisis de todos los casos de revisión producidos en el contexto del funcionamiento del sistema procesal penal acusatorio entre los años 2007 a 2013. Allí se identificó que de un total de 470 recursos

\footnotetext{
${ }^{97}$ LOFTUS/DOYLE/DYSART, Eyewitness Testimony, cit. nota n ${ }^{\circ}$ 26, pp. 84-85, SIMON, In Doubt, cit. nota $\mathrm{n}^{\circ} 29$, pp. 64-65. Este autor cita experimentos que dan cuenta que los retratos hablados pueden contaminar la memoria; LAMPINEN, The Psychology of Eyewitness Identification, cit. nota ${ }^{\circ}$ 94, pp. 134-138.

${ }^{98}$ SIMON, In Doubt, cit. nota n ${ }^{\circ} 29$, p. 83.

${ }^{99}$ Sección III.3.3. MINISTERIO PÚBLICO, Protocolo Interinstitucional de Reconocimiento de Imputados, cit. nota $\mathrm{n}^{\circ} 6$, p. 27.

100 MANZANERO/GONZÁLEZ, Avances en Psicología del Testimonio, cit. nota n 41, p. 105. Esta investigación da cuenta que el factor central para identificar voces es la familiaridad que se tenga con ellas.

${ }^{101}$ Se trata de un mecanismo procesal que permite rever sentencias condenatorias firmes en hipótesis reguladas en el artículo 473 del CPP. Una visión general de este mecanismo puede verse en HORVITZ, María Inés; LÓPEZ, Julián, Derecho Procesal Penal Chileno. Tomo II, Santiago: Editorial Jurídica de Chile, 2004, pp. $447-457$
} 
Polít. crim. Vol. 12, № 23 (Julio 2017), Art. 9, pp. 291-379.

[http://www.politicacriminal.cl/Vol_12/n_23/Vol12N23A9.pdf]

presentados, la Corte Suprema acogió 44 revisiones ${ }^{102}$. Dicha información ha sido complementada con el análisis de los casos de los años 2014-2015 realizado para efectos de esta investigación. En este período se presentaron 99 recursos de revisión y tres fueron $\operatorname{acogidos}^{103}$. En consecuencia, en el período comprendido entre los años 2007 y 2015 hubo un total de 47 condenas erróneas en Chile acreditadas por la Corte Suprema. El análisis de estos casos indica que en dos de ellos hubo reconocimientos oculares que contribuyeron a la condena de un inocente ${ }^{104}$. Se trata de los casos de Pedro Lobos ${ }^{105}$ y de Julio Robles ${ }^{106}$, los que han sido objeto de análisis detallado en otro trabajo ya publicado y sobre los que volveré en la próxima sección ${ }^{107}$.

Una segunda fuente se encuentra en los casos registrados por el Proyecto Inocentes llevado adelante por la Defensoría Penal Pública, desde el año 2013. Según lo que señala su página web, el proyecto pretende sensibilizar a la sociedad acerca de la posibilidad de que el sistema de justicia penal cometa errores por medio de la identificación y documentación de casos en que ello ha ocurrido ${ }^{108}$. Para el cumplimiento de este objetivo, el proyecto selecciona casos paradigmáticos de personas que han sufrido las consecuencias de una persecución penal en la que han existido errores de diversa índole que si hubieran sido

${ }^{102}$ DUCE, “Algunas Lecciones a Partir de Cuatro Casos”, cit. nota n 9, pp. 159-191, especialmente p. 166.

${ }^{103}$ Datos de los años 2014 y 2015 fueron obtenidos en la Dirección de Estudios, Análisis y Evaluación de la Corte Suprema, quien me proporcionó una planilla Excel con el listado completo de casos en el período. Dicho documento se encuentra en formato electrónico en poder del autor.

${ }^{104}$ En principio se trataría de una cifra muy por debajo de lo que arroja la evidencia disponible en los Estados Unidos que ya he citado. Me parece que esto se explica fundamentalmente en que esta base de datos abarca sólo de una pequeña porción de los casos en que es posible pensar el sistema incurre en errores importantes. Por de pronto, el foco en estos casos deja fuera todo tipo de hipótesis en donde los errores se producen sin condena. Además, quedan fuera los casos en que se puede haber condenado a una persona erróneamente pero ella no ha podido ejercer una acción de este tipo. En esta misma dirección, existe un acuerdo importante en la literatura comparada de entender que los casos de exoneración formal son sólo la punta del iceberg de un problema mucho mayor. Esto debido a que existen muchos casos de condenas erróneas que no llegan a estas instancias formales por diversos motivos o barreras de acceso. FINDLEY, Keith, "Adversarial Inquisitions: Rethinking the Search for the Truth", New York Law School Law Review, Vol. 56 (2011-2012), pp. 912-941, p. 918.

${ }^{105}$ Corte Suprema de Chile, Recurso de Revisión, Sentencia del 22 de febrero de 2012, Causa Rol n 12018 2011. Revisión acogida con unanimidad por la Corte Suprema. Lobos fue condenado el día 22 de febrero de 2008 por el $5^{\circ}$ Tribunal Oral en lo Penal de Santiago como autor de tres delitos de robo con intimidación a la pena de 10 años y un día de presidio mayor en su grado medio más la inhabilitación absoluta perpetua para cargos y oficios públicos y derechos políticos y la de inhabilitación absoluta para profesiones titulares durante el plazo de duración de la condena. Esta decisión le permitió obtener su libertad, habiendo cumplido más de tres años de la condena impuesta.

${ }^{106}$ Corte Suprema de Chile, Recurso de Revisión, Sentencia del 14 de enero de 2014, Causa Rol nº 11.109 2013. Revisión acogida en un voto de mayoría de cuatro a uno por la Corte Suprema. Robles fue condenado el día 12 de junio de 2012 por la segunda sala del Tribunal de Juicio Oral en lo Penal de Copiapó como autor del delito de robo por intimidación a la pena de cinco años y un día de presidio mayor en su grado mínimo, más las accesorias de inhabilitación absoluto perpetua para cargos y oficios públicos y derechos políticos y la de inhabilitación absoluta para profesiones titulares durante el período de duración de la condena. La decisión le permitió obtener su libertad luego de haber pasado 459 días preso.

${ }^{107}$ DUCE, “Algunas Lecciones A Partir de Cuatro Casos", cit. nota n 9, pp.149-208.

${ }^{108}$ Véase: http://www.proyectoinocentes.cl [visitado el 01.07.2016]. 
DUCE, Mauricio. "Reconocimientos oculares: una aproximación empírica a su funcionamiento y algunas recomendaciones para su mejora".

detectados en forma oportuna habrían evitado la extensión de procesos y sus consecuencias a las personas que fueron imputadas ${ }^{109}$.

A marzo de 2016 el proyecto registraba 47 casos. Dado que en la gran mayoría no concluyó con una condena, esto podría arrojar dudas acerca de su uso como fuente para medir el impacto de los reconocimientos en la condena de inocentes ${ }^{110}$. No obstante lo anterior, la literatura comparada en la materia ha venido señalado la necesidad de extender el análisis que tradicionalmente se ha realizado, cubriendo no sólo a los casos de personas condenadas sino también aquellos que dan cuenta de errores del sistema entendidos de una manera más amplia. En este sentido, siguiendo a Forst, si bien muchos de estos casos de errores del sistema no obedecen al mismo problema que aquellos de las condenas de inocentes, tratándose de las personas que han sufrido privaciones de libertad sin sentencia las causas que los generan son similares y sus efectos igualmente devastadores ${ }^{111}$. Por lo mismo, aún tratándose de una fuente algo distinta, parece arrojar información de utilidad en la construcción de una primera visión empírica sobre la materia en Chile.

Un problema adicional de esta base de datos es que el Proyecto Inocentes identifica sólo lo que considera como la principal causa de error en los casos seleccionados. Esto presenta limitaciones para tener una visión más completa de la dinámica que generó el error ya que de acuerdo a la investigación disponible en el ámbito comparado- los casos de este tipo se caracterizan por la confluencia de diversos factores que comparecen al mismo tiempo y que en su conjunto terminan explicando el resultado ${ }^{112}$. Aún con esta limitación, su análisis entrega información útil no disponible en otras fuentes. En este contexto, los problemas en la identificación ocular de personas constituyen el factor de mayor importancia estadística, estando presente como causa principal en un $31,91 \%$ del total de $\operatorname{casos}^{113}$, cifra sorprendentemente similar a la del National Registry of Exonerations de los Estados Unidos que he citado previamente.

En suma, aún con información escasa es posible identificar que los reconocimientos estarían teniendo un impacto relevante en la condena de inocentes en Chile y, más en general, en la producción de errores en el sistema. Por lo mismo, parece necesario

\footnotetext{
${ }^{109}$ Para estos efectos el proyecto trabaja con un comité editorial integrado por funcionarios de la Defensoría Penal Pública y expertos externos quienes seleccionan los casos siguiendo un conjunto de criterios desarrollados. Mayor información puede verse en: http://www.proyectoinocentes.cl/pag/33/365/comite_editorial [visitado el 01.07.2016].

${ }^{110}$ En efecto, sólo uno de los casos del proyecto fue exonerado por un recurso de revisión (un 2,12\% del total). Se trata del caso de Julio Robles que ya he citado. El resto concluyó por absolución (23 casos que representan el 48,93\% del total), sobreseimiento definitivo (20 casos que representan el 42,55\% del total) y por uso de la facultad de no perseverar (3 casos que representan un 6,38\% del total).

111 FORST, Brian, "Wrongful Convictions in a World of Miscarriages of Justice", en: HUFF, Ronald; KILLIAS, Martin (Eds.), Wrongful Conviction and Miscarriages of Justice: Causes and Remedies in North American and European Criminal Justice Systems, New York: Routledge, 2013, pp. 15-43, p.17.

112 SIMON, In Doubt, cit. nota ${ }^{\circ}$ 29, p. 7; GOULD et al., "Predicting Erroneous Convictions", cit. nota ${ }^{\circ}$ 45, pp. 478- 483 .

${ }^{113}$ Se trata de un factor presente en 15 de los 47 casos. Le siguen en importancia las declaraciones falsas de víctimas y testigos y la mala conducta de agentes del Estado, cada una presente en 13 casos $(27,65 \%$ del total). Más atrás está el uso de prueba pericial poco confiable, presente en 4 casos $(8,51 \%)$ y las confesiones falsas y mala conducta del defensor en 1 caso cada una $(2,12 \%)$.
} 
Polít. crim. Vol. 12, No 23 (Julio 2017), Art. 9, pp. 291-379.

[http://www.politicacriminal.cl/Vol_12/n_23/Vol12N23A9.pdf]

profundizar qué es lo que en concreto está ocurriendo en la práctica de estas diligencias, cuestión que abordo en la siguiente sección.

\section{Los reconocimientos en Chile: una descripción de las prácticas de la Región Metropolitana.}

Los principales hallazgos de esta investigación se presentarán divididos en seis temas específicos que permiten profundizar el conocimiento que disponemos hasta ahora en esta materia. Estos incluyen: frecuencia de uso; tipos de reconocimientos; descripción de procedimientos más habituales y sus problemas, litigación y valoración en las etapas previas a juicio; litigación, valoración e impugnación en juicio oral; y, conocimiento y capacitación en la materia.

\subsection{Frecuencia de las diligencias de reconocimiento.}

Una primera cuestión a indagar ha sido intentar determinar la frecuencia o habitualidad con la que se realizan las diligencias de reconocimiento en nuestro país y su uso como evidencia en los juicios orales. Las entrevistas a policías, fiscales y defensores, actores del sistema que tienen un conocimiento más cercano de las prácticas que se realizan durante la etapa de investigación, dan cuenta que las diligencias de reconocimientos son bastante habituales en el funcionamiento del sistema. A pesar de esto, resulta difícil obtener una cifra o porcentaje que sea compartido por todos los actores entrevistados ya que ellos se desempeñan en jurisdicciones diversas y muchos atendiendo casos de perfil muy distinto. Por ejemplo, un defensor estima que los reconocimientos estarían presentes en alrededor del $20 \%$ de los casos que lleva su unidad de defensa ${ }^{114}$ y otros en cambio elevan la cifra a un $50 \%{ }^{115}$.

Una primera variable que explica estas diferencias está en el tipo de delitos que conocen los diversos actores del sistema ${ }^{116}$. Así, por ejemplo, policías con trabajo investigativo en el área de delitos contra la vida señalan que los reconocimientos se practicarían en porcentajes que se mueven entre un mínimo de $80 \%$ y un máximo de $100 \%$ de los casos que investigan $^{117}$. Este porcentaje disminuye cuando se amplía el marco de análisis a otras categorías de delito. Por ejemplo, un fiscal señala que tratándose de robos con violencia o intimidación estas diligencias se realizan en más del $50 \%$ de los casos e incluso podrían llegar a un $70 \%$ de ellos ${ }^{118}$. Concuerda otro fiscal agregando que en materia de delitos sexuales, en cambio, se trata de una diligencia muy poco frecuente debido a que la mayor

\footnotetext{
${ }^{114}$ Entrevista Defensor $n^{\circ} 1,11$ de junio de 2015.

115 Por ejemplo: Entrevista Defensor n ${ }^{\circ} 2,17$ de junio de 2015 y Defensor $n^{\circ} 5,4$ de septiembre de 2015.

${ }^{116}$ Esta diferencia queda de manifiesto al revisar los resultados de las entrevistas a los abogados particulares que participan del sistema. Los abogados entrevistados cubren diversas áreas del ejercicio de la profesión en materia penal y sus impresiones van desde que se utiliza en un $90 \%$ de los casos tratándose de un abogado que ejerce en diversas áreas (Entrevista Abogado $n^{\circ} 1,4$ de mayo de 2015) a nunca, en el caso de un abogado

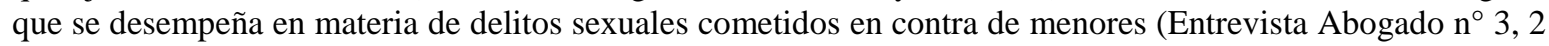
de julio de 2015).

${ }^{117}$ En esta dirección Entrevistas PDI n ${ }^{\circ} 1$ a 8.

${ }^{118}$ Entrevista Fiscal n ${ }^{\circ} 2,9$ de junio de 2015.
} 
DUCE, Mauricio. "Reconocimientos oculares: una aproximación empírica a su funcionamiento y algunas recomendaciones para su mejora".

cantidad de agresores sexuales son conocidos de la víctima ${ }^{119}$. Otro fiscal señala que tratándose de delitos económicos prácticamente no se realiza esta diligencia ${ }^{120}$. Como el lector podrá observar, se trata de una variable que introduce diferencias significativas.

Una segunda variable que explicaría las diferencias de porcentajes en el uso de los reconocimientos se vincula con la forma en que se inicia el procedimiento. Así, existe bastante consenso entre todos los entrevistados que la frecuencia de esta diligencia es alta cuando se está en presencia de delitos flagrantes ${ }^{121}$.

En este contexto, resulta interesante conocer la opinión de jueces de garantía en la materia. Ellos, en principio, no conocen todos los casos que son investigados y, por lo mismo, podrían existir algunas diferencias entre la percepción que tienen sobre este punto en comparación con la de policías, fiscales y defensores. Con todo, las opiniones de aquellos entrevistados tienden a ratificar que las diligencias de reconocimientos son frecuentes en promedio, pero con diferencias según tipo de delito y forma de ingreso. De esta forma, se señala que se trata de tasas especialmente altas en delitos violentos ${ }^{122}$, $\operatorname{robos}^{123}$ y casos flagrantes $^{124}$. En cambio, ratifican la idea que en delitos sexuales y otros, por ejemplo relativos a ley de drogas, ello ocurre con baja frecuencia ${ }^{125}$.

La realidad de lo que ocurre en juicios orales ordinarios llevados ante Tribunales Orales en lo Penal sí podría representar diferencias significativas. Como es sabido, sólo un porcentaje muy menor de los ingresos al sistema (menos de un $1 \%$ ) concluye por esta vía ${ }^{126}$. Esto hace que el perfil de casos que llegan a juicio sea algo distinto de aquellos que se resuelven en sede de garantía. No obstante lo anterior, la opinión mayoritaria de los jueces orales entrevistados es que los reconocimientos, en sus distintas formas, aparecen con bastante frecuencia en los juicios que ellos conocen. Algunos jueces incluso, considerando la identificación en la misma sala de audiencia como una actividad de reconocimiento, señalan que las hay en casi todos los juicios ${ }^{127}$. Sin considerar estos últimos, se aprecian diferencias al momento de cuantificar. Sus aprecionaciones a este respecto se basan nuevamente en los tipos de delitos que son conocidos en los distintos tribunales. Como he señalado, eso afecta el porcentaje global que cada uno entrega debido al diferente perfil de

\footnotetext{
${ }^{119}$ Entrevista Fiscal $n^{\circ}$ 6, 11 de septiembre de 2015. Concuerda con esto un abogado privado con experiencia central en delitos de orden sexual. Entrevista Abogado n ${ }^{\circ} 3,2$ de julio de 2015.

${ }^{120}$ Entrevista Fiscal $n^{\circ}$ 7, 2 de octubre de 2015.

${ }^{121}$ A modo ejemplar en esta línea puede verse Entrevista Fiscal $n^{\circ} 4,28$ de julio de 2015; Entrevista Fiscal $n^{\circ}$ 5, 4 de septiembre de 2015; Entrevista Fiscal $n^{\circ}$ 7, 2 de octubre de 2015; Entrevista Defensor $n^{\circ} 7,19$ de abril de 2015; y, Entrevista Defensor n ${ }^{\circ} 8,11$ de mayo de 2016.

${ }^{122}$ Por ejemplo: Entrevista Juez de Garantía ${ }^{\circ}$ 4, 8 de julio de 2015 (quien afirma que en delitos violentos de robo en prácticamente $100 \%$ de los casos existe reconocimiento).

${ }^{123}$ Entrevista Juez de Garantía n ${ }^{\circ} 8,4$ de enero de 2016.

${ }^{124}$ Entrevista Juez de Garantía n ${ }^{\circ} 2,25$ de junio de 2015; Entrevista Juez de Garantía n ${ }^{\circ} 3,26$ de junio de 2015; y, Entrevista Juez de Garantía n 7, 14 de septiembre de 2015.

${ }^{125}$ Entrevista Juez de Garantía n ${ }^{\circ}$ 6, 3 de septiembre de 2015.

${ }^{126}$ Las estadísticas del Ministerio Público del año 2015 dan cuenta que de un total de 1.288.523 ingresos se realizaron 11.046 juicios orales ante dichos tribunales en el período. MINISTERIO PÚBLICO, Boletín Estadístico Anual 2015, Santiago: Ministerio Público, 2016. Disponible en: http://www.fiscaliadechile.cl/Fiscalia/estadisticas/index.do [visitado el 01.07.2016].

${ }^{127}$ Por ejemplo: Entrevista Juez TOP n ${ }^{\circ} 3,2$ de julio de 2015 y Entrevista Juez TOP n ${ }^{\circ} 4,6$ de julio de 2015.
} 
Polít. crim. Vol. 12, No 23 (Julio 2017), Art. 9, pp. 291-379.

[http://www.politicacriminal.cl/Vol_12/n_23/Vol12N23A9.pdf]

casos que conocen en sus respectivas jurisdicciones. De esta forma, un juez señala que en su experiencia el $10 \%{ }^{128}$ de los casos tiene reconocimiento y otros indican que la tasa es cercana al $80 \%$ y $90 \%{ }^{129}$. A pesar de estas diferencias hay acuerdo importante que en delitos como los robos hay porcentajes muy altos de este tipo de diligencias (desde 50\% hacia arriba) ${ }^{130}$.

En definitiva, es posible sostener que los reconocimientos son una herramienta habitualmente utilizada por el sistema procesal penal chileno durante la etapa de investigación y que luego, naturalmente, se traduce en actividades probatorias en juicio oral. Esto sería especialmente intenso tratándose de algunas categorías de delitos en los que naturalmente el sistema trabaja con autores cuya identidad es desconocida para víctimas y testigos (vgr. robos) y aquellos que son sorprendidos en hipótesis de flagrancia.

\subsection{Tipos de reconocimientos.}

Como ya he señalado, en la literatura sobre la materia y el propio Protocolo del Ministerio Público, se identifican tres formas principales de reconocimiento (las ruedas de personas, las de fotografías y las exhibiciones), una complementaria (la exhibición de kardex fotográficos) y dos actividades asociadas (la elaboración de retratos hablados y la identificación en audiencias de juicio). En esta sección se pretende dar una imagen acerca de qué tipos de procedimiento y la frecuencia con la que ellos serían utilizados en nuestro país.

Existe un consenso muy significativo entre las diversas categorías de entrevistados de que la forma principal de reconocimiento es la de exhibición del imputado a la víctima o testigo $^{131}$. Incluso respecto de los entrevistados que no indican de manera precisa que este tipo de procedimiento represente un porcentaje mayoritario, se admite que es frecuentemente utilizado por las policías ${ }^{132}$. El estudio empírico sobre sentencias de TOP de la Región Metropolitana arroja el mismo resultado ya que indica que hubo exhibiciones en el $56,7 \%$ de las sentencias revisadas, siendo el procedimiento más frecuente ${ }^{133}$.

Como veremos más adelante, estas exhibiciones no se traducen necesariamente en un solo procedimiento estándar ni tampoco son llamadas de la misma forma por los entrevistados. No obstante, todas comparten la característica central de mostrarle en forma directa a la

\footnotetext{
${ }^{128}$ Entrevista Juez TOP n ${ }^{\circ} 5,8$ de julio de 2015.

${ }^{129}$ Entrevista Juez TOP n ${ }^{\circ} 1,9$ de junio de 2015 y Entrevista Juez TOP n ${ }^{\circ} 7,5$ de octubre de 2015.

${ }^{130}$ Entrevista Juez TOP $n^{\circ} 2,15$ de junio de 2015; Entrevista Juez TOP $n^{\circ} 5,8$ de julio de 2015; Entrevista Juez TOP ${ }^{\circ} 6,14$ de julio de 2015; y, Entrevista Juez TOP $n^{\circ} 7,5$ de octubre de 2015.

${ }^{131}$ La mayoría de fiscales, defensores y jueces entrevistados concuerdan con esto (68,3\% considerados como un universo). En la única categoría que se produce discrepancia es en los funcionarios de la PDI en donde el uso de set o ruedas fotográficas aparece como la principal diligencia, mencionada así por todos entrevistados de esa categoría. En mi opinión, esta diferencia se explica como consecuencia de un sesgo que introduce el tipo de funcionario PDI entrevistado que, como ya señalé, corresponde a una unidad especializada de investigación que lidia con poca frecuencia con casos de flagrancia.

${ }^{132}$ Ejemplos sobre este tema pueden verse en: Entrevista Fiscal $n^{\circ} 13,29$ de enero de 2016; Entrevista Juez de Garantía n ${ }^{\circ}$ 8, 4 de enero de 2016; y, Entrevista Carabinero ${ }^{\circ}{ }^{\circ}$, 10 de agosto de 2015.

${ }^{133}$ CATALÁN, Aproximación Empírica, cit. nota n ${ }^{\circ} 17$, p. 42.
} 
DUCE, Mauricio. "Reconocimientos oculares: una aproximación empírica a su funcionamiento y algunas recomendaciones para su mejora".

víctima o al testigo la persona sospechosa para que señale si se trata o no del autor del delito en contextos de flagrancia. La relación entre exhibiciones y detenciones en estos casos se describe bien por un Juez de Garantía que señala:

"Si uno mira al sistema en general, lo primero que se ve es que el gran porcentaje de casos que llevamos son detenciones por flagrancia...El problema es que hemos ampliado la flagrancia a tales puntos que la mayoría no lo son, son ficticias, son simbólicas, y ahí hay un espacio para los reconocimientos dentro de 24 horas donde llega y te muestran al sujeto en la comisaría..."134.

La segunda diligencia que aparece con más frecuencia es la rueda o set fotográfico. En esta dirección, todos los entrevistados que indican que aquella más frecuente es la exhibición, señalan que la que le sigue es el set o rueda fotográfica. Además, la gran mayoría de los que no ponen en primer lugar de frecuencia a las exhibiciones, indican que éste sería el procedimiento principal $^{135}$. El estudio empírico sobre sentencias TOP de la Región Metropolitana vuelve a ratificar esto. En efecto, en un 52,3\% de los casos examinados hubo un reconocimiento fotográfico, siendo el segundo tipo más frecuente un poco por debajo de las exhibiciones ${ }^{136}$.

Las ruedas de personas, en cambio, parecieran utilizarse con frecuencias porcentualmente muy menores ${ }^{137}$. Varios jueces entrevistados incluso señalan que no les ha tocado ver reconocimientos de este tipo en el último tiempo ${ }^{138}$ y todos los funcionarios de la PDI concuerdan en que en la actualidad no las hacen. Fuera de estos, la mayoría de los entrevistados señala que se trata de procedimientos que se realizan, pero en muy pocos casos o de manera más bien excepcional ${ }^{139}$. Fiscales y funcionaros policiales parecen estar de acuerdo con que la razón sería las complejidades que supone desde el punto de vista organizativo y de infraestructura realizar una rueda de personas que permita satisfacer los

\footnotetext{
${ }^{134}$ Entrevista Juez de Garantía n ${ }^{\circ} 1,7$ de mayo de 2015.

${ }^{135}$ Como ya adelanté todos los funcionarios de la PDI entrevistados se pronunciaron en esta dirección. Además, en este sentido: Entrevista Carabinero $n^{\circ} 2,11$ de octubre de 2015; Entrevista Defensor $n^{\circ} 1,11$ de junio de 2015; y, Entrevista Defensor n ${ }^{\circ} 6,1$ de abril de 2016.

${ }^{136}$ CATALÁN, Aproximación Empírica, cit. nota n 17, p. 42.

${ }^{137}$ El estudio sobre sentencias TOP de la Región Metropolitana nuevamente apoya esta afirmación ya que sólo un 4,5\% de los casos revisados incluyó un procedimiento de este tipo. Véase: CATALÁN, Aproximación Empírica, cit. nota $\mathrm{n}^{\circ} 17$, p. 42.

${ }^{138}$ Ejemplos de esto son: Entrevista Juez de Garantía n ${ }^{\circ}$ 6, 3 de septiembre de 2015; Entrevista Juez TOP $n^{\circ}$ 4, 6 de julio de 2015; Entrevista Juez TOP n ${ }^{\circ} 5,8$ de julio de 2015; y, Entrevista Juez TOP n ${ }^{\circ}$, 5 de octubre de 2015 .

${ }^{139}$ Ejemplos de esto se dan en: Entrevista Fiscal $n^{\circ} 2,9$ de junio de 2015; Entrevista Fiscal $n^{\circ} 3,10$ de julio de 2015; Entrevista Fiscal $n^{\circ}$ 7, 2 de octubre de 2015; Entrevista Fiscal $n^{\circ} 11,7$ de enero de 2016; Entrevista Fiscal $n^{\circ} 13,29$ de enero de 2016; Entrevista Defensor $n^{\circ} 5,4$ de septiembre de 2015; Entrevista Defensor $n^{\circ}$ 6, 1 de abril de 2016; Entrevista Juez de Garantía n ${ }^{\circ}$ 1, 7 de mayo 2015; Entrevista Juez Garantía $n^{\circ} 2,25$ de junio de 2015; Entrevista Juez de Garantía n ${ }^{\circ}$ 3, 26 de junio de 2015; Entrevista Juez de Garantía n ${ }^{\circ}$ 5, 15 de julio de 2015; Entrevista Juez de Garantías n ${ }^{\circ}$ 7, 14 de septiembre de 2015; Entrevista Juez TOP n 1,9 de junio de 2015; Entrevista Juez TOP $n^{\circ} 3,2$ de julio de 2015; Entrevista Carabinero ${ }^{\circ} 1,10$ de agosto de 2015; Entrevista Carabinero $n^{\circ}$ 2, 11 de octubre de 2015; Entrevista Abogado $n^{\circ} 1,4$ de mayo de 2015; y, Entrevista Abogado ${ }^{\circ} 4,22$ de julio de 2015.
} 
Polít. crim. Vol. 12, № 23 (Julio 2017), Art. 9, pp. 291-379.

[http://www.politicacriminal.cl/Vol_12/n_23/Vol12N23A9.pdf]

estándares planteados en el Protocolo ${ }^{140}$. Recordemos que el Protocolo exige, entre otras cuestiones, que éstas deben estar compuestas por al menos seis personas de aspecto y vestimenta similar. En esta dirección un funcionario de la PDI señala: "La rueda de presos es muy complicada, hay que tener a personas con estándares similares, ¿de dónde los saco? Yo nunca lo he hecho." ${ }^{141}$. Apuntando a problemas de infraestructura otro funcionario de la PDI indica: "La rueda de imputados es difícil que se dé, porque no hay dependencias específicas para hacerlo, ni las condiciones para llevarlo a cabo." ${ }^{142}$. Concuerdan con estas ideas los fiscales, pero varios agregan algunas razones de fondo algo más críticas respecto al trabajo policial que explicarían la situación. Así uno indica que:

"Las ruedas de imputados son muy pocas por temas de infraestructura. En Chile no hay cultura de rueda de reconocimiento, se colocan los mismos policías de la unidad, personas que no tienen la misma apariencia física y esto se explica porque se hacen en las comisarías y ahí no tienes más que a los funcionarios y a los detenidos..."143.

Algo más críticas son las declaraciones de otro fiscal que luego de hacer afirmaciones similares a las recién transcritas señala "...además, por parte de los funcionarios existe apuro en realizar el procedimiento, por lo mismo este no es el camino más fácil."144. Un defensor aporta elementos adicionales desde su punto de vista para explicar este fenómeno que explicarían el por qué desde ese rol tampoco existiría una demanda intensa para realizar este tipo de procedimientos: "La rueda de reconocimiento es más difícil de realizar, aparte que implica reconocer formalmente el reconocimiento, entonces es dispararse en las piernas" 145 , claro que luego agrega circunstancias bajo las cuáles sí podrían darse buenas razones para solicitarlas.

La utilización de kardex, en el sentido que he definido en este trabajo, no parece ser muy relevante en las distintas entrevistas y sólo en algunos casos menores es mencionada como un procedimiento más bien de tipo residual ${ }^{146}$.

Los retratos hablados tampoco parece ser muy frecuentes y varios entrevistados indican que ellos nunca se realizan ${ }^{147}$ o de manera muy excepcional ${ }^{148}$. Sólo un fiscal señala ocuparlos mucho pero "en la medida que sea posible" y, en todo caso, asumiendo que "...no es un reconocimiento, es un antecedente para poder hacer después diligencias de

\footnotetext{
${ }^{140}$ Por ejemplo, un fiscal atribuye una disminución de estos procedimientos directamente al Protocolo. Entrevista Fiscal $n^{\circ} 3,10$ de julio de 2015. Incluso algún juez señala que se trata de una explicación que han escuchado de los fiscales en la materia. Entrevista Juez de Garantía n ${ }^{\circ}$ 1, 7 de mayo de 2015.

${ }^{141}$ Entrevista PDI N4, 4 de febrero de 2016.

${ }^{142}$ Entrevista PDI $n^{\circ}$ 5, 4 de febrero de 2016.

${ }^{143}$ Entrevista Fiscal no ${ }^{\circ}$, 9 de junio de 2015.

${ }^{144}$ Entrevista Fiscal $n^{\circ} 11,7$ de enero de 2016.

${ }^{145}$ Entrevista Defensor $n^{\circ} 6,1$ de abril de 2016.

${ }^{146}$ Por ejemplo: Entrevista Fiscal n ${ }^{\circ} 8,28$ de diciembre de 2015 y Entrevista PDI n ${ }^{\circ} 6,4$ de febrero de 2016.

${ }^{147}$ Por ejemplo: Entrevista Juez de Garantía n ${ }^{\circ}$ 7, 14 de septiembre de 2015; Entrevista Juez TOP n ${ }^{\circ} 1,9$ de junio de 2015; y, Entrevista Juez TOP n ${ }^{\circ}$ 7, 5 de octubre de 2015.

${ }_{148}$ Entrevista Juez TOP n 3, 2 de julio de 2015; Entrevista Juez de Garantía n5, 15 de julio de 2015; Entrevista PDI $n^{\circ} 1,20$ de enero de 2016; y, Entrevista Defensor n ${ }^{\circ} 6,1$ de abril de 2016.
} 
DUCE, Mauricio. "Reconocimientos oculares: una aproximación empírica a su funcionamiento y algunas recomendaciones para su mejora".

reconocimiento."149. Estos mismos hallazgos se ratifican en las opiniones de los retratistas de Carabineros y la PDI en un reportaje publicado el año 2015 en un periódico nacional. Allí, un funcionario del OS-9 de Carabineros que confecciona los retratos señala que hay semanas en los que realiza tres y otras 15. En ambos casos se trata de un número bajo para el total de investigaciones que se llevan a cabo. Las declaraciones de los funcionarios de ambas instituciones dan cuenta, además, que dichos retratos son utilizados como antecedentes para desplegar líneas de investigación. En esta dirección el jefe de la OS-9 de carabineros dio cuenta de que "...con el dibujo de una persona no se puede condenar a nadie, pero que los retratos sí entregan información valiosa cuando se barajan varias líneas de investigación a la vez." " . Otro tema distinto es la calidad que puedan tener dichos retratos. No se trató de un tema abordado por la mayoría de los entrevistados, no obstante un fiscal describe su experiencia con ellos señalando: “...los retratos hablados son muy

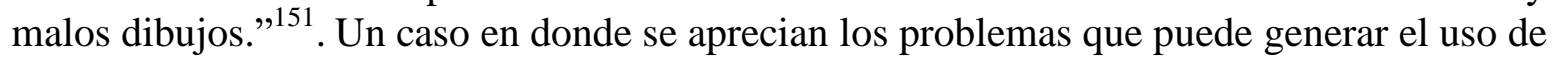
estos retratos es el de Cristián López, quien fue reconocido como autor de dos delitos de violación el año 2010 a partir inicialmente de un retrato hablado (con posterioridad en set fotográfico y finalmente en rueda de imputados). Luego de ser sometido a prisión preventiva por decisión de la Corte de Apelaciones de Santiago fue liberado al establecerse que su ADN no coincidía con el obtenido en las víctimas, acreditándose así su inocencia. Uno de los problemas del retrato hablado es que este era en blanco y negro y no permitía distinguir de ojos del autor del delito (de color verde) que no era coincidente con los de López (de color café). Ese fue uno de los puntos clave que luego llevó a las víctimas a confundirse en los reconocimientos posteriores ${ }^{152}$.

Algo distinto es lo que ocurre en el desarrollo de las audiencias de juicio oral. Si bien existe alguna discrepancia entre distintos actores acerca de la regularidad en la que se le solicita a

${ }^{149}$ Entrevista Fiscal $n^{\circ}$ 9, 4 de enero de 2016. En la misma línea Entrevista PDI $n^{\circ} 1,20$ de enero de 2016 , quien que le da a esta diligencia solamente "fines orientativos" y Entrevista Defensor n 6, 1 de abril de 2016 , que dice "es el paso previo para tener un reconocimiento posterior."

${ }^{150}$ DOMEYKO, Antonia, "Los Dibujantes Detrás de los Más Buscados”, Revista El Sábado, n854, 31 de enero de 2015, pp. 10-14, en:

http://diario.elmercurio.com/detalle/index.asp?id=\%7b04c66d3e-b168-49d5-95e8-8692938c68c4\%7d\#

[visitado el 01.07.2016]. Recomiendo la revisión del reportaje completo ya que presenta elementos muy interesantes para evaluar la forma en que los retratos hablados se confeccionan en Chile. Por ejemplo, se señala que en el caso del OS-9 de Carabineros hay tres retratistas, dos de los cuáles son autodidactas y que los tres ocupan el sistema tradicional de dibujar a mano alzada sobre la base de la descripción de la víctima. En el caso de la PDI este trabajo se realiza en el Laboratorio de Criminalística, específicamente en la sección de "Dibujo y Planimetría", donde se señala que cuentan con tres herramientas: un software computacional que realiza dibujos a color; el sistema "Identikit" que permite construir rostros con el uso plantillas de mica transparente que contienen pedazos del rostro; y, finalmente, con el dibujo a mano alzada. Los entrevistados manifiestan reservas sobre el uso de los sistemas tecnológicos y, por el contrario, clara preferencia por el sistema tradicional de dibujo a mano.

${ }^{151}$ Entrevista Fiscal $n^{\circ} 10,6$ de enero de 2016.

152 Datos generales del caso pueden revisarse en:

http://www.proyectoinocentes.cl/casos/detalle/35/cristian_lopez-rocha [visitado el 01.07.2016]. Se trató de un caso con bastante cobertura mediática. Uno de los artículos más recientes corresponde a una entrevista realizada a López más de cinco años después de ocurrido los hechos. Ella puede verse en URTUBIA, Eduardo, "Cristián López en la más dura: 'El Estado destruyó mi vida'”, La Cuarta, 3 de agosto de 2015, en: http://www.lacuarta.com/noticias/cronica/2015/08/63-186960-9-cristian-lopez-en-la-mas-dura-el-estadodestruyo-mi-vida.shtml [visitado el 01.07.2016]. 
Polít. crim. Vol. 12, No 23 (Julio 2017), Art. 9, pp. 291-379.

[http://www.politicacriminal.cl/Vol_12/n_23/Vol12N23A9.pdf]

la víctima identifique el autor, un porcentaje relevante de los entrevistados sostiene que se trata de una práctica habitual o incluso que se da en casi todos los casos. Por ejemplo, en esta dirección se pronuncian varios fiscales ${ }^{153}$ y también los jueces de tribunal oral en lo penal entrevistados quienes, por sus funciones, naturalmente debieran tener un conocimiento fino del asunto ${ }^{154}$. Uno de ellos incluso sostiene que esta actividad se ha llegado a practicar de manera excesiva en juicio al sostener que “...es un abuso, se ha establecido como práctica generalizada en cualquier tipo de juicio....aunque el imputado haya sido pariente o dependiente de la víctima se le pide que lo reconozca". ${ }^{155}$.

La revisión de las bases de datos de los recursos de revisión y del Proyecto Inocentes de la Defensoría Penal Pública, ocupadas como muestra de análisis ejemplar, arrojan resultados similares al recogido en las entrevistas respecto a los tipos de reconocimientos que serían más frecuentes, pero con algún matiz. El total de casos de ambas bases que contienen reconocimientos es de 17 , pero uno de ellos se repite por lo que el número final es $16^{156}$. De estos, en 14 pude identificar información completa de cómo fueron efectuados estos procedimientos.

Un primer dato interesante es que en ocho de estos casos, es decir, en un 57,1\%, hubo más de una actividad de reconocimiento, normalmente dos o tres ${ }^{157}$. Respecto a los tipos de reconocimientos, el que aparece con mayor presencia es el de set fotográfico que está presente en siete casos $(50 \%)^{158}$. Le siguen las exhibiciones que se realizaron en seis 6 casos $(42,85 \%)^{159}$. Más atrás están las ruedas de personas practicadas en cinco casos $(35,71 \%)^{160}$ y los retratos hablados en el mismo número ${ }^{161}$. El uso de kardex sólo aparece

${ }^{153}$ Entrevista Fiscal $n^{\circ}$ 2, 9 de junio de 2015; Entrevista Fiscal ${ }^{\circ}$ 6, 11 de septiembre de 2015; Entrevista Fiscal $^{\circ}$ 7, 2 de octubre de 2015; Entrevista Fiscal n ${ }^{\circ}$ 8, 28 de diciembre de 2015; Entrevista Fiscal ${ }^{\circ}$ 9, 4 de enero de 2016; Entrevista Fiscal $n^{\circ} 10,6$ de enero de 2016; Entrevista Fiscal n ${ }^{\circ} 11,7$ de enero de 2016; y, Entrevista Fiscal ${ }^{\circ}$ 12, 12 de enero de 2016.

${ }^{154}$ Entrevista Juez TOP n ${ }^{\circ}$ 1, 9 de junio de 2015; Entrevista Juez TOP n³, 2 de julio de 2015; y, Entrevista Juez TOP $n^{\circ} 6,14$ de julio de 2015. En contraposición Entrevista Juez TOP n², 15 de junio de 2015, que afirma que en la actualidad han disminuido los reconocimientos en juicio respecto a la práctica previa, siendo pocos.

${ }^{155}$ Entrevista Juez TOP n ${ }^{\circ} 6,14$ de julio de 2015.

${ }^{156}$ Los casos del Proyecto Inocentes en que el reconocimiento errado es identificado como el factor principal son 15. Los casos de revisión en cambio son solo dos.

${ }^{157}$ Se trata de los casos de: Enzo Fernández; Julio Robles, Pedro Lobos; Marcelo Avilés; Adrián Zarricueta; José Luis Cares; Luis Loyola y Cristián López. Todos ellos, con excepción del de Pedro Lobos, pueden ser revisados en http://www.proyectoinocentes.cl/casos/listado [visitado el 01.07.2016].

${ }^{158}$ Se trata de los casos de: Enzo Fernández; Julio Robles, Pedro Lobos; Marcelo Avilés; Adrián Zarricueta; Tamarín y Zúñiga; y Cristián López. Todos ellos, con excepción del de Pedro Lobos, pueden ser revisados en http://www.proyectoinocentes.cl/casos/listado [visitado el 01.07.2016].

${ }^{159}$ Se trata de los casos de: Enzo Fernández; Julio Robles, José Luis Cares; Luis Loyola; Molina y González; y, Pardo y otros. Todos ellos pueden ser revisados en http://www.proyectoinocentes.cl/casos/listado [visitado el 01.07.2016].

${ }^{160}$ Se trata de los casos de: José Luis Cares, Cristián López, Pardo y otros; Roberto Vergara; y, Pedro Lobos. Todos ellos, con excepción al de Pedro Lobos, los que pueden ser revisados en http://www.proyectoinocentes.cl/casos/listado [visitado el 01.07.2016].

${ }^{161}$ Se trata de los casos de: Marcelo Avilés; Adrián Zarricueta; José Luis Cares; Cristián López; y, Pedro Lobos). Todos ellos, con excepción al de Pedro Lobos, los que pueden ser revisados en http://www.proyectoinocentes.cl/casos/listado [visitado el 01.07.2016]. 
DUCE, Mauricio. "Reconocimientos oculares: una aproximación empírica a su funcionamiento y algunas recomendaciones para su mejora".

en dos casos $(14,28 \%)^{162}$ y en la misma cantidad de casos es posible identificar otro tipo de actividades de reconocimiento ${ }^{163}$. La investigación sobre las sentencias TOP de la Región Metropolitana también da cuenta del fenómeno de la existencia de casos en lo que hay dos o más tipos de reconocimientos, pero con una frecuencia estadística algo menor que los casos ejemplares. Así, en un $16,4 \%$ se produjo esta situación, siendo la más frecuente la combinación entre exhibiciones y luego set fotográficos posteriores (en un 63,4\% del total de los casos en donde hubo dos o más reconocimientos) ${ }^{164}$.

\subsection{Descripción y principales problemas.}

En esta sección me abocaré a describir las formas en que se llevan adelante los procedimientos de reconocimientos y a identificar los principales problemas que se estarían produciendo de acuerdo a las entrevistas y datos obtenidos a partir de las fuentes de información descritas anteriormente. Como ya he dicho, el foco de esta investigación está en la Región Metropolitana. Debido a que, como ya he desarrollado en la sección anterior, hay dos procedimientos que por lejos serían los más frecuentes y comunes en el funcionamiento práctico del sistema me focalizo en la descripción de ellos.

\subsubsection{Las exhibiciones.}

Como ya he señalado, el Protocolo no regula este tipo de diligencias de reconocimiento, por lo que su ejecución queda entregada completamente a la práctica policial. En este contexto, la investigación me ha permitido identificar que los procedimientos a través de los cuáles se efectúan las exhibiciones pueden agruparse en tres formatos distintos. En algunos casos son los propios entrevistados quienes hacen esta diferenciación en forma específica ${ }^{165}$, pero en la mayoría ellos surgen de las descripciones que entregan acerca de cómo se efectúan estos procedimientos y de las prácticas que es posible detectar en los casos en análisis.

La primera modalidad, al parecer la más común, se produce en contextos de flagrancia donde las policías se constituyen en el sitio del suceso y entrevistan a la víctima. Luego, ésta es subida al vehículo policial y se procede de manera inmediata a realizar rondas en el sector cercano al delito con la expectativa que la víctima identifique a un potencial autor. En caso que esto ocurra, se entiende se cumplen con los supuestos previstos en el artículo 130 letra e) del CPP, lo que habilita a los funcionarios policiales para proceder a la detención por flagrancia. Recordemos que esta regla opera en casos en que las víctimas que reclaman auxilio señalen como autor o cómplice de un delito a una persona dentro de las doce horas siguientes a la comisión del delito (tiempo inmediato en el lenguaje de la

\footnotetext{
162 Se trata de los casos de: Luis Loyola y Pedro Lobos, los que pueden ser revisados en http://www.proyectoinocentes.cl/casos/listado [visitado el 01.07.2016].

${ }_{163}$ Así, en el caso Enzo Fernández el reconocimiento se produce ya que la víctima revisa por su cuenta una foto en facebook del imputado y en el de Rodrigo Iturra la víctima reconoce causalmente al imputado en consultorio de salud que visitó con posterioridad a la comisión del delito. Estos casos pueden ser revisados en http://www.proyectoinocentes.cl/casos/listado [visitado el 01.07.2016].

${ }^{164}$ CATALÁN, Aproximación Empírica, cit. nota ${ }^{\circ}$ 17, p. 43.

${ }^{165}$ Por ejemplo: Entrevista Defensor n5, 4 de septiembre de 2015 y Entrevista Juez de Garantía $n^{\circ} 1,7$ de mayo de 2015.
} 
Polít. crim. Vol. 12, No 23 (Julio 2017), Art. 9, pp. 291-379.

[http://www.politicacriminal.cl/Vol_12/n_23/Vol12N23A9.pdf]

norma $)^{166}$. Una vez detenido, algunos entrevistados indican que es normal que nuevamente se le exhiba el sospechoso a la víctima en el mismo lugar de la detención, ahora con mayor cercanía para confirmar la identificación ${ }^{167}$. También puede ocurrir que a partir de la identificación que realiza la víctima desde el vehículo no se proceda a la detención sino que antes se haga un control de identidad con el objeto de registrar al sospechoso y verificar si porta las especies del delito, caso en el cual luego se procede a la detención por flagrancia ${ }^{168-169}$. Un fiscal describe esta dinámica de la siguiente forma: "Lo primero es mostrárselo a la víctima, el 90\% de los casos siendo sincero, tienen un sospechoso en 10 minutos y lo muestran a la víctima, el cara a cara es típico, tener a la víctima en el carro policial y mostrárselo para que lo identifique es algo típico."170. Otro señala: "Lo que informa la policía es que la víctima no apunta al primero que ve, se indica que es alguien con certeza y, además, existe descripción previa, muchas veces también se encuentran con especies robadas." Al valorar la eficacia de esta modalidad el mismo fiscal decía: "Si la víctima erró, puede ser, pero al final uno hace un juego de factores: tiempo inmediato, descripción. Uno ve si el imputado es o no culpable, por sus actitudes, por su expresión. Las víctimas son capaces de reconocer porque las caras siempre quedan grabadas en su memoria." ${ }^{171}$.

Una segunda modalidad se produce cuando las policías toman a alguien en custodia y se lo exhiben en forma directa a la víctima o testigo, ya sea en la comisaría u otro lugar. Para ello normalmente cuentan previamente con algún tipo de descripción física o de vestimentas dada por la víctima, lo que les permite identificar al potencial sospechoso. Aparentemente la situación común es que ello ocurre en el recinto policial ${ }^{172}$. En ese contexto, el procedimiento opera sobre la base de solicitar a la víctima concurra al recinto policial, momento en el cual se le exhibe en forma directa al sospechoso. Dicha persona se encuentra allí ya que ha sido detenida previamente, está sometida a un control de identidad o incluso en algunos casos debido a que voluntariamente decidió concurrir frente a la "invitación" realizada por los funcionarios. En cualquiera de los casos, esta modalidad se

\footnotetext{
${ }^{166}$ Describen en sus rasgos esenciales este procedimiento todos los defensores entrevistados. Además, puede verse -entre otros- Entrevista Fiscal ${ }^{\circ} 2,9$ de junio de 2015; Entrevista Fiscal n ${ }^{\circ} 3,10$ de julio de 2015; Entrevista Fiscal $n^{\circ}$ 4, 28 de julio de 2015; Entrevista Fiscal ${ }^{\circ}$ 5, 4 de septiembre de 2015; y, Entrevista Fiscal $\mathrm{n}^{\circ}$ 1, 7 de enero de 2016. El estudio empírico realizado en las sentencias TOP de la Región Metropolitana complementa estos hallazgos e indica que un 15,8\% de las exhibiciones fueron realizadas en un período que va entre los 60 minutos luego de ocurrido los hechos y las 24 horas. Debe tenerse presente que un $44,7 \%$ de estos reconocimientos no hay datos sobre el tiempo transcurrido entre los hechos y la exhibición. Véase: CATALÁN, Aproximación Empírica, cit. nota n 17, p. 45.

${ }^{167}$ Entrevista Defensor $n^{\circ} 4,2$ de julio de 2015.

${ }^{168}$ Entrevista Juez de Garantía no 3, 26 de junio de 2015.

${ }^{169}$ La investigación empírica de sentencias TOP de tribunales de la Región Metropolitana muestra que esta primera modalidad, en sus distintas variantes, sería efectivamente la más frecuente. Así, del universo total de casos en dónde hubo una exhibición, en un $42,1 \%$ ésta se produjo en un carro policial y en otro $39,5 \%$ en la vía pública. CATALÁN, Aproximación Empírica, cit. nota nº 17, p. 43.

${ }^{170}$ Entrevista Fiscal n ${ }^{\circ} 2,9$ de junio de 2015.

${ }^{171}$ Entrevista Fiscal n ${ }^{\circ} 11,7$ de enero de 2016.

${ }^{172}$ El estudio empírico sobre sentencias TOP muestra que un 10,5\% de las exhibiciones se produjeron en el cuartel policial. A ello debiera sumarse a esta modalidad de exhibiciones parte del 39,5\% en donde ello se produce en la vía pública y que ya había citado. CATALÁN, Aproximación Empírica, cit. nota n 17, p.43.
} 
DUCE, Mauricio. "Reconocimientos oculares: una aproximación empírica a su funcionamiento y algunas recomendaciones para su mejora".

caracteriza por ser un acto de selección de un sospechoso que es mostrado en forma directa a la víctima para efectos de su reconocimiento.

Un ejemplo de lo anterior se encuentra en el caso de Julio Robles, aún cuando con algunos elementos de diferenciación. El caso se inicia a propósito de los hechos ocurridos el 4 de agosto de 2010 en la ciudad de Copiapó en los que se cometió un robo con intimidación al interior de un almacén. El 8 de agosto de 2010 se realizó un reconocimiento por medio de exhibición de un set fotográfico que incluía la fotografía de Robles a una de las víctimas, la que a la fecha era menor de edad. En este procedimiento se reconoció a Robles como el autor del delito. Con el objetivo de "asegurar" el reconocimiento, ese mismo día, aproximadamente a las 14:00 horas, la víctima es llevada por funcionario de Carabineros a cargo del procedimiento en el vehículo policial al domicilio de Julio Robles y se estaciona al frente de la casa. La víctima observa desde el interior del vehículo a Robles mientras conversa con los funcionarios policiales. Luego se le pide identificar al sujeto, lo que hace. La observación de la víctima se produce desde el interior vehículo policial estacionado a una cierta distancia que el mismo describe como "lejos"173. Como se puede observar, se trata de un caso típico de exhibición uno a uno en el que la víctima es acarreada por la policía para mostrarle al sospechoso. Las particularidades de este caso son que el reconocimiento no se produce en flagrancia y, además, que previamente se había realizado un reconocimiento en set fotográfico. Esto es bastante inusual ya que normalmente lo que ocurre es a la inversa, es decir, a partir de un primer reconocimiento en una exhibición se realizan otros reconocimientos posteriores de mejor calidad ${ }^{174}$.

Otro ejemplo de este tipo de esta modalidad de exhibición se da en el caso de Mauricio Pardo. A los cuatro imputados del caso se les acusó de haber cometido un asalto en una pizzería en un auto de color blanco. Ello desata una búsqueda masiva de automóviles de las mismas características en sectores cercanos. Algunos minutos después del asalto, Carabineros encuentra a Pardo y a un acompañante al interior de un automóvil de color y otros rasgos similares a la salida de un domicilio particular y los detiene. Se ingresa también a dicho domicilio y se procede a detener a otros dos jóvenes. Carabineros retuvo por cerca de una hora a los cuatro jóvenes, tiempo en el cual llevó a este domicilio a tres de las víctimas del robo que manifestaron reconocer a los cuatro jóvenes como autores del delito $^{175}$. Como se puede apreciar, también se trataría de un caso de exhibición, pero efectuado en el domicilio de uno de los sospechosos.

La tercera modalidad es una variante de la anterior ya que también se produce el reconocimiento al interior del recinto policial. Lo que cambia en este caso es que se trata de situaciones en que normalmente la víctima se encuentra esperando o realizando alguna diligencia al interior del recinto y "espontáneamente" reconoce al sospechoso al verlo en el

\footnotetext{
${ }^{173}$ Descripción resumida de Mauricio Duce, véase en: DUCE, “Algunas Lecciones A Partir de Cuatro Casos”, cit. nota $\mathrm{n}^{\circ} 9$, p. 160-164.

${ }^{174}$ Por ejemplo, Entrevista Defensor n 8, 11 de mayo de 2016. A nivel de caso puede verse el de Pedro Lobos en el que los reconocimientos parten con un retrato hablado, luego se realiza el en set fotográficos y finalmente se concluye utilizando una rueda de imputados realizada en un recinto penitenciario. Detalles en DUCE, “Algunas Lecciones A Partir de Cuatro Casos", cit. nota n 9, pp. 154-159.

${ }^{175}$ Mayores detalles del caso pueden verse en http://www.proyectoinocentes.cl/casos/detalle/32/mauriciopardo-vallejos j-bs-r-a-p-y-ygp [visitado el 01.07.2016].
} 
Polít. crim. Vol. 12, № 23 (Julio 2017), Art. 9, pp. 291-379.

[http://www.politicacriminal.cl/Vol_12/n_23/Vol12N23A9.pdf]

mismo lugar ${ }^{176}$. En estos casos no hay una exhibición propiamente tal de parte de las policías, sino la confluencia de "circunstancias fortuitas" que permiten a la víctima hacer el reconocimiento por casualidad. Así, por ejemplo lo describe un defensor señalando que: “... espontáneamente la víctima reconoció al imputado mientras venía bajando del furgón en la comisaría o en la vereda....."

Como se puede observar, detrás de estas tres modalidades de exhibición se refleja una práctica bastante heterogénea de las policías que daría cuenta de la inexistencia de protocolos claros de actuación institucionales que se hagan cargos de las particularidades específicas que presenta esta diligencia en las diversas situaciones que quedan cubiertas por la flagrancia. Que el Protocolo no se haga cargo de este tipo de procedimientos agrava la situación ya que parece conceder discrecionalidad absoluta en su ejecución.

Más allá de este problema, muchos de los actores entrevistados cuestionan la real "espontaneidad" de estos procedimientos. Por ejemplo, un juez de TOP indica que "...la verdad es que la práctica nos ha enseñado que carabineros los lleva a propósito cerca de donde está la víctima para que ésta diga 'oiga, esos son'."178. Otro juez TOP manifiesta su desconfianza señalando que "El problema es cuando no son o te producen dudas de que se haya producido la situación tal cual se relata, es decir, que haya ocurrido eso de que espontáneamente lo vio". ${ }^{179}$. El relato de un fiscal es particularmente ilustrador de esta desconfianza. Señala, a propósito de referirse a los problemas que presenta el trabajo policial en las diligencias de reconocimiento, que

"Tienen que saber que si detienen a alguien tiene que ser por algo, darse el trabajo de contextualizar el origen del set fotográfico y ese es el problema que uno ve ¿Cómo llegó la foto del imputado ahí? Siempre responden con esos reconocimientos espontáneos, justo llegó la víctima a la Comisaría y lo vio." ${ }^{\text {180 }}$.

Un defensor manifiesta dudas sobre la real espontaneidad del procedimiento y la veracidad con la que se registran al ejemplificar con que "...tienen al tipo haciéndole un control de identidad en la comisaría y llega la víctima y lo reconoció mientras estaba sentado en el escritorio de funcionarios de carabineros. Por lo menos eso es lo que llega en el parte, esa es la historia formal, pareciera que todo es muy casual."181.

La desconfianza surge ya que se estima que muchos de ellos son "armados" por la policía para saltarse procedimientos más complejos y asegurar así la detención rápida del sospechoso. Por ejemplo, un defensor apunta que "Toda la espontaneidad se salta a la formalidad. Ojo no puedes acreditar espontaneidad. No tienes registro."182. En parte, esto estaría permitido por la mala calidad de los registros de las exhibiciones o derechamente su

\footnotetext{
${ }^{176}$ Por ejemplo, cuando la víctima llega a hacer la denuncia al recinto policial. Entrevista Defensor $\mathrm{n}^{\circ} 1,11$ de junio de 2015.

${ }^{177}$ Entrevista Defensor $n^{\circ}$ 3, 2 de julio de 2015.

${ }^{178}$ Entrevista Juez TOP n ${ }^{\circ} 2,15$ de junio de 2015.

${ }^{179}$ Entrevista Juez TOP n ${ }^{\circ} 5,8$ de julio de 2015.

${ }^{180}$ Entrevista Fiscal n ${ }^{\circ} 10,6$ de enero de 2016.

${ }^{181}$ Entrevista Defensor $n^{\circ}$ 5, 4 de septiembre de 2015.

${ }^{182}$ Entrevista Defensor $n^{\circ} 3,2$ de julio de 2015.
} 
DUCE, Mauricio. "Reconocimientos oculares: una aproximación empírica a su funcionamiento y algunas recomendaciones para su mejora".

ausencia. Sobre este punto de la diferencia entre la práctica y la información que se registra en las exhibiciones otro defensor sostiene: "Una cosa es la que se hace y otra es la que queda por escrito". ${ }^{183}$. Un juez de garantía pone énfasis en la poca información que existe sobre estos reconocimientos espontáneos lo que le genera dudas acerca de los mismos. Señala que los registros contienen sólo "La mera circunstancia de que se reconoció espontáneamente. Sin indicar porqué, ni cuáles fueron las características, ni las típicas que son por defecto en los partes policiales: 'lo reconoció por su vestimenta y sus rasgos físicos"."184. Un defensor apunta sobre esto que algunos jueces excusan la falta de registro debido a que se trata de primeras actuaciones en donde no se puede exigir mucho. En su opinión, en cambio, “...debiera ser al revés, es la flagrancia el momento en que más se debiera exigir registro." ${ }^{185}$. Volveré sobre este tema de los registros un poco más adelante.

A las modalidades anteriores de reconocimientos, algunos entrevistados agregan una cuarta forma de exhibición, las que podrían ser descritas como situaciones de "flagrancia pura" o "reconocimiento espontáneo verdadero". Se trata de casos en los que la víctima del delito no pierde de vista o hace seguimiento al autor desde el momento en que se comete el delito y éste es luego detenido por las policías en ese contexto, es decir, donde hay una cercanía temporal muy estrecha entre delito y la posterior detención. En consecuencia, se trata de casos en donde se produce una hipótesis tradicional de flagrancia en un sentido estricto. ${ }^{186}$ Se trataría de un tipo de procedimiento que -en opinión de los entrevistados- genera menos preocupaciones o desconfianzas que los anteriores ya que respondería a una dinámica de hechos, por una parte, inevitable, pero también a un contexto en donde no habría tantas dudas acerca de la confiabilidad del reconocimiento.

\subsubsection{Los reconocimientos fotográficos.}

Reviso ahora la forma en que se ejecutan los reconocimientos en set fotográficos, para lo cual divido la presentación en los componentes centrales que integran este procedimiento.

\section{a) Los estándares del Protocolo y su cumplimiento general.}

A diferencia del caso anterior, los reconocimientos fotográficos se encuentran expresamente regulados en el Protocolo del Ministerio Público. El procedimiento se inicia con la realización de una descripción previa del testigo o la víctima que incluya la caracterización física del sujeto de la forma más completa que sea posible, incluyendo aspectos como el sexo, la edad aproximada, características físicas como la descripción de contextura, rasgos faciales, existencia de marcas o cicatrices, etc. También señala la

\footnotetext{
${ }^{183}$ Entrevista Defensor $n^{\circ} 7,19$ de abril de 2016.

${ }^{184}$ Entrevista Juez de Garantía n ${ }^{\circ} 4,8$ de julio de 2015.

${ }^{185}$ Entrevista Defensor $n^{\circ} 1,11$ de junio de 2015.

${ }^{186}$ Por ejemplo: Entrevista Fiscal ${ }^{\circ} 13,29$ de enero de 2016 y Entrevista Juez de Garantía n ${ }^{\circ} 5,15$ de julio de 2015. El estudio empírico realizado en las sentencias TOP de la Región Metropolitana muestra que un 10,5\% de las exhibiciones fueron realizadas en un período que va entre los primeros diez minutos desde ocurridos los hechos que podrían corresponder a este tipo de casos. CATALÁN, Aproximación Empírica, cit. nota $\mathrm{n}^{\circ} 17, \mathrm{p}$. 45.
} 
Polít. crim. Vol. 12, No 23 (Julio 2017), Art. 9, pp. 291-379.

[http://www.politicacriminal.cl/Vol_12/n_23/Vol12N23A9.pdf]

necesidad de levantar información sobre vestimentas del sospechoso ${ }^{187}$. De estas descripciones debiera dejarse constancia en un acta respectiva ${ }^{188}$.

Respecto al desarrollo del reconocimiento mismo, el Protocolo establece que se trata de una diligencia individual, es decir, evitando que participen más de una víctima y testigo a la vez a efectos de impedir que se comuniquen entre sí y eso pueda contaminar su ejercicio de reconocimiento $^{189}$. Lógica similar se aplica tratándose de los sospechosos, ya que si hay más de uno, ellos debieran incorporarse en set fotográficos distintos para hacer ejercicios de reconocimiento autónomos ${ }^{190}$. Los funcionarios que administran el procedimiento deben iniciar la diligencia explicando sus objetivos, evitar el uso de lenguaje, gestos o cualquier tipo de comunicación que pueda inducir a la víctima o testigo a reconocer a un sujeto determinado y, en todo caso, deben advertir que el sospechoso podría no estar incluido en las fotografías que se le presentarán ${ }^{191}$.

Un aspecto clave del procedimiento es la conformación del set de fotografías que se exhiben para efectos del reconocimiento. El Protocolo exige que se elaboren al menos dos set cada uno con diez fotografías. Uno de ellos debiera tener al sospechoso y el otro no, sin poder repetir la imagen del mismo sospechoso en el mismo set. Los distractores, es decir las fotografías de los no sospechosos, deben ser personas completamente desvinculadas de los hechos imputados. Ellos, además, deben tener semejanzas con la persona descrita previamente por la víctima o testigo. Las fotografías deben ser lo más actuales posibles y tener las mismas proporciones y colores. Además, deben ser exhibidas en forma sucesiva, es decir, una a una ${ }^{192}$. Finalmente, la diligencia debe ser registrada, para lo cual el Protocolo contiene un acta escrita tipo en la cual se deben llenar casilleros con información que de cuenta del seguimiento de los pasos previos ${ }^{193}$.

Las descripciones realizadas por los actores entrevistados respecto al nivel de cumplimiento de estas reglas, y la forma en que en la práctica son llevadas adelante estas diligencias de reconocimientos, dan cuenta de apreciaciones bien diversas. Con todo, la imagen general

\footnotetext{
${ }^{187}$ MINISTERIO PÚBLICO, Protocolo Interinstitucional de Reconocimiento de Imputados, cit. nota $n^{\circ} 6$, $\mathrm{p}$. 21

${ }^{188}$ MINISTERIO PÚBLICO, Protocolo Interinstitucional de Reconocimiento de Imputados, cit. nota $\mathrm{n}^{\circ} 6, \mathrm{p}$. 14.

${ }^{189}$ Desde la literatura especializada se ha establecido que cualquier influencia en la decisión de la víctima o testigo, incluso proveniente de otra víctima o testigo puede afectar la confiabilidad del reconocimiento. En esta dirección la recomendación básica que se efectúa es que ellos no deben ser expuestos a ningún tipo de información que permita identificar al sospechoso de ninguna fuente, por eso se recomienda que los procedimientos de reconocimientos que involucran a varios testigos se hagan asegurando que no exista contacto entre ellos antes y durante su desarrollo. Véase SIMON, In Doubt, cit. nota n ${ }^{\circ} 29$, p. 83.

${ }^{190}$ MINISTERIO PÚBLICO, Protocolo Interinstitucional de Reconocimientos de Imputados, cit. nota $\mathrm{n}^{\circ} 6, \mathrm{p}$. $21,22$.

${ }^{191}$ MINISTERIO PÚBLICO, Protocolo Interinstitucional de Reconocimiento de Imputados, cit. nota $\mathrm{n}^{\circ} 6$, $\mathrm{p}$. 22.

${ }^{192}$ MINISTERIO PÚBLICO, Protocolo Interinstitucional de Reconocimiento de Imputados, cit. nota $\mathrm{n}^{\circ}$ 6, $\mathrm{p}$. 24.

${ }^{193}$ MINISTERIO PÚBLICO, Protocolo Interinstitucional de Reconocimiento de Imputados, cit. nota $\mathrm{n}^{\circ} 6$, pp. 31-34.
} 
DUCE, Mauricio. "Reconocimientos oculares: una aproximación empírica a su funcionamiento y algunas recomendaciones para su mejora".

que es posible construir es que en la práctica el nivel de cumplimiento del Protocolo en los reconocimientos fotográficos sería sólo parcial.

Este fue un tema que se indagó específicamente en las entrevistas a policías, físcales y defensores quienes tienen un contacto de primera mano con estas diligencias. Como podría esperarse, ya que se trata de una normativa que regula su propio trabajo, los policías entrevistados manifiestan los niveles de cumplimiento más alto del Protocolo en esta materia. Así, todos los funcionarios de la PDI entrevistados describen la utilización de procedimientos bastante similares a la estructura descrita en el Protocolo, aún cuando en algunos temas específicos se detectan apartamientos relevantes como veré más adelante ${ }^{194}$. La opinión de los fiscales, en cambio, está mucho más dividida. Hay un grupo de ellos que efectivamente sostiene hay cumplimiento razonable del Protocolo ${ }^{195}$ y otro equivalente en número, en tanto, que plantea que se producen apartamientos significativos del mismo ${ }^{196}$. En el camino intermedio algunos sostienen una posición con matices ya sea derivados de los niveles de cumplimiento ${ }^{197}$ o estableciendo diferencias por tipo de funcionario a cargo de su realización ${ }^{198}$. En el otro extremo, la opinión de los defensores es mayoritaria en identificar apartamientos relevantes del Protocolo por parte de las policías ${ }^{199}$.

Las entrevistas a estos mismos actores, sumando a los jueces, me permitió identificar en dónde se producirían los principales apartamientos al procedimiento establecido en el Protocolo.

\footnotetext{
${ }^{194}$ No ocurre esto tratándose de los dos carabineros entrevistados los que relatan prácticas bastante disímiles en la materia.

${ }^{195}$ La regla general es que estos fiscales reconocen niveles de cumplimiento adecuado del Protocolo pero igual identifican algunas excepciones y problemas. En esta dirección, por ejemplo, Entrevista Fiscal n ${ }^{\circ} 7,2$ de octubre de 2015; Entrevista Fiscal n ${ }^{\circ}$ 8, 28 de diciembre de 2015; Entrevista Fiscal n ${ }^{\circ}$ 9, 4 de enero de 2016; Entrevista Fiscal $n^{\circ}$ 11, 7 de enero de 2016. Una postura algo más extrema sostiene otro fiscal quien indica: "Yo nunca he visto que se aparten, si supiera de casos lo diría porque eso nos desprestigia como fiscales ante los jueces". Entrevista Fiscal n 13, 29 de enero de 2016.

${ }^{196}$ En esta dirección Entrevista Fiscal n ${ }^{\circ}$ 1, 7 de mayo de 2015; Entrevista Fiscal no 2, 9 de junio de 2015; Entrevista Fiscal $n^{\circ} 10,6$ de enero de 2016; y, Entrevista Fiscal ${ }^{\circ} 12,12$ de enero de 2016. Es interesante destacar que en ambas posturas los fiscales pertenecen a distintas fiscalías regionales, lo que muestra que los cumplimientos e incumplimientos del Protocolo no estarían focalizados en un territorio específico, sino que indistintamente en toda la Región Metropolitana.

${ }^{197}$ Por ejemplo, un fiscal sostiene: "Es usual que se aparten de los protocolos, pero no la regla general". Entrevista Fiscal n ${ }^{\circ}$ 4, 28 de julio de 2015.

${ }^{198}$ Un fiscal señala: "Hay una diferencia abismante entre carabineros y PDI. Los reconocimientos de la PDI son de mucho mayor fiabilidad y eso se nota en los set fotográficos y en los propios formatos que tiene la PDI para los reconocimientos y se nota que -a diferencia de carabineros que yo creo se están tomando muy livianamente este protocolo- la PDI sí que los ha aplicado respecto a los set fotográficos". Entrevista Fiscal $\mathrm{n}^{\circ} 5,4$ de septiembre de 2015. También se pronuncia sobre estas marcadas diferencias Entrevista Fiscal n ${ }^{\circ} 1,7$ de mayo de 2015. Otro fiscal identifica las diferencias de calidad de los reconocimientos asociado a los niveles de especialidad del cuerpo policial a cargo de la diligencia. Entrevista Fiscal n ${ }^{\circ} 6,11$ de septiembre de 2015. Algunos defensores, también identifican diferencias claras de calidad entre distintos organismos policiales, pero en un contexto de incumplimiento general del Protocolo (Entrevista Defensor $n^{\circ} 3,2$ de julio de 2015 y Entrevista Defensor n ${ }^{\circ} 4,2$ de julio de 2015).

${ }^{199}$ Entrevista Defensor n ${ }^{\circ} 2,17$ de junio de 2015; Entrevista Defensor n ${ }^{\circ} 3,2$ de julio de 2015; Entrevista Defensor $^{\circ}{ }^{4}$, 2 de julio de 2015; Entrevista Defensor n ${ }^{\circ} 5,4$ de septiembre de 2015; Entrevista Defensor $n^{\circ}$ 6, 1 de abril de 2016; y, Entrevista Defensor n 7, 19 de abril de 2016.
} 
Polít. crim. Vol. 12, № 23 (Julio 2017), Art. 9, pp. 291-379.

[http://www.politicacriminal.cl/Vol_12/n_23/Vol12N23A9.pdf]

Una primera cuestión que aparece mencionada en forma persistente tiene que ver con la calidad y precisión de las descripciones previas. Como ya he señalado, se trata de un componente central del Protocolo ya que, por una parte, permite discriminar si la víctima o testigo está en condiciones de realizar un reconocimiento y, por la otra, confeccionar un set de fotografías que cumpla con los estándares fijados por el propio instrumento (especialmente la similitud que debiera existir entre las características del sospechoso y la de los rellenos). Dos son los problemas frecuentemente mencionados. El primero y más grave es que varios jueces y defensores afirman que estas descripciones no existen en muchos $\operatorname{casos}^{200}$. Esto es ratificado en el estudio empírico de sentencias TOP de la Región Metropolitana el que indica que en un $45,7 \%$ de los casos no hubo descripción previa ${ }^{201}$. Como el lector podrá comprender, se trata de un problema gravísimo ya que la confiablidad del procedimiento completo se construye a partir de este elemento. De menos gravedad, pero igualmente problemático, es que muchas de las descripciones son formuladas en términos demasiado generales o vagas, lo que afecta la calidad del procedimiento posterior. Se trata de un tema que es mencionado por jueces ${ }^{202}$, fiscales ${ }^{203}$ y defensores $^{204}$. Un buen ejemplo de este tipo de descripciones previas se da en el caso de Julio Robles que ya he citado. Allí la víctima mayor de edad describe al asaltante de su almacén como "...un sujeto desconocido de 20 a 25 años, contextura mediana, pelo semicorto negro, barba creciente, tez morena, de 1,65 estatura...". Su hijo, por su parte, lo describe indicando que se trata de “...un sujeto de 25 años, contextura mediana, pelo semicorto color negro...,"205. Como se puede apreciar, si bien las descripciones presentan concordancia en varios aspectos, ellas se refieren a características bastante gruesas del autor como la edad y contextura, pero casi no incluyen elementos específicos del rostro u otros que pudieran diferenciar al potencial autor de un número muy grande de personas que podría satisfacer tal descripción. Pensemos en cómo se podrían traducir descripciones de este tipo en la selección de fotografías de los rellenos.

Más allá de estos problemas, se pudo detectar un nivel importante de desconfianza en varios actores acerca de las descripciones previas que da a conocer la policía, derivadas de

\footnotetext{
${ }^{200}$ Entrevista Juez TOP n ${ }^{\circ}$ 1, 9 de junio de 2015; Entrevista Juez TOP n ${ }^{\circ} 2,15$ de junio de 2015 (quien señala “...por regla general no se entregan características físicas de los sujetos, por lo general lo que se entrega son vestimentas...."); Entrevista de Juez TOP n ${ }^{\circ}$, 5 de octubre de 2015; Entrevista Juez de Garantía n ${ }^{\circ} 2,25$ de junio de 2015 (quien señala “...rara vez una sabe cuál es la descripción de la víctima.”); Entrevista Fiscal n 6 , 11 de septiembre de 2015; y, Entrevista Defensor n 3, 2 de julio de 2015. El tema también es mencionado en Entrevista Defensor $\mathrm{n}^{\circ}$ 7, 19 de abril de 2016, pero referido a la falta de descripción previa en las exhibiciones realizadas en contextos de flagrancia.

${ }^{201}$ CATALÁN, Aproximación Empírica, cit. nota n ${ }^{\circ}$ 17, p. 51.

${ }^{202}$ Entrevista Juez de Garantía n ${ }^{\circ} 2,25$ de junio de 2015.

${ }^{203}$ Entrevista Fiscal n ${ }^{\circ} 8,28$ de diciembre de 2015 (quien señala "se debería describir con mayor detenimiento características personales, estatura, vestimentas...”). Entrevista Fiscal n 9, 4 de enero de 2016 (quien señala "Falta una buena descripción. Normalmente hay buena descripción de vestimenta y no lo otro.").

${ }^{204}$ Entrevista Defensor $n^{\circ} 1,11$ de junio de 2015; Entrevista Defensor n ${ }^{\circ} 2,17$ de junio de 2015; y, Entrevista Defensor $n^{\circ} 8,11$ de mayo de 2016 .

${ }^{205}$ Estas descripciones están tomadas textualmente de la declaración voluntaria prestada por ambas víctimas a Carabineros el día 4 de agosto de 2010 y que se registran como anexo al parte de denuncia contenido en la carpeta investigativa del fiscal (documento en formato electrónico en poder del autor).
} 
DUCE, Mauricio. "Reconocimientos oculares: una aproximación empírica a su funcionamiento y algunas recomendaciones para su mejora".

la rapidez con la que se realizan los procedimientos y, especialmente, de la precariedad de los registros en donde ellas se consignan ${ }^{206}$. Sobre esto último realizaré un análisis con algo más de profundidad en la próxima sección ya que se trata de un problema serio que afecta la confiabilidad de todo tipo de procedimiento de reconocimiento.

La comunicación entre funcionarios y víctimas y testigos.

La investigación me permitió identificar también la existencia de problemas a nivel de las comunicaciones que se realizan entre los funcionarios encargados de la diligencia con los testigos y las víctimas. Como se recordará, el Protocolo impone que en todas las comunicaciones debe evitarse el uso de lenguaje inductivo y debe advertirse que la persona sospechosa podría no estar en las fotografías que se exhiben ${ }^{207}$. Los entrevistados manifiestan dudas sobre el cumplimiento de ambas cuestiones.

Por una parte, varios expresan que no es claro que sean formuladas las advertencias sobre la no presencia del sospechoso ${ }^{208}$ o el análisis de su contenido arroja dudas de que estas que estén orientadas a evitar que los testigos se sientan forzados a identificar a un sospechoso. El segundo de estos problemas pareciera ser el más habitual. Así, por ejemplo, si bien los policías entrevistados señalan que se hacen las advertencias previas ${ }^{209}$, cuando algunos de ellos las describen con más detalle se aprecia que su contenido es algo distinto a lo buscado por el Protocolo. En esta línea, un carabinero consultado sobre el punto, al relatar lo que hace pone énfasis en que el sentido de estas advertencias es evitar la doble victimización. Así, señala que su objetivo es “...tratar siempre a la víctima con lo que ella solicite y requiere, darle siempre la tranquilidad, primero llegar a la seguridad interna de ella, que ella pueda estar tranquila y poder proceder tranquilamente a tomar declaración, para poder enseñarle el set...". 210 . En una dirección similar un funcionario de la PDI expresa que la función de estas instrucciones es intentar convencer a la víctima para que colabore con la

\footnotetext{
${ }^{206}$ Entre otros véase, Entrevista Defensor $n^{\circ} 1,11$ de junio de 2015; Entrevista Defensor $n^{\circ} 2,17$ de junio de 2015; Entrevista Fiscal n ${ }^{\circ}$ 2, 9 de junio de 2015; Entrevista Fiscal n ${ }^{\circ} 6,11$ de septiembre de 2015; Entrevista Fiscal ${ }^{\circ}$ 10, 6 de enero de 2015; Juez de Garantía n ${ }^{\circ}$ 1, 7 de mayo de 2015; Entrevista Juez de Garantía n ${ }^{\circ}$, 25 de junio de 2015; Entrevista Juez de Garantía n 4, 8 de julio de 2015; y, Entrevista Juez de Garantía n ${ }^{\circ}$, 4 de enero de 2016.

${ }^{207}$ Como analicé en su oportunidad, se trata de aspectos muy positivos del Protocolo que encuentran apoyo en las prácticas recomendadas a partir de la evidencia científica disponible. Según esta cualquier inducción del funcionario a cargo de la diligencia puede afectar la calidad de la identificación. A su vez, la sola advertencia que la persona podría no estar en el set fotográfico disminuye en un porcentaje estadísticamente significativo la probabilidad de error del reconocimiento.

${ }^{208}$ Se trataría de un problema menos extendido de acuerdo a los entrevistados, ya que sólo es mencionado categóricamente por uno de ellos, aún cuando varios manifiestan dudas debido a los formatos de registro de la actividad. Entrevista Defensor n ${ }^{\circ}$ 5, 4 de septiembre de 2015.

${ }^{209}$ Un funcionario de la PDI describe el proceso de información señalando "Se le dan a conocer primero sus derechos, luego se le indica que si está en condiciones de poder reconocer se le muestra el set fotográfico, teniendo que indicar si reconoce y en qué porcentaje y también decirles que puede no estar, porque hay un set en donde no está el imputado, entonces se le dice esto." Entrevista PDI n 3, 20 de enero de 2016. Otro lo describe señalando: "Las instrucciones que se dan es que principalmente esté tranquila, que no es obligación que reconozcan a alguien y que no va a defraudar si es que no reconoce a nadie, se le dice que se le van a exhibir alrededor de 20 fotografías y que a partir de ellas puede identificar libremente al sujeto". Entrevista PDI ${ }^{\circ} 7,4$ de febrero de 2016.

${ }^{210}$ Entrevista Carabinero n ${ }^{\circ} 2,11$ de octubre de 2015.
} 
Polít. crim. Vol. 12, No 23 (Julio 2017), Art. 9, pp. 291-379.

[http://www.politicacriminal.cl/Vol_12/n_23/Vol12N23A9.pdf]

identificación, agregando que “...se trata de darle tranquilidad a la víctima o testigo para que reconozca, no se le induce a nada." 211 . Como se puede apreciar, el foco no parece estar tanto en asegurar confiabilidad de la diligencia sino permitir que sea realizada. Al poner acento en esto, es probable que se genere algún tipo de inducción a reconocer.

A lo anterior, se suma que del análisis de las entrevistas se generan dudas de que el lenguaje utilizado por los policías durante el desarrollo de la diligencia sea el más idóneo y que el uso de ciertas formas al ejecutarlas, podrían inducir a la víctima o testigo independiente que se haya hecho una advertencia previa. Así, un ejemplo se produce en la declaración de un funcionario de la PDI. Éste, luego de reconocer hacer las advertencias previas a víctimas y testigos en un formato bastante parecido al esperado por el Protocolo, relata que luego les dice "....que la imagen puede estar un poco cambiada, que se fije en la forma de ojos, cara, puede estar más gordo, con pelo teñido, tatuajes, etc. Se le hace mención a todo esto para que no lo pase de alto. Si la persona no reconoce a nadie, se hace una repasada con más lentitud o con más calma." ${ }^{, 12}$. Como se puede observar, el énfasis posterior a las aclaraciones tiende más bien a guiar a la víctima o al testigo en que debe reconocer, a tal punto que se indica que las características físicas podrían ser diferentes y a mostrarle una segunda vez el set de fotografías. Más extrema es la opinión de un juez de garantía que, al referirse a los diálogos que se generan entre policías y víctimas, sostiene que en su experiencia “...las policías presionaban un poco a la víctima: 'oiga, acá tenemos que reconocer a alguien"."213. Todo esto explicaría la percepción de un fiscal respecto a las altas tasas de reconocimiento que se dan en su jurisdicción cuando se realizan a través de set fotográficos. Este fiscal señala: "Ahora, cómo ocurre y qué ocurre, no lo sé porque no estoy presente. Lo que es llamativo es que de 20 reconocimientos fotográficos, en 18 o 19 se reconoce y eso me llama la atención." ${ }^{214}$.

\section{d) La composición de los set fotográficos.}

Finalmente, existe un acuerdo importante en todas las categorías de entrevistados que un área en donde se producen problemas relevantes de cumplimiento de las reglas del Protocolo se da en materia de composición de los set fotográficos.

Una primera cuestión en esta materia tiene que ver con el número de las fotografías. Como se señaló, el Protocolo exige la construcción de dos set con diez fotografías cada uno. Los entrevistados manifiestan una enorme disparidad respecto al cumplimiento de este estándar. Existe un grupo que manifiesta su cumplimiento estricto ${ }^{215}$, pero luego varios señalan que los set se integran con números tan diversos que van desde las tres fotografías a las $30^{216}$.

\footnotetext{
${ }^{211}$ Entrevista PDI $n^{\circ}$ 4, 4 de febrero de 2016.

${ }^{212}$ Entrevista PDI n ${ }^{\circ} 8,4$ de febrero de 2016.

${ }^{213}$ Entrevista Juez de Garantía n ${ }^{\circ} 4,8$ de julio de 2015.

${ }^{214}$ Entrevista Fiscal no 2,9 de junio de 2015.

${ }^{215}$ En este se encuentran principalmente los fiscales, por ejemplo, Entrevista Fiscal $\mathrm{n}^{\circ} 6,11$ de septiembre de 2015; Entrevista Fiscal n ${ }^{\circ}$ 7, 2 de octubre de 2015; y, Entrevista Fiscal n 13, 29 de enero de 2016. También la mayoría de los funcionarios policiales entrevistados.

${ }^{216}$ Por ejemplo, un abogado señala se exhiben de 15 a 20 fotografías (Entrevista Abogado ${ }^{\circ} 1,4$ de mayo de 2015); un defensor, por su parte, indica que se trata de 10 a 15 fotografías (Entrevista Defensor $\mathrm{n}^{\circ} 1,11$ de
} 
DUCE, Mauricio. "Reconocimientos oculares: una aproximación empírica a su funcionamiento y algunas recomendaciones para su mejora".

Esta disparidad y apartamiento del Protocolo incluso es reconocido por un funcionario de carabineros y otro de la PDI que relatan que los set se construyen con 10 a 12 fotografías ${ }^{217}$. Más allá del número específico, pareciera nuevamente que se trata de un tema en el que las prácticas son muy heterogéneas $^{218}$.

En casos más extremos, aún cuando no mencionados con tanta frecuencia, se relatan procedimientos en los que se muestra a la víctima una o pocas fotografías, lo que hace que este procedimiento se transforme en una suerte de exhibición o show up no presencial ${ }^{219}$, como ocurrió en el caso de Luis Loyola del año 2012. Él fue imputado de un delito de robo con violación y su identificación como sospechoso se produce a partir del reconocimiento practicado por la víctima de una fotografía exhibida por la policía (como se llega a él en calidad de sospechoso es una cuestión que no aparece clara en el caso). Luego dicho reconocimiento es reforzado por otro realizado en la modalidad de rueda de sospechosos. La persecución penal en contra de señor Loyola concluyó cuando fue capaz de acreditar una coartada sólida (estaba trabajando el día y hora del incidente) y el resultado de un examen de ADN practicado por muestras obtenidas en el sitio del suceso descartó su participación en los hechos ${ }^{220}$. Esto también ocurrió tratándose del caso de Pedro Lobos. Como se estableció en el recurso de revisión, se exhibió sólo una fotografía a las víctimas $^{221}$.

Un segundo problema en la composición de los set tiene que ver con la integración de los mismos. Dos son las características centrales que debe cumplir desde este punto de vista. La primera es que las personas que lo integran deben tener un cierto nivel de similitud al sospechoso, al menos corresponder a una misma descripción para verificar si se está en condiciones reales de reconocer a un individuo dentro de un grupo. La segunda, es que dentro de ellos debiera haber sólo un sospechoso y el resto ser "rellenos" o "cebos" de manera de poder descartar identificaciones erróneas de personas no involucradas en el delito. La investigación identificó problemas en ambas cuestiones.

junio de 2015); otros de sólo 10 (Entrevista Defensor $n^{\circ} 2,17$ de junio de 2015 y Entrevista Defensor $n^{\circ}$ 6, 1 de abril de 2016) y, finalmente, uno eleva esa cifra a 30 (Entrevista Defensor $n^{\circ} 5,4$ de septiembre de 2015).

${ }^{217}$ Entrevista a Carabinero n ${ }^{\circ} 2,11$ de octubre de 2015 y Entrevista a PDI n ${ }^{\circ} 3,20$ de enero de 2016.

${ }^{218}$ El estudio empírico sobre sentencias TOP de la Región Metropolitana vuelve a confirmar este hallazgo. Lo primero que llama la atención de los resultados es que en un 34,3\% de los casos no se registran datos acerca del número de fotografías exhibidas a la víctima o testigo. En un 11,4\% de ellos se exhiben entre una y diez fotografías; en un $40 \%$ entre diez y 20; y, en un 14,3\% entre 20 y 30. CATALÁN, Aproximación Empírica, cit. nota $\mathrm{n}^{\circ} 17$, p. 47.

${ }^{219}$ Por ejemplo: Entrevista Defensor n ${ }^{\circ}$ 7, 19 de abril de 2016; Entrevista Defensor n ${ }^{\circ}$ 8, 11 de julio de 2016 (quien luego de relatar el procedimiento señala "Sin embargo, yo creo que lo que hacen es que la víctima dice 'él fue' y sacan su foto y la agregan..."); y, Entrevista Fiscal n 10, 6 de enero de 2016 (quien señala "El set fotográfico es el que más se utiliza, pero no como en las películas, sino que cuando la persona tiene dudas y pide verlo para ver si fue o no. Supongamos que un sujeto cometió un delito pero alcanza a arrancar y los pillan. La víctima tiene dudas que sea él, entonces carabineros se lo muestra a la víctima por medio del set fotográfico, pero no en persona porque ahí habría inducción.”).

${ }^{220}$ Mayores detalles del caso pueden verse en: http://www.proyectoinocentes.cl/casos/detalle/25/luis loyolatorreblanca [visitado el 01.07.2016].

${ }^{221}$ Corte Suprema de Chile, Recurso de Revisión, Sentencia del 22 de febrero de 2012, Causa Rol n 12018 2011. 
Polít. crim. Vol. 12, № 23 (Julio 2017), Art. 9, pp. 291-379.

[http://www.politicacriminal.cl/Vol_12/n_23/Vol12N23A9.pdf]

Respecto a la similitud, una parte del problema se explica por la vaguedad o derechamente inexistencia de descripciones previas de parte de la víctima o testigo según ya he tenido oportunidad de mencionar. Más allá de eso, varios entrevistados manifiestan que esta sería una debilidad de la forma en que se construyen los set. Un fiscal describe este problema señalando que

“...supuestamente deben ser de características similares y ahí está el gran pero porque buscan del RUT de manera aleatoria para que sean de la misma edad, pero que de repente haya características similares es otra cosa. Hay un tema respecto a los reconocimientos sobre todo por tiempo. No hay tiempo para seleccionar las fotografías. ${ }^{, 222}$.

Afirmaciones y preocupaciones similares son manifestadas por varios jueces de garantía 223 y de tribunal oral en lo penal. ${ }^{224}$ Por ejemplo un juez TOP da cuenta en su experiencia en juicio oral que

“...según ellos incorpora rostros similares de personas, uno se da cuenta con el contrainterrogatorio que no es así, de hecho hemos tenido juicios en los que se ha autorizado -porque viene como prueba de la defensa- el set fotográfico y uno lo compara y se da cuenta que las personas no tienen las mismas características."225.

Otro relata un caso más extremo al indicar que en los set ocurre que “...algunas veces hemos visto que se juntan hombres con mujeres, mujeres con niños, calvos con personas de pelo largo....entonces ¿qué seriedad hay aquí?"226. Un juez de garantía, por su parte, explica que "...es que no hay suerte de homologación o parecido entre las personas que son mostradas, no hay parecidos y la policía no hace un set de calidad... los set no reflejan un patrón parecido. ${ }^{227}$. Incluso un funcionario de la PDI entrevistado reconoce este problema ofreciendo una explicación: “...otra cosa es el tema de características físicas, ya que es algo subjetivo. Yo puedo encontrar similares a dos personas, pero otro puede encontrarlo completamente distinto." 228 .

\footnotetext{
${ }^{222}$ Entrevista Fiscal n ${ }^{\circ}$ 7, 2 de octubre de 2015.

${ }^{223}$ Entrevista Juez de Garantía n ${ }^{\circ}$ 4, 8 de julio de 2016 y Entrevista Juez de Garantía n ${ }^{\circ}$ 6, 3 de septiembre de 2015.

${ }^{224}$ Entrevista Juez Top n ${ }^{\circ}$ 1, 9 de junio de 2015; Entrevista Juez Top n ${ }^{\circ} 2,15$ de junio de 2015; Entrevista Juez Top n 3, 2 de julio de 2015; y, Entrevista Juez Top n ${ }^{\circ}$, 5 de octubre de 2015.

${ }^{225}$ Entrevista Juez Top n ${ }^{\circ} 2,15$ de junio de 2015.

${ }^{226}$ Entrevista Juez Top n ${ }^{\circ}$ 7, 5 de octubre de 2015. Si bien esta última opinión aparece algo extrema, hay otra evidencia que ratificaría problema de este nivel con el uso de las bases de datos fotográficas. Así, la PDI de Valdivia ha llevado adelante un proyecto denominado Kardex Antidelincuencial Clasificado (KADAC) que se construyó sobre la base de un diagnóstico en el que se reconoce problemas serios en las bases de datos de fotografías que dispone la PDI en donde no se discrimina por sexo, edad y en la que se presentan serios problemas de actualización. La experiencia, con todo, está destinada a mejorar los procesos de exhibición de kardex sin sospechoso y no los set fotográficos. Sobre esta experiencia y su diagnóstico puede verse LLANQUIMÁN, Alex, et. al:: "Kardex Antidelincuencial Clasificado (KADAC)", en: FUNDACIÓN PAZ CIUDADANA, Buenas prácticas para el análisis delictual en América Latina 2015, Santiago: Fundación Paz Ciudadana, 2016, pp. 136-156.

${ }_{227}^{22}$ Entrevista Juez de Garantía n ${ }^{\circ}$ 6, 3 de septiembre de 2015.

${ }^{228}$ Entrevista PDI n ${ }^{\circ}$ 5, 4 de febrero de 2015.
} 
DUCE, Mauricio. "Reconocimientos oculares: una aproximación empírica a su funcionamiento y algunas recomendaciones para su mejora".

Con menor frecuencia que lo anterior, algunos entrevistados identifican como problema el que los set de fotografías estarían construidos con más de un sospechoso. La afirmación de un juez de tribunal oral en lo penal describe esto al señalar: “....es súper habitual que los set fotográficos sólo se hacen con delincuentes que cometen los mismos delitos, en el mismo sector geográfico donde fue detenido el acusado... Siempre va a ser un delincuente o por lo menos un tipo que ha tenido una pasada por el sistema."229. Si bien se trata de una preocupación de otros entrevistados, ella es manifestada con menos claridad y fuerza ${ }^{230}$. Un caso donde se refleja esta práctica y los problemas que puede generar es en el de Adrián Zarricueta del año 2013. Zarricueta es imputado de cometer un delito robo con violación a una pasajera de un taxi colectivo que él habría conducido. $\mathrm{Su}$ vínculo con el caso se produce luego que se le exhibiera a la víctima un set de fotografías compuesto por todos los choferes de la línea de colectivos, es decir, en el cual todos eran potenciales sospechosos y el que fuera elegido podría razonablemente ser el verdadero autor. Ahí la víctima señala reconocer a Zarricueta con un $90 \%$ de certeza. Su fotografía estaba incluida a pesar que él había dejado de trabajar en esa línea de colectivos alrededor seis meses antes de los hechos. El señor Zarricuenta estuvo 80 días en prisión preventiva hasta que se acreditó gracias a un examen de ADN practicado sobre la base de muestras biológicas encontradas en la víctima que no podía ser el autor del delito que se le imputaba ${ }^{231}$.

La explicación del problema del uso de set sin cebos podría estar en parte en lo que mencionan dos funcionarios de la PDI entrevistados. Según uno de ellos las dificultades emanarían de las exigencias que impone el Protocolo en casos complejos, así sostiene que "....a veces nosotros tenemos 6 ó 7 imputados....se nos hace difícil tener 70 personas para un set y otras 70 para otro...."232. Otro, al dar explicaciones en los casos en donde se producen apartamientos del Protocolo identifica como un problema el que "...no haya cantidad de fotografías que se requieren." 233 .

Un último problema detectado en las entrevistas se refiere a la calidad de las fotografías que se utilizan y su actualización ${ }^{234}$. Un grupo importante de entrevistados indica que las fotografías utilizadas son en blanco y negro lo que genera dificultades importantes para practicar reconocimientos de calidad y luego evaluarlos ${ }^{235}$. Para los funcionarios de la PDI una parte importante del problema se explica en las carencias de la base de datos que utilizan ya que la regla general es que se recurra a la base que tiene el Registro Civil, la cual presentaría algunos problemas. Así, uno sostiene que

\footnotetext{
${ }^{229}$ Entrevista Juez Top n ${ }^{\circ} 3,2$ de julio de 2015.

${ }^{230}$ Entrevista Juez Top n ${ }^{\circ}$ 2, 15 de junio de 2015; Entrevista Juez Top n ${ }^{\circ}$ 5, 8 de julio de 2015; y, Entrevista Juez Top $n^{\circ} 7,5$ de octubre de 2015.

231 Mayores detalles del caso pueden verse en: http://www.proyectoinocentes.cl/casos/detalle/46/adrianzarricueta toro [visitado el 01.07.2016].

${ }^{232}$ Entrevista PDI n ${ }^{\circ} 2,20$ de enero de 2016.

${ }^{233}$ Entrevista PDI n ${ }^{\circ} 5,4$ de febrero de 2016.

${ }^{234}$ Por ejemplo, un juez de garantía señala que “...la calidad de la muestra es pésima.” Entrevista Juez de garantía $n^{\circ} 6,3$ de septiembre de 2015. Un defensor apunta que "Todavía no están 100\% homologadas el tipo de fotografías", Entrevista Defensor n ${ }^{\circ} 1,11$ de junio de 2015.

${ }^{235}$ Por ejemplo, Entrevista Defensor n ${ }^{\circ}$ 6, 1 de abril de 2016; Entrevista Fiscal n ${ }^{\circ} 10,6$ de enero de 2016; y, Entrevista Juez de Garantía n ${ }^{\circ} 4,8$ de julio de 2015.
} 
Polít. crim. Vol. 12, № 23 (Julio 2017), Art. 9, pp. 291-379.

[http://www.politicacriminal.cl/Vol_12/n_23/Vol12N23A9.pdf]

"Generalmente la imagen se obtiene del registro Civil, esto tiene una problemática porque a veces tenemos un imputado de 16 ó 17 años que no tienen ID y no podemos acceder a su imagen o, en otro caso, sacó el carné cuando tenía 10 años. En esos casos accedemos a imágenes de Gendarmería de Chile si ha estado antes detenido o Facebook."

Este mismo funcionario señala con posterioridad que

"La fotografía del Registro Civil a veces discrepa mucho con la realidad, a veces están más gordos, más flacos, más deteriorados" "236, otro indica que "El problema es que son fotos de personas que están en el Registro Civil, donde la foto es distinta a la realidad, donde realmente no se parecen, las fotos juegan en contra., 237 .

En buena medida, tal como identifican otros funcionarios, es que con el paso del tiempo se trata de una base que queda obsoleta ${ }^{238}$.

\subsubsection{Algunos problemas comunes y sus explicaciones.}

He dejado esta sección final para analizar algunos problemas que parecen presentarse con persistencia en todo tipo de reconocimientos o que son más bien de corte estructural, por lo mismo, con posibilidades de afectar la confiabilidad de cómo estas diligencias se están realizando más allá de formar parte de un paso necesario de algunas de sus modalidades.

\section{a) Registros precarios y poco confiables.}

Como he sugiriendo en secciones anteriores, un elemento que se observa como extremadamente problemático es la forma en que se están registrando los procedimientos de reconocimiento de diverso tipo. Para poder realizar un control mínimo a la calidad y confiabilidad de los mismos se requiere contar con información precisa y muy detallada acerca de cómo estos fueron llevados adelante. Por lo mismo, como ya mencioné, una de las recomendaciones centrales que proviene de la literatura especializada es la necesidad de mantener un registro completo del procedimiento, preferiblemente de carácter audiovisual. También tuve oportunidad de señalar que el Protocolo se hace cargo en forma deficiente de este tema al establecer, por una parte, la necesidad de un registro, pero a la vez operando sobre la base de que este se satisface con un acta escrita que incluye aspectos relativamente formales o que puede ser llenada con poco contenido, por lo que existe un riesgo que la información necesaria para evaluar su calidad y confiabilidad no esté presente. El caso de Julio Robles es una buena muestra del problema que presentan este tipo de registros. El análisis de las actas de reconocimiento realizados por las dos víctimas muestra que en ambos casos se inicia con una primera página que corresponde a un formulario pre-impreso en el que se consignan datos formales y luego en su segunda página se adjunta la foto de la persona reconocida con una escritura a mano de las víctimas señalando que dicha foto fue

\footnotetext{
${ }^{236}$ Entrevista PDI n ${ }^{\circ} 2,20$ de enero de 2016.

${ }^{237}$ Entrevista PDI n ${ }^{\circ} 4,4$ de febrero de 2016.

${ }^{238}$ Entrevista PDI n ${ }^{\circ}$, 4 de febrero de 2016 y Entrevista PDI n 7, 4 de febrero de 2016.
} 
DUCE, Mauricio. "Reconocimientos oculares: una aproximación empírica a su funcionamiento y algunas recomendaciones para su mejora".

efectivamente reconocida ${ }^{239}$. En ninguna de estas se entrega información con algún nivel de detalle siquiera sobre las instrucciones entregadas por los funcionarios que administraron el procedimiento, la respuesta o afirmaciones específicas de las víctimas, las otras fotografías exhibidas, el tiempo tomado para reconocer la foto, etc. La lectura de las actas da cuenta que, en cambio, ellas contienen información absolutamente estandarizada y que no incluye detalles o elementos relevantes, todo lo cual impide un control serio de los procedimientos respectivos.

El caso de Julio Robles es previo al desarrollo del Protocolo, por lo que la investigación intentó indagar si en la actualidad la calidad de los registros había mejorado. Un primer hallazgo en esta materia es que los entrevistados en forma unánime señalan que los registros en la actualidad son realizados efectivamente por escrito por medio de actas similares a las que contiene el Protocolo. Una excepción a esto se produce tratándose de las exhibiciones realizadas en contexto de flagrancia. En ese caso se detectaron dos tipos de prácticas. En primer lugar, debido a la dinámica en que se producen algunas de ellas, no se deja registro alguno ${ }^{240}$. Esto es lo que ocurrió, por ejemplo, en el caso de Julio Robles respecto al reconocimiento realizado por medio su exhibición a una de las víctimas quien lo observó sentada en el vehículo policial. Allí, el único "registro" fue la memoria del propio funcionario policial a cargo de la exhibición. Con todo, la situación más común pareciera ser que las actas más formales son reemplazadas por menciones a esta diligencia que se incluyen en el parte policial en donde se registra la detención. ${ }^{241}$ Como ya he señalado, esto resulta consistente en un contexto en donde el Protocolo no regula en forma explícita a las exhibiciones, por lo que los contenidos de registro exigidos a las otras formas de reconocimiento no se plantean a este tipo de actividades.

En cualquiera de estos formatos, la opinión bastante unánime es que los registros presentan serios problemas de calidad y dificultan el comprender cómo efectivamente fueron llevados adelante los procedimientos de reconocimiento. Así, por ejemplo, al referirse a los problemas que presenta la realización de estas diligencia, un Juez de Garantía señaló: "El principal problema es que no hay registro claro de cómo fue realizado el reconocimiento." 242 . Otro, al referirse a los reconocimientos, manifiesta que "...ni siquiera están bien registrados, entonces uno nunca sabe como son..."243. Opiniones de este tipo se repiten insistentemente entre otros actores del sistema entrevistados ${ }^{244}$.

\footnotetext{
${ }^{239}$ Dichas actas ocupan las fojas 13 a 14 y 15 a 16 de la carpeta investigativa del fiscal. Se trata de un documento en formato electrónico en poder del autor.

${ }^{240}$ Por ejemplo, un fiscal señala sobre las exhibiciones que "El problema es que esa información muchas veces no queda registrada en la carpeta." Entrevista Fiscal $n^{\circ} 10,6$ de enero de 2015. Un defensor señala, por su parte, "Para nosotros es muy difícil demostrar que se lo mostraron, porque nunca se toma registro de esto". Entrevista Defensor $n^{\circ} 2,17$ de junio de 2015.

${ }^{241}$ Por ejemplo: Entrevista Juez de Garantía n ${ }^{\circ} 4,8$ de julio de 2015 (quien señala que los partes incluyen cláusulas del estilo: “...lo reconoció por su vestimenta y rasgos físicos.”); y, Entrevista Defensor $n^{\circ} 8,1$ de mayo de 2016.

${ }^{242}$ Entrevista Juez de Garantía n ${ }^{\circ}$ 5, 15 de julio de 2015.

${ }^{243}$ Entrevista Juez de Garantía ${ }^{\circ}$ 2, 25 de junio de 2015.

${ }^{244}$ Entrevista Defensor $n^{\circ} 1,11$ de junio de 2015; Entrevista Defensor $n^{\circ} 2,17$ de junio de 2015; Entrevista Defensor $n^{\circ}$ 3, 2 de julio de 2015; Entrevista Fiscal $n^{\circ} 1,7$ de mayo de 2015; Entrevista Fiscal $n^{\circ} 2,9$ de junio de 2015; Entrevista Juez de Garantía n ${ }^{\circ}$ 1, 7 de mayo de 2015; Entrevista Juez de Garantía n 3, 26 de junio
} 
Polít. crim. Vol. 12, No 23 (Julio 2017), Art. 9, pp. 291-379.

[http://www.politicacriminal.cl/Vol_12/n_23/Vol12N23A9.pdf]

Esta precariedad en los registros genera problemas de confianza en distintos actores. Un Juez de Garantía lo explica así:

"Primero tiene que ver con la calidad del registro, no se filman, simplemente se hacen actas y desconfiamos de ellas. Tú le preguntas a cualquier testigo o víctima y le pasan los papeles y se firma, no sabemos cómo se hizo, es un acto de fe y en juicio nos enteramos recién si los carabineros mienten. ${ }^{, 245}$.

En palabras de un fiscal esto se describe de la siguiente forma al referirse a la información que reciben sobre los reconocimientos: "Yo te diría que en general la calidad no es mala, lo que no sé, y te lo digo por lo que me pasó en esta causa, que no sé si veraz..."246. En similares términos un defensor público señala "Una cosa es lo que se hace y otra es lo que queda escrito...Luego se pone en el registro que mostraron variadas fotos cuando en realidad no fue así."247.

Un problema específico respecto a la calidad de los registros en los reconocimientos practicados en set fotográficos que es destacado por varios de los entrevistados tiene que ver con la falta de inclusión de las fotografías exhibidas y que no fueron reconocidas por la víctima o testigo. ${ }^{248}$ En otros casos, el problema es de acceso a dichas fotografías o, al menos, en un formato que permita controlar su calidad. Un defensor describe esto señalando:

“...en algunos casos hemos tenido que pedir la cautela de garantías para que se acompañen las fotografías cuando son en color, porque te las mandan en blanco y negro. A veces ni siquiera en la carpeta investigativa están bien adjuntadas. Entonces muchas veces tenemos que pedir esto para temas de reconocimiento, por ejemplo, se dijo era moreno y resulta que en la foto no se aprecia bien." ${ }^{249}$.

Otro indica: "Las fotografías creo no son en colores, pero para nosotros es difícil de saber porque siempre nos llegan las copias en blanco y negro y cuando se solicita el original nunca se da."${ }^{, 250}$.

Como se puede apreciar, las formas de registro utilizadas en la actualidad constituyen un problema serio en el control de calidad de las diligencias de reconocimientos realizadas. Esto expone a fiscales y jueces a adoptar decisiones con información limitada y que podría conducir a decisiones erróneas.

de 2015; Entrevista Juez de Tribunal Oral en lo Penal $n^{\circ}$ 4, 6 de julio de 2015; Entrevista Juez de Tribunal Oral en lo Penal n ${ }^{\circ}$ 5, 8 de julio de 2015; y, Entrevista Abogado n 4, 22 de julio de 2015.

${ }^{245}$ Entrevista Juez de Garantía n ${ }^{\circ} 1,7$ de mayo de 2015.

${ }^{246}$ Entrevista Fiscal n ${ }^{\circ}$ 6, 11 de septiembre de 2015.

${ }^{247}$ Entrevista Defensor n ${ }^{\circ}$ 7, 19 de abril de 2016.

${ }^{248}$ Sobre este punto, entre otros, Entrevista Juez tribunal Oral en lo Penal, $\mathrm{n}^{\circ} 4,6$ de julio de 2015.

${ }^{249}$ Entrevista Defensor $n^{\circ} 1,11$ de junio de 2015.

${ }^{250}$ Entrevista Defensor n ${ }^{\circ}$ 6, 1 de abril de 2016. 
DUCE, Mauricio. "Reconocimientos oculares: una aproximación empírica a su funcionamiento y algunas recomendaciones para su mejora".

No uso de doble ciego.

Ya ha sido señalado que una de las recomendaciones principales respecto a la forma de llevar adelante las diligencias de reconocimiento que surgen de la literatura especializada es asegurar que los funcionarios a cargo de su ejecución no tengan conocimiento de quien es la persona sospechosa de manera de evitar que transmitan pistas a la víctima o testigo que los lleve a realizar el proceso de identificación más allá de su memoria. También mencioné que en este punto el Protocolo era deficiente ya que establecía sólo como una aspiración ("idealmente") que los funcionarios policiales que las realicen no hayan participado en las fases previas de la investigación.

Como era posible esperar en este escenario, existe bastante unanimidad en los entrevistados respecto a que lo normal en el funcionamiento del sistema es que los funcionarios policiales que llevan adelante las diligencias hayan intervenido en actividades anteriores y conozcan al sospechoso ${ }^{251}$. Este hallazgo es ratificado por el estudio sobre sentencias TOP de la Región Metropolitana ${ }^{252}$.

Lo interesante en este punto es que incluso varios funcionarios de la PDI identifican también que se trata de un área problemática. Si bien algunos de ellos enfatizan el cumplimiento de este estándar ${ }^{253}$, hay otros que lo identifican como algo problemático. Así, por ejemplo, uno refiriéndose al doble ciego sostiene que "Eso no pasa. Hay inconvenientes porque hay poco recurso humano, muchos policías intervienen en la investigación y no tengo uno que no sea cercano a ella", luego agrega "Cerca del $80 \%$ lo hace un funcionario que sí tiene participación en la investigación." ${ }^{254}$. Otro es incluso más enfatizo al señalar que "95 a 98\% de los procedimientos se apartan", refiriéndose al Protocolo, debido al no

\footnotetext{
${ }^{251}$ Se pronuncia explícitamente sobre esta materia identificándola como un problema en el funcionamiento del sistema defensores, fiscales, jueces de garantía y de juicio oral. Véase: Entrevista Defensor $\mathrm{n}^{\circ} 1,11$ de junio de 2015; Entrevista Defensor $n^{\circ} 3,2$ de julio de 2015; Entrevista Defensor $n^{\circ} 4,2$ de julio de 2015; Entrevista Defensor $n^{\circ}$ 5, 4 de septiembre de 2015; Entrevista Defensor $n^{\circ} 6,1$ de abril de 201; Entrevista Fiscal $n^{\circ}$ 2, 9 de junio de 2015; Entrevista Fiscal $n^{\circ}$ 4, 28 de julio de 2015; Entrevista Fiscal $n^{\circ}$ 5, 4 de septiembre de 2015; Entrevista Fiscal n ${ }^{\circ}$ 6, 11 de septiembre de 2015; Entrevista Fiscal n ${ }^{\circ}$ 10, 6 de enero de 2016; Entrevista Fiscal n ${ }^{\circ}$ 12, 12 de enero de 2016; Entrevista Juez de Garantía n ${ }^{\circ}$ 1, 7 de mayo de 2015; Entrevista Juez de Garantía n ${ }^{\circ}$ 2, 25 de junio de 2015; Entrevista Juez de Garantía n 4, 8 de julio de 2015; Entrevista Juez de Garantía n ${ }^{\circ}$ 5, 15 de julio de 2015; Entrevista Juez de Garantía n ${ }^{\circ}$ 7, 14 de septiembre de 2015; Entrevista Juez TOP n ${ }^{\circ}$ 3, 2 de julio de 2015; Entrevista Juez TOP $\mathrm{n}^{\circ}$ 6, 14 de julio de 2015; y, Entrevista Juez TOP n ${ }^{\circ} 7,5$ de octubre de 2015.

${ }^{252}$ Sólo en un $20 \%$ de esos casos hubo doble ciego, en tanto que en un $42,9 \%$ no lo hubo. Finalmente, en un $37,1 \%$ la sentencia no registró datos sobre este punto crucial dando cuenta de la poca relevancia que estaría teniendo al momento de la toma de decisiones sobre la calidad y confiabilidad de estas diligencias. CATALÁN, Aproximación Empírica, cit. nota n 17, p. 48.

${ }^{253}$ Un funcionario sostiene sobre este punto que "Generalmente el protocolo lo debe hacer quien no tomó la declaración, para que no sea inductivo o no esté contaminado. Casi siempre se cumple, porqué es fácil, le pides a alguien más de la oficina". Entrevista PDI $n^{\circ} 7,4$ de febrero de 2016. Otro señala: “...es tomada por un oficial distinto al que tomó la declaración y el que hace el acta policial”. Entrevista PDI n ${ }^{\circ} 2,20$ de enero de 2016.

${ }^{254}$ Entrevista PDI n ${ }^{\circ}$ 4, 4 de febrero de 2016.
} 
Polít. crim. Vol. 12, No 23 (Julio 2017), Art. 9, pp. 291-379.

[http://www.politicacriminal.cl/Vol_12/n_23/Vol12N23A9.pdf]

cumplimiento de la exigencia de doble ciego ${ }^{255}$. Este tema también es abordado por uno de los carabineros entrevistados él que, frente a la pregunta de quién debe realizar la diligencia de reconocimiento, responde: "El personal aprehensor, personalmente e independiente del grado, la antigüedad o el cargo que esté ejerciendo. Si es él el que detuvo es él que debe adoptar el procedimiento en un 100\%."256.

En buena parte de los casos objeto de análisis en este trabajo se produjo el fenómeno que los funcionarios a cargo de la investigación fueron quienes también llevaron adelante los procedimientos posteriores de reconocimiento. Esto ratificaría que se trata de una práctica muy habitual del sistema. Paradigmáticos en este sentido son nuevamente los casos de Julio Robles y Pedro Lobos. En ambos, ellos fueron efectuados por el mismo carabinero que estaba a cargo del procedimiento. En consecuencia, se trataba de personas que conocían el nombre y las fotografías de los sospechosos antes de realizar la diligencia de exhibición de set fotográfico ${ }^{257}$.

\section{c) Procedimientos sugestivos.}

Han sido mencionadas en forma previa una serie de prácticas que tienen incidencia en la confiabilidad de los reconocimientos. Varias de ellas abren espacios a que los ejercicios de reconocimiento sean productos de la sugestión o inducción de víctimas y testigos, como por ejemplo, el lenguaje utilizado por los funcionarios. Junto con estas cuestiones, las entrevistas dan cuenta que hay otro grupo de conductas y acciones de parte de quienes ejecutan las diligencias que hacen que el riesgo de la inducción sea enorme. Dentro del conjunto muy heterogéneo de cuestiones que es posible identificar en las entrevistas me detengo en aquellas que me parecen más graves y son mencionadas con mayor frecuencia por los entrevistados.

En materia de exhibiciones es donde aparentemente hay más espacios para el fenómeno de inducción. Como ya decía, hay distinta evidencia que indica que la espontaneidad de muchos de esos reconocimientos no es tal. A ello se suma el que, según relatan varios entrevistados, no sería poco frecuente que los funcionarios policiales le muestren directamente a víctimas y testigos al sospechoso preguntando cuestiones como si "ese es el delincuente." 258 . Como se podrá apreciar, se trata de un tipo de reconocimiento en el que se deja muy poco espacio a la identificación libre que debieran realizar víctimas y testigos. Más sutil, pero igualmente problemático que lo anterior, es la descripción que realiza un juez al describir algunos reconocimientos señalando que hay: “...casos en los que la persona ya está detenido y como que la víctima pasa por el lado sin procurar con que no la vea antes. Se genera una predisposición porque ya vio a una persona detenida." ${ }^{259}$. Esto es

\footnotetext{
${ }^{255}$ Entrevista PDI n ${ }^{\circ} 8,4$ de febrero de 2016. Otro entrevistado señala, al describir el procedimiento, algo que da cuenta de una práctica problemática al señalar lo siguiente "Siempre hay dos personas para realizar el reconocimiento, debe ser alguien que sea del caso". Entrevista PDI nº 6, 4 de febrero de 2016.

${ }^{256}$ Entrevista Carabinero n ${ }^{\circ} 2,11$ de octubre de 2015.

${ }^{257}$ DUCE, “Algunas Lecciones A Partir de Cuatro Casos", cit. nota n ${ }^{\circ}$ 9, pp. 173-174.

${ }^{258}$ En esta dirección, por ejemplo, Entrevista Fiscal n ${ }^{\circ} 3,10$ de julio de 2015; Entrevista Juez TOP n ${ }^{\circ} 2,15$ de junio de 2015; Entrevista Juez TOP n ${ }^{\circ}$ 6, 14 de julio de 2015; Entrevista Juez TOP n ${ }^{\circ}$ 8, 22 de diciembre de 2015; y, Entrevista Defensor n ${ }^{\circ}$ 8, 19 de abril de 2016.

${ }^{259}$ Entrevista Juez TOP n ${ }^{\circ} 1,9$ de junio de 2015.
} 
DUCE, Mauricio. "Reconocimientos oculares: una aproximación empírica a su funcionamiento y algunas recomendaciones para su mejora".

reiterado por otro juez que relata que "En muchas ocasiones las defensas han levantado el problema de que las víctimas o los testigos han visto previamente ingresar en calidad de detenidos a las unidades policiales a quien luego va a intentar reconocer, con toda la inducción que eso significa." ${ }^{260}$. Estas conductas generan un entorno evidente en el cuál víctimas y testigos son presionadas para reconocer más allá del ejercicio genuino de su memoria. Un fiscal describe muy bien este fenómeno al señalar que en "En contexto de flagrancia la exhibición es realizada pero no en buenos término. La víctima probablemente dirá que sí es, se siente compelida a decir que sí y puede que se aprenda el rostro del sujeto." $" 261$. En la contracara la reacción de los jueces frente a esto es descrita de la siguiente forma “...los tribunales muchas veces tenemos que estar absolviendo porque no tenemos reconocimientos claros $\mathrm{y}$ hay dudas sobre la sugestionabilidad de los testigos o víctimas. $" 262$.

Tratándose de los reconocimientos en set fotográfico, una práctica adicional identificada es que no siempre la víctima o testigo se encuentra separada de otras víctimas y testigos al momento de practicar la identificación. Esto constituye un evidente riesgo ya que la elección de un sospechoso puede estar contaminada por la identificación que ya se ha realizado previamente y que se ha presenciado. Esta es la experiencia que ha vivido un juez que sostiene: “...una de las víctimas decía que cuando le habían exhibido en el computador las fotografías el otro testigo estaba atrás..."263. Esto ocurrió también en el caso de Julio Robles. En la declaración prestada por una de las víctimas al Ministerio Público durante la etapa de investigación se consigna el siguiente párrafo:

"En el reconocimiento en Carabineros yo estaba con mi hijo que fue testigo del hecho, nos mostraron 4 ó 5 fotos, nos dijeron que reconociéramos si era alguno de ellos, mi hijo fue el primero en reconocer y yo estuve de acuerdo, por las facciones, pues yo lo había visto. Carabineros me dijo que decidiera cuál era la foto, sin indicar ninguna en particular. $" 264$.

A estos problemas debe agregarse, como un fenómeno común, la existencia de diversos procedimientos de reconocimiento en un mismo caso. Estos generan el problema de "visiones sucesivas" de un mismo sospechoso. Se trata de una práctica problemática ya que, como he tenido oportunidad de mencionar, la literatura especializada señala que en el segundo reconocimiento ya no es posible determinar con precisión si el testigo o víctima reconoce al autor del delito o simplemente a la persona que ya identificó en una primera diligencia. Cabe recordar que se trata también de una cuestión no resuelta satisfactoriamente en el Protocolo el cual señala que no hay obstáculo para la realización de esta diligencia más de una vez. Este problema es identificado por varios entrevistados

\footnotetext{
${ }^{260}$ Entrevista Juez TOP n ${ }^{\circ} 6,14$ de julio de 2015.

${ }^{261}$ Entrevista Fiscal $n^{\circ} 2,9$ de junio de 2015. Otro fiscal, reconociendo los problemático de estas prácticas, entrega una justificación al señalar “...pero hay que entender que no es el único medio de prueba, si no es así se entiende que se exija un mayor estándar”. Entrevista Fiscal n 11,7 de enero de 2016.

${ }^{262}$ Entrevista Juez TOP ${ }^{\circ} 7,5$ de octubre de 2015.

${ }^{263}$ Entrevista Juez de Garantía n ${ }^{\circ} 5,15$ de julio de 2015.

264 Declaración de 28 de febrero de 2012 contenida en la página 22 de la carpeta investigativa del fiscal (documento en formato electrónico en poder del autor).
} 
Polít. crim. Vol. 12, № 23 (Julio 2017), Art. 9, pp. 291-379.

[http://www.politicacriminal.cl/Vol_12/n_23/Vol12N23A9.pdf]

quienes sostienen se trata de una forma regular de operación del sistema ${ }^{265}$. Esto se reflejaría en casos como los de Cristián López y Pedro Lobos. En ambos hubo en primer lugar un retrato hablado. Luego un reconocimiento en set fotográfico. Con posterioridad una diligencia de rueda de imputados presentes y, finalmente, en juicio oral se pidió a las víctimas reconocer al acusado. La pregunta obvia que generan estos procedimientos de múltiples reconocimientos es a quién efectivamente reconocen las víctimas en la segunda y tercera diligencia.

\section{d) Algunas explicaciones de los actores entrevistados.}

He dejado para el final de esta parte una breve sección destinada a presentar algunas explicaciones que entregan los actores del sistema al conjunto de problemas identificados previamente. La principal mencionada por todas las categorías de entrevistados tiene que ver con la falta de capacitación de quienes realizan las diligencias de reconocimiento. Debido a su importancia y el hecho que está vinculado a otras cuestiones que fueron objeto de indagación dejaré este tema para una sección posterior de este mismo capítulo.

Otro factor que surge de las entrevistas, es el nivel de autonomía que dispondrían los funcionarios policiales para llevar adelante estas diligencias. Así, por ejemplo, algunos jueces entrevistados identifican que los problemas de calidad que detectan en la forma que se ejecutan las diligencias de reconocimiento se explicarían, al menos en parte, como consecuencia de la autonomía y poca supervisión del Ministerio Público. En palabras de uno de los entrevistados al referirse a la mala calidad de los reconocimientos: "Lo que yo creo explica esto es que los fiscales tienen poco tiempo de hacer el trabajo correctamente, entonces delegan mucho en el trabajo de la policía y la policía hace el trabajo como le parece." $" 266$.

De acuerdo a lo que establece expresamente el Protocolo no se trataría de una facultad autónoma de las policías de aquellas contempladas en el artículo 83 del CPP y, por lo mismo, siempre requeriría una orden o instrucción previa del fiscal. La práctica parece indicar lo contrario. Sólo una porción menor de los fiscales y policías entrevistados afirma que las diligencias de reconocimiento emanan generalmente de una orden previa de los fiscales $^{267}$. Otros matizan señalando que algunas veces se realizan de manera autónoma y

\footnotetext{
265 Entre otros, Entrevista Fiscal $n^{\circ}$ 2, 9 de junio de 2015; Entrevista Fiscal $n^{\circ} 10,6$ de enero de 2016; Entrevista Defensor $\mathrm{n}^{\circ}$ 6, 1 de abril de 2016; Entrevista Defensor $\mathrm{n}^{\circ}$ 7, 19 de abril de 2016; Entrevista Defensor $\mathrm{n}^{\circ}$ 8, 11 de mayo de 2016; Entrevista Juez TOP ${ }^{\circ}$ 4, 6 de julio de 2015; y, Entrevista Juez TOP $\mathrm{n}^{\circ}$ 6, 14 de julio de 2014. El estudio empírico sobre sentencias TOP pudo determinar que en un 25,7\% de los reconocimientos en set fotográficos hubo previamente una exhibición del sospechoso a la víctima o testigo. CATALÁN, Aproximación Empírica, cit. nota n ${ }^{\circ} 17$, p. 48.

${ }^{266}$ Entrevista Juez TOP $n^{\circ} 3,2$ de julio de 2015. Sosteniendo un análisis similar véase también Entrevista Juez TOP ${ }^{\circ}$ 6, 14 de julio de 2015 y Entrevista Juez de Garantía n ${ }^{\circ} 1,7$ de mayo de 2015.

${ }^{267}$ Por ejemplo, Entrevista Fiscal $n^{\circ} 7,2$ de octubre de 2015; y, Entrevista Fiscal n ${ }^{\circ} 8,28$ de diciembre de 2015 (aún cuando reconoce que excepcionalmente se realizan de manera autónoma).
} 
DUCE, Mauricio. "Reconocimientos oculares: una aproximación empírica a su funcionamiento y algunas recomendaciones para su mejora".

otras si existe orden previa del fiscal ${ }^{268}$. Un grupo más importante, en cambio, reconoce que en la práctica estas diligencias se realizan de manera autónoma por las policías ${ }^{269}$.

Las razones que entregan algunos fiscales para explicar la distancia entre la regulación del Protocolo y la práctica obedece a la imposibilidad de controlar y hacer seguimiento al trabajo de terreno que hacen las policías. Por su parte, en el caso de algunos de los funcionarios pareciera existir una discrepancia más profunda acerca del alcance de sus facultades legales ya que sostiene que la autonomía de estos procedimientos surge del propio mandato de la ley ${ }^{270}$.

Otras explicaciones sobre los problemas de calidad de estas diligencias surgen de las percepciones policiales. Se pueden identificar tres explicaciones que ayudan a comprender los problemas que se han descrito y que no he mencionado previamente. En primer lugar, algunos funcionarios señalan que existe un problema de recursos disponibles que les permitan realizar los procedimientos en forma adecuada. Así, por ejemplo, lo señala un funcionario de la PDI al indicar: "Siempre he creído que hay un tema de recursos en todo sentido"271, quien luego al especificar los alcances de su opinión señala que esto impide realizar las ruedas de imputados y genera problemas de escasez de recursos humanos para la ejecución de otro tipo de procedimientos ${ }^{272}$. Una segunda explicación tiene que ver con las diferencias de criterios existentes en las distintas unidades del Ministerio Público con las que les corresponde trabajar, lo que hace que en ocasiones se les pidan cosas distintas. En palabras de un funcionario de la PDI, "La falencia que siempre existirá son los criterios que existen en las cuatro zonas de la fiscalía, porque aplican el mismo protocolo en forma distinta." 273 . Otro agrega que "El problema que identifico y que es frecuente es que existen distintas fiscalías y cada una tiene su forma de trabajar." ${ }^{274}$. Finalmente, otros funcionarios indican que los problemas estarían más bien al nivel de falta de comunicación y coordinación entre fiscales y policías lo que generaría dificultades en su trabajo concreto. Un funcionario de la PDI lo pone en términos bastante fuertes al indicar que "Hay fiscales que no tienen idea cómo trabajamos, entonces las instrucciones que dan o diligencias se vuelven una pérdida de tiempo.”275.

\footnotetext{
268 Por ejemplo, Entrevista PDI n 1 , 20 de enero de 2016 (quien focaliza la autonomía a los casos de flagrancia) y Entrevista PDI ${ }^{\circ} 2,20$ de enero de 2016.

${ }^{269}$ En esta dirección: Entrevista Fiscal n ${ }^{\circ} 2,9$ de junio de 2015; Entrevista Fiscal n ${ }^{\circ} 10,6$ de enero de 2016; Entrevista Fiscal $n^{\circ}$ 11, 7 de enero de 2016; Entrevista Fiscal $n^{\circ}$ 12, 12 de enero de 2016; Entrevista PDI $n^{\circ} 6$, 4 de febrero de 2016; y, Entrevista PDI n ${ }^{\circ}$ 8, 4 de febrero de 2016.

${ }^{270}$ En esta línea Entrevista PDI $n^{\circ}$ 3, 20 de enero de 2016; Entrevista PDI n ${ }^{\circ}$ 6, 4 de febrero de 2016; y Entrevista PDI n ${ }^{\circ} 8,4$ de febrero de 2016, el que cualifica su afirmación sólo al sitio del suceso.

${ }^{271}$ Entrevista PDI ${ }^{\circ}$ 5, 4 de febrero de 2016.

${ }^{272}$ Opiniones similares son manifestadas también en Entrevista PDI n ${ }^{\circ}$ 6, 4 de febrero de 2016. Concuerdan al menos en parte con esto algunos fiscales. Véase Entrevista Fiscal n ${ }^{\circ} 3,10$ de julio de 2015; Entrevista Fiscal $\mathrm{n}^{\circ}$ 5, 4 de septiembre de 2015; y, Entrevista Fiscal n ${ }^{\circ} 13,29$ de enero de 2016 (quien limita su afirmación a la falta de elementos técnicos). También concuerda con esto un juez oral que limita su afirmación a la falta de infraestructura adecuada. Entrevista Juez TOP n ${ }^{\circ} 8,22$ de diciembre de 2015.

${ }^{273}$ Entrevista PDI n ${ }^{\circ} 1,20$ de enero de 2016.

${ }^{274}$ Entrevista PDI $n^{\circ}$ 4, 4 de febrero de 2016.

${ }^{275}$ Entrevista PDI $n^{\circ}$ 5, 4 de febrero de 2016. Sobre el mismo problema también se pronuncia Entrevista PDI $\mathrm{n}^{\circ}$ 6, 4 de febrero de 2016. Concuerdan con esto Entrevista Juez de Garantía ${ }^{\circ}$ 2, 25 de junio de 2015; y,
} 
Polít. crim. Vol. 12, № 23 (Julio 2017), Art. 9, pp. 291-379.

[http://www.politicacriminal.cl/Vol_12/n_23/Vol12N23A9.pdf]

Los fiscales tienen una visión distinta. El problema principal destacado por varios entrevistados es que perciben que hay una cierta presión para que los funcionarios policiales produzcan resultados rápidos, lo que los llevaría a saltarse reglas de procedimiento y del Protocolo ${ }^{276}$.

Finalmente, quisiera mencionar una explicación que es referida por un defensor y un juez oral que parece apuntar a un tema extremadamente sensible y que debiera considerarse con cuidado. En apreciación de ellos, el apartamiento al Protocolo vendría dado por la convicción que tendrían los funcionarios policiales de la culpabilidad de ciertos sujetos que investigan. En ese entorno, es probable que algunas reglas del Protocolo se vean como obstáculos relativamente formales para llevar adelante una persecución penal exitosa y sientan justificado o menos problemático su incumplimiento ${ }^{277}$. Estas razones podrían explicar en parte el apresuramiento en llevar adelante los procedimientos que mencioné previamente.

\subsubsection{Litigación y valoración de los reconocimientos en sede de garantías.}

Durante la investigación se intentó también indagar respecto a las prácticas de litigación y valoración judicial de los reconocimientos durante la etapa de investigación e intermedia. Esto incluye principalmente el debate de medidas cautelares personales como la prisión preventiva y luego las discusiones de admisión y exclusión de prueba que se realizan en la Audiencia de Preparación de Juicio Oral (en adelante APJO).

Me parece que hay un nivel de consenso importante en los entrevistados en dos materias. La primera es que los jueces de garantía le otorgan un valor o peso importante a las diligencias de reconocimientos para adoptar decisiones en esta etapa, ya sea de medidas intrusivas, cautelares personales u otras cuestiones. La mayoría de los defensores ${ }^{278}$ y fiscales ${ }^{279}$ están de acuerdo sobre la importancia que le asignan los jueces de garantía a esta diligencia para tomar sus decisiones. Un fiscal describe esto de la siguiente forma:

Entrevista Juez de Garantía $\mathrm{n}^{\circ} 5,15$ de julio de 2015. Un juez oral pone énfasis en la falta de retroalimentación una vez concluidos los casos. Entrevista Juez TOP n ${ }^{\circ}$ 7, 5 de octubre de 2015.

${ }^{276}$ En esta línea Entrevista Fiscal n ${ }^{\circ} 1,7$ de mayo de 2015 (quien atribuye esto a la presión por llevar detenidos en procesos de flagrancia); Entrevista Fiscal n ${ }^{\circ} 2,9$ de junio de 2015 (quien lo atribuye a presiones de orden interno); Entrevista Fiscal $n^{\circ}$ 9, 4 de enero de 2016; Entrevista Fiscal $\mathrm{n}^{\circ} 12,12$ de enero de 2016 (quien identifica un problema de "ansiedad por avanzar rápido"); y, Entrevista Fiscal n 13, 29 de enero de 2016. Podría también ubicarse en este contexto de presión/ansiedad por actuar rápido la opinión de otro fiscal que considera la existencia de una suerte de exceso de entusiasmo policial en la ejecución de estas diligencias. Entrevista Fiscal $n^{\circ}$ 4, 28 de julio de 2015. Concuerda con la premura de los procedimientos como un factor relevante Entrevista Juez TOP n ${ }^{\circ} 2,15$ de junio de 2015.

${ }^{277}$ Entrevista Defensor $n^{\circ}$ 8, 11 de mayo de 2016 (quien señala: "Ellos creen que fue una persona entonces es simple llegar y no cumplir el protocolo"); y, Entrevista Juez TOP n 2, 15 de junio de 2015 (quien sostiene: "A ellos les basta con su verdad policial y ellos se convencen que tal es el sujeto y punto.")

278 Entrevista Defensor $n^{\circ} 1,11$ de junio de 2015; Entrevista Defensor $n^{\circ}$ 5, 4 de septiembre de 2015; Entrevista Defensor $n^{\circ}$ 6, 1 de abril de 2016; Entrevista Defensor $n^{\circ}$ 7, 19 de abril de 2016; y, Entrevista Defensor $\mathrm{n}^{\circ} 8,11$ de mayo de 2015. También se manifiesta de acuerdo con esto Entrevista Abogado $\mathrm{n}^{\circ} 1,4$ de mayo de 2015.

${ }^{279}$ Entrevista Fiscal $n^{\circ} 2,9$ de junio de 2015; Entrevista Fiscal $n^{\circ} 3,10$ de julio de 2015; Entrevista Fiscal $n^{\circ}$ 4, 28 de julio de 2015; Entrevista Fiscal $n^{\circ}$ 5, 4 de septiembre de 2015; y, Entrevista Fiscal $n^{\circ} 6,11$ de septiembre de 2015 . 
DUCE, Mauricio. "Reconocimientos oculares: una aproximación empírica a su funcionamiento y algunas recomendaciones para su mejora".

"Para el juez es importante el tema del reconocimiento, de hecho, yo diría que para la cautelar de prisión preventiva es primordial, o sea, si no hay reconocimiento -al menos este reconocimiento básico que se hace en el carro policial que consta en el parte- lo más probable es que no se decrete la prisión preventiva."280.

Otro fiscal da cuenta de la posición de los jueces con las siguientes palabras: “A mi me da la impresión que para ellos es muy importante y ellos te preguntan ¿y la víctima lo reconoció? ¿Y qué dijo en el reconocimiento? ¿Qué participación dijo que tenía? Es tema para ellos, es muy importante." 281.

En las declaraciones de fiscales y defensores existen algunos matices, pero en general no cambian la lógica general que en su percepción los reconocimientos serían un elemento de relevancia a considerar para la toma de decisiones de parte de los jueces. Por ejemplo un defensor señala que "Les pesa bastante a la hora de decidir. El caso de un fiscal con reconocimiento es mucho más sólido que otro sin. Pero también les pesa a la inversa, un mal reconocimiento a veces les echa abajo todo, restando credibilidad al fiscal frente al juez."282. Como se puede apreciar, el matiz estaría en el rol que juega tanto para fundar una decisión de otorgar una medida como para rechazarla, pero en ambos casos se trata de un factor significativo.

Todos los jueces de garantía entrevistados manifiestan acuerdo con esta visión sobre la importancia de los reconocimientos ${ }^{283}$. Algunos expresan adicionalmente que los criterios utilizados para valorarlos varían mucho de juez en juez, mostrando que existe en esta área un debate importante entre ellos ${ }^{284}$, incluso identificando que parte del problema tiene que ver con la falta del desarrollo de criterios claros por parte de los tribunales superiores en la materia $^{285}$. Otros sostienen una visión bastante crítica del trabajo que en la materia hacen sus colegas. Así, por ejemplo, un juez pone énfasis en decir que el único control de calidad que la mayoría de los jueces hacen de los reconocimientos para tomar decisiones es el análisis de las formalidades del acta con lo cual “...sino está formalmente hay un mal punto, pero si está formalmente hay un buen punto." ${ }^{286}$. Otro juez indica que a la mayoría de sus colegas "le basta" con la existencia de un reconocimiento para acreditar el supuesto material de la solicitud de prisión preventiva ${ }^{287}$. Para otro, el problema está en los bajos estándares que los jueces exigen tratándose de la solicitud de medidas intrusivas, las cuáles

\footnotetext{
${ }^{280}$ Entrevista Fiscal $n^{\circ} 5,4$ de septiembre de 2015.

${ }^{281}$ Entrevista Fiscal $n^{\circ} 6,11$ de septiembre de 2015.

${ }^{282}$ Entrevista Defensor $n^{\circ} 1,11$ de junio de 2015.

${ }^{283}$ Entrevista Juez de Garantía n ${ }^{\circ}$ 1, 7 de mayo de 2015 (quien destaca especialmente el peso que tienen para decretar medidas intrusivas); Entrevista Juez de Garantía $n^{\circ} 2,25$ de junio de 2015; Entrevista Juez de Garantía n $^{\circ}$ 3, 26 de junio de 2015; Entrevista Juez de Garantía n 4, 8 de junio de 2015; Entrevista Juez de Garantía n $^{\circ}$ 5, 15 de julio de 2015; Entrevista Juez de Garantía nº 6, 3 de septiembre de 2015; Entrevista Juez de Garantía n ${ }^{\circ}$ 7, 14 de septiembre de 2015; y, Entrevista Juez de Garantía n 8, 4 de enero de 2016.

${ }^{284}$ En esta dirección Entrevista Juez de Garantía n ${ }^{\circ} 4,8$ de junio de 2015; Entrevista Juez de Garantía ${ }^{\circ} 6,3$ de septiembre de 2015; y, Entrevista Juez de Garantía n 8, 4 de enero de 2016.

${ }^{285}$ Entrevista Juez de Garantía n ${ }^{\circ}$ 3, 26 de junio de 2015 y Entrevista Juez de Garantía n 6, 3 de septiembre de 2015.

${ }^{286}$ Entrevista Juez de Garantía n ${ }^{\circ} 2,25$ de junio de 2015.

${ }^{287}$ Entrevista Juez de Garantía n ${ }^{\circ}$ 7, 14 de septiembre de 2015.
} 
Polít. crim. Vol. 12, No 23 (Julio 2017), Art. 9, pp. 291-379.

[http://www.politicacriminal.cl/Vol_12/n_23/Vol12N23A9.pdf]

podrían decretarse aún con diligencias de investigación de baja confiabilidad. Explica esto señalando que

"En las medidas intrusivas es donde los jueces tienen estándares muy bajos (no tanto en los juicios orales)....Mi percepción es que la mayoría de los jueces de garantía no tiene estándares altos, sino que bajos frente a medidas intrusivas. Por lo tanto, frente a cualquier rumor se dan las mismas, incluso el allanamiento, las interceptaciones telefónicas y derechamente detenciones." ${ }^{288}$.

Un segundo punto en el que existe bastante consenso entre los entrevistados es en relación a que las exclusiones de prueba en la APJO generadas por la realización de diligencias de reconocimientos mal efectuadas o por fuera de los supuestos del Protocolo es, en el mejor de los eventos, una cuestión excepcional ${ }^{289}$. En los pocos casos en que esta se daría sería en su exclusión en situaciones graves como, por ejemplo, cuando no hay registro de las diligencias o se trata de actuaciones en las que hay evidentes infracciones vinculadas al debido proceso o a garantías procesales. Un defensor explica esta dinámica señalando “...tiene que ser muy notorio el elemento, sino la mayoría de los jueces hacen caso al argumento típico del Ministerio Público de que esto es un tema de valoración de prueba y no de admisión." 290 . Otro relata algo bastante similar al indicar que

"Cuando es más o menos grosero nos va bien, pero en general no tan bien. ¿Qué te dice el Ministerio Público? Esto es un tema de valoración. Siempre nos va mal en la Corte, porque ella tiende a re-incorporar al testigo excluido porque dicen que esto se trata de un tema de valoración que debe ser ponderado por el tribunal oral, por lo que excluirlo a priori no es correcto." 291 .

Como se puede apreciar, la explicación que surge de estas opiniones es que los actores del sistema no percibirían como un problema de admisibilidad el que los reconocimientos se hagan de forma que no asegure su confiabilidad. Sólo habría un problema de esta naturaleza en casos de vulneración de garantías más o menos evidentes.

Vinculado al punto anterior, el área en la que existe discrepancia entre los entrevistados es en la frecuencia con la cual defensores presentan cuestionamientos de admisibilidad y exclusión de estos reconocimientos en la APJO. Así, la mayoría de los defensores señala que litiga en esta materia con cierta frecuencia, aún cuando reconocen que los resultados son favorables en pocos $\operatorname{casos}^{292}$. En el otro extremo, fiscales y jueces de garantía opinan

\footnotetext{
${ }^{288}$ Entrevista Juez de Garantía n ${ }^{\circ} 1,7$ de mayo de 2015.

${ }^{289}$ Entrevista Defensor $n^{\circ} 1,11$ de junio de 2015; Entrevista Defensor $n^{\circ} 3,2$ de julio de 2015; Entrevista Defensor $n^{\circ} 4,2$ de julio de 2015; Entrevista Defensor $n^{\circ}$ 6, 1 de abril de 2016; y, Entrevista Defensor $n^{\circ} 8$, 11 de mayo de 2015. También se manifiestan de acuerdo con esto Entrevista Abogado $\mathrm{n}^{\circ} 1,4$ de mayo de 2015 y Entrevista Abogado ${ }^{\circ}$ 4, 22 de julio de 2015. A nivel de los fiscales Entrevista Fiscal $n^{\circ} 2,9$ de junio de 2015 y Entrevista Fiscal $n^{\circ} 10,6$ de enero de 2015. Entre los jueces de garantía Entre vista Juez de Garantía $n^{\circ}$ 1, 7 de mayo de 2015; Entrevista Juez de Garantía n 2, 25 de junio de 2015; y, Entrevista Juez de Garantía $\mathrm{n}^{\circ} 5,15$ de julio de 2015 .

${ }^{290}$ Entrevista Defensor $n^{\circ} 1,11$ de junio de 2015.

${ }^{291}$ Entrevista Defensor $n^{\circ} 3,2$ de julio de 2015.

${ }^{292}$ Entrevista Defensor $n^{\circ} 1,11$ de junio de 2015; Entrevista Defensor n ${ }^{\circ} 3,2$ de julio de 2015; Entrevista Defensor $n^{\circ} 4,2$ de julio de 2015; y, Entrevista Defensor $n^{\circ} 8,11$ de mayo de 2015. Comparte esta opinión un
} 
DUCE, Mauricio. "Reconocimientos oculares: una aproximación empírica a su funcionamiento y algunas recomendaciones para su mejora".

que es excepcional el que los defensores litiguen esta materia ${ }^{293}$. Incluso hay un grupo mayoritario de los entrevistados que señala que derechamente este es un tema que no se litiga en la $\mathrm{APJO}^{294}$, algunos dejando entrever que los reconocimientos sólo pueden ser cuestionados en sede de valoración ${ }^{295}$. El comportamiento poco proactivo de los defensores en esta materia podría explicarse como consecuencia de una actitud derrotista frente a los resultados que obtienen regularmente en las APJO. Al final del día, si la probabilidad de éxito es baja, una tendencia natural es no hacer un esfuerzo que no traerá resultados $\operatorname{positivos}^{296}$.

La exclusión de los reconocimientos poco confiables es un tema en extremo complejo, aún en el ámbito comparado que tiene mucho más desarrollo que nuestro país ${ }^{297}$. Por lo mismo, no puedo abordar en detalle el problema legal en esta sección cuyo objetivo es el de describir prácticas, pero algo volveré sobre este punto en el capítulo final destinado a revisar las propuestas de mejora. Lo que me interesa dejar consignado en esta parte es que el litigio de exclusión es escaso y con pocos resultados. Ello parece obedecer tanto a la concepción que tienen los actores acerca de cuál es la sede adecuada para discutir estas materias, como probablemente la falta de criterios claros de cómo proceder en ellas.

\subsubsection{Litigación y valoración de los reconocimientos en juicio oral e impugnaciones.}

Al igual que en la sección anterior, durante la investigación se intentó indagar sobre el impacto de los reconocimientos en juicio. Específicamente pude obtener información acerca del peso o valoración que los jueces le entregan a la prueba que da cuenta de las diligencias de reconocimiento, la calidad del litigio de las partes (especialmente focalizando el análisis en el trabajo de los defensores) y, finalmente, si es que la valoración de estas diligencias es causa habitual de recursos de nulidad.

fiscal Entrevista Fiscal n 9, 4 de enero de 2016 y un juez de garantía Entrevista Juez de Garantía n ${ }^{\circ} 1,7$ de mayo de 2015.

${ }^{293}$ Entrevista Fiscal n ${ }^{\circ}$ 1, 7 de mayo de 2015; Entrevista Fiscal n ${ }^{\circ}$ 11, 7 de enero de 2016; Entrevista Juez de Garantía n ${ }^{\circ}$ 2, 25 de junio de 2015; Entrevista Juez de Garantía n 5, 15 de julio de 2015; y, Entrevista Juez de Garantía ${ }^{\circ}$ 6, 3 de septiembre de 2015 (quien señala que en la actualidad este tipo de litigio sería "casi inexistente").

${ }^{294}$ Varios fiscales se manifiestan en esta dirección. Entre ellos Entrevista Fiscal n`3, 10 de julio de 2015; Entrevista Fiscal n ${ }^{\circ}$ 4, 28 de julio de 2015; Entrevista Fiscal n ${ }^{\circ}$ 5, 4 de septiembre de 2015; Entrevista Fiscal $\mathrm{n}^{\circ}$ 6, 11 de septiembre de 2015; Entrevista Fiscal n ${ }^{\circ}$ 8, 28 de diciembre de 2015; Entrevista Fiscal $\mathrm{n}^{\circ}$ 13, 29 de enero de 2016. Dentro de los jueces de garantía: Entrevista Juez de Garantía n ${ }^{\circ} 3,26$ de junio de 2015; Entrevista Juez de Garantía n 4, 8 de julio de 2015; Entrevista Juez de Garantía n ${ }^{\circ}$ 7, 14 de septiembre de 2015; y, Entrevista Juez de Garantía n ${ }^{\circ}$ 8, 4 de enero de 2016. Incluso un defensor reconoce este escenario: Entrevista Defensor $\mathrm{n}^{\circ}$ 5, 4 de septiembre de 2015.

${ }^{295}$ Entrevista Fiscal n ${ }^{\circ} 11,7$ de enero de 2016 y Entrevista Defensor n ${ }^{\circ}$ 5, 4 de septiembre de 2015.

${ }^{296}$ Esta es una de las explicaciones que en los Estados Unidos se dan respecto al pobre desempeño de los defensores en la exclusión de los reconocimientos. WELLS/GREATHOUSE/SMALARZ, Why do motions, cit. nota $\mathrm{n}^{\circ} 28$, p. 179.

${ }^{297}$ Para quienes deseen tener una visión panorámica del desarrollo del debate académico y jurisprudencial en los Estados Unidos en la materia recomiendo: GARRETT, Brandon, "Eyewitness and Exclusion", Vanderbilt Law Review, Vol. 66 (2012), pp. 451-506; y WELLS/GREATHOUSE/SMALARZ, Why do motions, cit. nota $\mathrm{n}^{\circ} 28$. 
Polít. crim. Vol. 12, № 23 (Julio 2017), Art. 9, pp. 291-379.

[http://www.politicacriminal.cl/Vol_12/n_23/Vol12N23A9.pdf]

Parto por el último punto ya que en él hay un consenso bastante fuerte entre los distintos entrevistados. El uso de los reconocimientos y su valoración en juicio son una causa poco frecuente para fundar los recursos de nulidad. En este punto las opiniones están divididas entre un grupo importante que estima derechamente que no se recurre de nulidad por razones vinculadas a los reconocimientos ${ }^{298}$ y otro que ello se hace sólo en algunos $\operatorname{casos}^{299}$. Una minoría muy pequeña da cuenta que se trataría de una práctica frecuente ${ }^{300}$.

En materia del tipo de recurso de nulidad utilizado cuando se ocupa dicho mecanismo, hay también un consenso importante en que el principal sería el de nulidad absoluta del artículo 374 letra e) del CPP referido a la omisión de algunos de los requisitos de las sentencia previstos en el artículo 342 del mismo cuerpo legal. Se esgrime como causal la falta de razón suficiente y también la infracción a los principios de la lógica cuando la sentencia se funda en un reconocimiento que los defensores estiman como poco confiable. En la apreciación que ellos mismos realizan, se indica que lo normal es que estos recursos no sean acogidos ${ }^{301}$. La idea que parecería primar en las cortes sobre el punto es explicada por un juez oral al señalar que se trataría de un área que “...es de valoración de los jueces no más y la corte no se puede meter en los hechos que se tuvieron como acreditados."302. En la misma lógica un fiscal explica su posición sobre los recursos de nulidad que ha conocido en la materia señalando que "Hay un tema de que la nulidad va como apelación encubierta. Pero como la nulidad es un recurso de derecho estricto y las cortes no van al fondo...no van más allá." 303 . Esta situación es consistente con lo ocurrido en el caso de Julio Robles. Allí, su defensa privada interpuso recurso de nulidad en contra de la sentencia condenatoria fundado en la causal de nulidad absoluta del artículo 374 letra e) en relación al artículo 343 letra c), ambos del $\mathrm{CPP}^{304}$. En lo central el recurso cuestiona la calidad de los reconocimientos y el comportamiento del funcionario policial a cargo de ellos. La Corte de Apelaciones de Copiapó rechaza el recurso el día 10 de septiembre de 2012 argumentando que la sentencia contiene una explicación clara, lógica y completa de los hechos acreditados

\footnotetext{
${ }^{298}$ Entrevista Defensor n ${ }^{\circ}$ 5, 4 de septiembre de 2015; Entrevista Defensor n ${ }^{\circ}$ 6, 1 de abril de 2016; Entrevista Fiscal $n^{\circ}$ 2, 9 de junio de 2015; Entrevista Fiscal $n^{\circ} 4$, 28 de julio de 2015; Entrevista Fiscal $n^{\circ} 5$, 4 de septiembre de 2015; Entrevista Fiscal n ${ }^{\circ}$ 10, 6 de enero de 2016; Entrevista Fiscal n ${ }^{\circ} 12,12$ de enero de 2016; Entrevista Fiscal n ${ }^{\circ}$ 13, 29 de enero de 2016; Entrevista Juez TOP n ${ }^{\circ}$ 6, 14 de julio de 2015; Entrevista Juez TOP n ${ }^{\circ}$ 7, 5 de octubre de 2015; y, Entrevista Juez TOP n ${ }^{\circ}$ 8, 22 de diciembre de 2015.

${ }^{299}$ Entrevista Defensor ${ }^{\circ} 1,11$ de junio de 2015; Entrevista Defensor $n^{\circ}$ 7, 19 de abril de 2016; Entrevista Defensor $^{\circ}{ }^{8}$ 8, 11 de mayo de 2016; Entrevista Fiscal n ${ }^{\circ}$ 8, 28 de diciembre de 2015; Entrevista Fiscal $n^{\circ} 11$, 7 de enero de 2016; Entrevista Juez TOP n ${ }^{\circ} 1,9$ de junio de 2015; Entrevista Juez TOP $n^{\circ} 2,15$ de junio de 2015; y, Entrevista Juez TOP n ${ }^{\circ}$ 4, 6 de julio de 2015.

${ }^{300}$ Entrevista Fiscal ${ }^{\circ}$ 9, 4 de enero de 2016; Entrevista Defensor n ${ }^{\circ} 3,2$ de julio de 2015; y Entrevista Defensor $\mathrm{n}^{\circ} 4,2$ de julio de 2015.

${ }^{301}$ Por ejemplo Entrevista Defensor n ${ }^{\circ}$ 3, 2 de julio de 2015; Entrevista Defensor n ${ }^{\circ}$ 8, 11 de mayo de 2016; Entrevista Juez TOP nº 1, 9 de junio de 2015; y, Entrevista Juez TOP n ${ }^{\circ} 2,15$ de junio de 2015.

${ }^{302}$ Entrevista Juez TOP ${ }^{\circ} 6,14$ de julio de 2015.

${ }^{303}$ Entrevista Fiscal n ${ }^{\circ} 11,7$ de enero de 2016.

${ }^{304}$ La causal del artículo 374 letra e) permite anular una sentencia en la que se hubieren omitido algunos requisitos del artículo 342, en este caso concreto de su letra c), es decir, "la exposición clara, lógica y completa de cada uno de los hechos y circunstancias que se dieren por probados, fueren ellos favorables o desfavorables al acusado, y de la valoración de prueba que fundamentaren dichas conclusiones de acuerdo al artículo 297"
} 
DUCE, Mauricio. "Reconocimientos oculares: una aproximación empírica a su funcionamiento y algunas recomendaciones para su mejora".

y que no corresponde a la Corte revisar la valoración de credibilidad de la prueba que ha hecho el tribunal de juicio oral ${ }^{305}$.

Secundariamente se afirma que se recurre de nulidad fundándose en la causal del artículo 373 letra a), es decir, invocando que ha existido violación sustancial de garantías en el desarrollo del proceso, también con limitado éxito.

Concluyendo sobre este primer punto, de acuerdo a los entrevistados, no estaría instalado como una práctica frecuente el cuestionamiento de los juicios orales basado en la valoración que se haga de reconocimientos de baja confiabilidad o producidos por fuera de los supuestos del Protocolo.

\section{b) Valoración de parte de los tribunales.}

Una primera cuestión a indagar en las entrevistas fue el peso o valor que los jueces de juicio oral otorgan a la prueba que se refiere a los reconocimientos para fundar sus sentencias. Aún cuando con diversos matices, me parece identificar un consenso fuerte en las distintas categorías de entrevistados acerca de que los jueces atribuyen un valor importante a estas pruebas al momento de decidir los casos ${ }^{306}$. Este peso estaría tanto como una evidencia que permite formar convicción de condena como en otros casos para absolver. La importancia de esta diligencia para efectos de formar su convicción es mencionada de manera explícita por la mayoría de los defensores ${ }^{307}$, fiscales ${ }^{308}$ y reconocido también por los jueces orales ${ }^{309}$.

Las diferencias se presentan a la hora de revisar los matices con los cuáles se argumenta esta idea general. El principal se produce al momento de describir los criterios utilizados por los jueces en la valoración de los reconocimientos. Así, un grupo de defensores y fiscales entrevistados estima que los jueces operan sobre la base de criterios poco claros, con algunos prejuicios o incluso valorándolos de manera algo mecánica. Por ejemplo, un

\footnotetext{
${ }^{305}$ Corte de Apelaciones de Copiapó, Recurso de Nulidad, Sentencia del 10 de septiembre de 2010, Causa Rol $\mathrm{n}^{\mathrm{o}}$ 130-2012 (documento en formato electrónico en poder del autor).

${ }^{306}$ El estudio empírico sobre sentencias TOP de la Región Metropolitana permitió establecer que en el 70,4\% de los casos examinados los reconocimientos fueron considerados como confiables por el tribunal en su fallo y un $29,6 \%$ no. CATALÁN, Aproximación Empírica, cit. nota n ${ }^{\circ} 17$, p. 75.

${ }^{307}$ Entrevista Defensor ${ }^{\circ} 1,11$ de junio de 2015; Entrevista Defensor ${ }^{\circ} 2,15$ de junio de 2015; Entrevista Defensor $^{\circ}{ }^{3}$ 3, 2 de julio de 2015; Entrevista Defensor $n^{\circ}$ 4, 2 de julio de 2015; Entrevista Defensor $n^{\circ}$ 5, 4 de septiembre de 2015; Entrevista Defensor n ${ }^{\circ}$ 7, 19 de de abril de 2016; y, Entrevista Defensor n ${ }^{\circ} 8,11$ de mayo de 2015. Además se pronuncia también en la misma línea Entrevista Abogado n 1,4 de mayo de 2015 y Entrevista Abogado n ${ }^{4}$, 22 de julio de 2015.

${ }^{308}$ Entrevista Fiscal n ${ }^{\circ}$ 2, 9 de junio de 2015; Entrevista Fiscal ${ }^{\circ} 4,28$ de julio de 2015; Entrevista Fiscal ${ }^{\circ}$ 5, 4 de septiembre de 2015; Entrevista Fiscal $n^{\circ}$ 6, 11 de septiembre de 2015; Entrevista Fiscal $n^{\circ} 8,28$ de diciembre de 2015; Entrevista Fiscal n ${ }^{\circ}$ 11, 7 de enero de 2016; Entrevista Fiscal n ${ }^{\circ} 12,12$ de enero de 2016; y, Entrevista Fiscal n ${ }^{\circ} 13,29$ de enero de 2016.

${ }_{309}$ Entrevista Juez TOP n ${ }^{\circ} 2,15$ de junio de 2015; Entrevista Juez TOP n ${ }^{\circ} 3,2$ de julio de 2015; Entrevista Juez TOP n ${ }^{\circ}$ 4, 6 de julio de 2015; Entrevista Juez TOP n ${ }^{\circ}$ 5, 8 de julio de 2015; Entrevista Juez TOP n ${ }^{\circ} 6,14$ de julio de 2015; y, Entrevista Juez TOP n ${ }^{\circ}$ 7, 5 de octubre de 2015. A ello habría que sumar a un juez de garantía que se pronuncia sobre esta materia a propósito de su rol en el procedimiento simplificado. Entrevista Juez de Garantía n ${ }^{\circ}$ 5, 15 de julio de 2015.
} 
Polít. crim. Vol. 12, No 23 (Julio 2017), Art. 9, pp. 291-379.

[http://www.politicacriminal.cl/Vol_12/n_23/Vol12N23A9.pdf]

defensor señala sobre este punto: "Mi impresión es que en general hay muchos prejuicios, creo que aún el tribunal le da mucho valor al reconocimiento que se hace ahí en el tribunal." "310. Un fiscal se refiere al mismo tema señalando que "No hay mayor análisis, se indica que es reconocido por la víctima, por los funcionarios que lo detuvieron y no hay más análisis, salvo que haya una discusión profunda por la defensa acerca del reconocimiento."311. Otro, de manera más extrema, se refiere al punto indicando: “...el tema pasa casi que por un mandamiento, una invocación divina de que si la víctima dice que es, nada más importa, si la víctima dice que es él, no hay nada más que hacer."312.

Este fenómeno es reconocido por algunos jueces. Uno de ellos señala, respecto a la valoración que realizan sus colegas del tribunal en juicio, que "No hay mucho cuestionamiento de cómo se producen los reconocimientos en general" y agrega "Si los reconoció la víctima, estamos listos." 313 . En la contracara, varios entrevistados dan cuenta de que los jueces harían un escrutinio crítico sobre la calidad y confiabilidad de los reconocimientos para lo cual utilizan diversos criterios de análisis. Un defensor señala que los jueces "Son abiertos al reconocimiento en la medida de que realmente cumpla.",314. Un juez oral explica lo que considera son estos estándares de cumplimiento indicando que "Un reconocimiento sólo tiene que cumplir con ciertos estándares de fondo. Si es que es uno sólo y en condiciones oscuras o dudosas, no le damos mucho valor. Cumpliendo el Protocolo del MP bastaría."315. En la misma línea otro juez manifiesta: "En el tribunal donde yo trabajo y con jueces conocidos, existe un estándar similar. Se entiende que el Protocolo es un buen estándar en la medida que se cumple con él. Eso está instalado."316.

Estas últimas opiniones hablarían de un impacto positivo del Protocolo, en la medida que estaría contribuyendo a desarrollar y uniformar criterios de valoración por parte de los tribunales orales. Así, un juez explica como se ha ido avanzando poco a poco en contar con criterios más comunes en su tribunal, los que no existían antes: "A propósito de la llegada del Protocolo del MP como que ha tendido a unificarse la valoración. Antes no."317. Con todo, esto es disputado por algunos jueces y fiscales. Así, un fiscal señala sobre esta materia: "Pero no existen en general criterios uniformes, son todos dispares, depende del tribunal" 318 . Esta evidencia pareciera estar demostrando que las prácticas instaladas en la materia son aún bastante dispares. Si bien el Protocolo estaría jugando algún rol en la uniformización de criterios, las realidades de los tribunales aún serían dispersas.

\footnotetext{
${ }^{310}$ Entrevista Defensor $n^{\circ} 5,15$ de julio de 2015 .

${ }^{311}$ Entrevista Fiscal $n^{\circ} 11,7$ de enero de 2016.

${ }^{312}$ Entrevista Fiscal $n^{\circ} 2,9$ de junio de 2015.

${ }^{313}$ Entrevista Juez TOP $n^{\circ}$ 6, 14 de julio de 2015. Otro juez entrega una idea similar al poner énfasis que si el reconocimiento que se presenta en juicio viene de la etapa de investigación va a pesar mucho y en juicio el acto de identificación que la víctima será casi una pura formalidad. Entrevista Juez TOP $\mathrm{n}^{\circ} 5,8$ de julio de 2015.

${ }^{314}$ Entrevista Defensor $n^{\circ} 3,2$ de julio de 2015. En esta misma línea Entrevista Juez TOP $n^{\circ} 2,15$ de junio de 2015.

${ }^{315}$ Entrevista Juez Top n ${ }^{\circ}$ 4, 6 de julio de 2015.

${ }^{316}$ Entrevista Juez TOP n ${ }^{\circ} 8,22$ de diciembre de 2015.

${ }^{317}$ Entrevista Juez TOP $\mathrm{n}^{\circ} 7,5$ de octubre de 2015.

${ }^{318}$ Entrevista Fiscal $n^{\circ} 5,4$ de septiembre de 2015. En una línea similar Entrevista Defensor $n^{\circ} 1,11$ de junio de 2015
} 
DUCE, Mauricio. "Reconocimientos oculares: una aproximación empírica a su funcionamiento y algunas recomendaciones para su mejora".

En este contexto, resultan muy ilustrativos los hallazgos de la investigación empírica sobre sentencias TOP de la Región Metropolitana. Dicha investigación permitió profundizar sobre los criterios concretos utilizados por los tribunales tanto para establecer la confiabilidad de los reconocimientos como para argumentar en contra de ella. Así, dentro de los criterios más frecuentes utilizados se encontraron: la existencia de una descripción previa (30\%); el apoyo de prueba adicional (30\%); la existencia de varios testigos o víctimas que reconocen al imputado (20\%); el hecho que el reconocimiento se haya producido en la audiencia de juicio (18\%); el que la víctima o testigo haya tenido buena percepción de los hechos (16\%); la concordancia entre la descripción previa realizada y las características del imputado (14\%); el que una misma persona realice múltiples reconocimientos (12\%); que el set fotográfico se haya construido adecuadamente (10\%); además de otras que tienen menciones porcentualmente menores ${ }^{319}$.

Como se puede apreciar, si bien algunos de los criterios podrían ser considerados como elementos técnicos que están regulados en el Protocolo, la mayoría abordan cuestiones bastante diversas. Tampoco aparecen criterios que se disparen en porcentajes muy altos en relación a otros.

La misma investigación de sentencias TOP contiene información sobre los criterios utilizados para rechazar la confiabilidad de los reconocimientos. Así, dentro de los criterios más frecuentes utilizados se encontraron: el que no hubiera descripción previa o que esta fuere inconsistente con imputado o muy general (38\%); la ausencia o deficiente reconocimiento en juicio oral (28\%); la no comparecencia a juicio de la víctima o funcionario que practicó reconocimiento $(23 \%)$; el set fotográfico o rueda de imputados mal confeccionado (23\%); la poca o nulas condiciones de percepción (19\%); la existencia de instrucciones inductivas (19\%); el no haberse cumplido con el doble ciego (19\%); el que el imputado haya sido exhibido o reconocido antes de realizar la diligencia (15\%); y, la falta de registro del reconocimiento $(9 \%)^{320}$.

Nuevamente aparecen algunos factores que podrían ser entendidos como propios del Protocolo (por ejemplo la inadecuada confección set y ruedas). Con todo, siguen llamando la atención otros elementos. Por ejemplo, en ambos resultados el reconocimiento que se practica en la audiencia de juicio es un elemento relevante ya sea para afirmar o afectar la confiabilidad de la diligencia a pesar que desde el punto de vista de la ciencia no tienen mucho valor ya que corresponde a una actividad en donde no está asegurado un genuino ejercicio de la memoria. Analizados en su conjunto, estos datos parecen mostrar que efectivamente no existen criterios homogéneos entre los jueces y que todavía se basan en varios elementos que podrían ser considerados cuestionables desde el punto de vista de los hallazgos de la ciencia.

Nuevos matices en las opiniones de los entrevistados son posibles de identificar respecto a si el peso de los reconocimientos es decisivo por sí solo o debe requerirse de evidencia

\footnotetext{
${ }^{319}$ CATALÁN, Aproximación Empírica, cit. nota $n^{\circ} 17$, p. 76, tabla $n^{\circ} 18$. La base se construye sobre los 50 reconocimientos que fueron considerados confiables $(70,4 \%)$ del total de la muestra.

${ }^{320}$ CATALÁN, Aproximación Empírica, cit. nota ${ }^{\circ} 17$, p. 86, tabla n ${ }^{\circ} 19$. La base se construye sobre los 21 reconocimientos que fueron considerados no confiables $(29,6 \%)$ del total de la muestra.
} 
Polít. crim. Vol. 12, № 23 (Julio 2017), Art. 9, pp. 291-379.

[http://www.politicacriminal.cl/Vol_12/n_23/Vol12N23A9.pdf]

adicional para formar convicción sobre los hechos que se juzgan. En esta dirección varios entrevistados mencionan que, a pesar de la significancia probatoria de los reconocimientos que ya he mencionado, muchos jueces exigen elementos adicionales de corroboración para formar su convicción. Un juez oral explica bien este punto planteando una postura que da cuenta también de una evolución en el tiempo en la materia:

"Depende del delito. Es un antecedente fuerte en los robos, sobre todo cuando ha habido un tiempo y no persecución inmediata. Es importante pero no es el único. Siempre exigimos corroboración. Ya no condenamos por la simple imputación de una persona, sino que exigimos corroboración de esa incriminación por una fuente de información diversa que lo justifique para que logremos el estándar de convicción." ${ }^{321}$.

Ideas similares son expresadas por otros entrevistados ${ }^{322}$.

\section{c) Capacidad de litigación de los intervenientes en juicio.}

Finalmente, un último tema indagado en materia de juicio oral se refirió al nivel de debate o contradicción que genera el uso de los reconocimientos en juicio. En este sentido, se indagó preferentemente sobre el comportamiento de los defensores y su capacidad de cuestionar en juicio diligencias de reconocimiento realizadas sin cumplir los parámetros básicos establecidos por la literatura especializada o por el Protocolo. En un contexto en donde se ha podido mostrar que hay niveles de apartamiento importantes en las prácticas de estos estándares uno debiera pensar que en juicio se genera mucho debate sobre la prueba a través de la cual se introducen los reconocimientos. Antes de entrar a las prácticas de litigación debe señalarse que, de acuerdo a los propios entrevistados, el formato tradicional en el cual se introduce los reconocimientos en la audiencia de juicio es por medio de la declaración de los funcionarios policiales a cargo de la diligencia y las declaraciones de víctimas y testigos. En consecuencia, la capacidad de cuestionamiento de esas diligencias pasa centralmente por la posibilidad de contraexaminar a dichas pruebas y, eventualmente, presentar alguna evidencia autónoma sobre la materia.

Las visiones acerca de cuán activa son las defensas en el cuestionamiento de los reconocimientos en juicio varían de manera significativa según el rol que cumplen los entrevistados. Los fiscales y jueces orales tienen una apreciación mixta en la materia. Un grupo de ellos sostiene que los defensores cuestionan con frecuencia la calidad de los reconocimientos en juicio ${ }^{323}$ y otro equivalente sostiene que ellos no son tan habituales o

\footnotetext{
${ }^{321}$ Entrevista Juez TOP $\mathrm{n}^{\circ} 7,5$ de octubre de 2015.

${ }^{322}$ Entrevista Juez TOP ${ }^{\circ} 1,9$ de junio de 2015; Entrevista Fiscal $n^{\circ} 72$ de octubre de 2015; Entrevista Fiscal $\mathrm{n}^{\circ}$ 10, 6 de enero de 2016; y, Entrevista Fiscal $\mathrm{n}^{\circ}$ 12, 12 de enero de 2016. El estudio empírico sobre sentencias TOP muestra también la existencia de diferencias importantes en el punto, pero con una tendencia a no darle tanto peso a esta evidencia. Así, en un 20,9\% de las sentencias el reconocimiento fue una prueba decisiva para condenar, en tanto en un 55,2\% dicha diligencia no bastó por sí sola para condenar y en un 23,9\%, a pesar de ella, no se condenó. CATALÁN, Aproximación Empírica, cit. nota n 17, p. 113.

${ }^{323}$ Entrevista Fiscal $n^{\circ}$ 5, 4 de septiembre de 2015; Entrevista Fiscal $n^{\circ}$ 6, 11 de septiembre de 2015; Entrevista Fiscal $n^{\circ}$ 10, 6 de enero de 2016; Entrevista Fiscal $n^{\circ} 13,29$ de enero de 2016; Entrevista Juez TOP $\mathrm{n}^{\circ}$ 2, 15 de junio de 2015; Entrevista Juez TOP $\mathrm{n}^{\circ} 3,2$ de julio de 2015; Entrevista Juez TOP $\mathrm{n}^{\circ} 5,8$ de julio de 2015; Entrevista Juez TOP n 7, 5 de octubre de 2015; y, Entrevista Juez TOP $n^{\circ} 8$.
} 
DUCE, Mauricio. "Reconocimientos oculares: una aproximación empírica a su funcionamiento y algunas recomendaciones para su mejora".

tienden a concentrarse en algunos casos precisos particularmente cuestionables ${ }^{324}$. Los defensores, por su parte, manifiestan en forma más unánime cuestionar la calidad de los reconocimientos de manera frecuente ${ }^{325}$. Con todo, varios reconocen que es difícil hacerlo y eso mismo los obliga a seleccionar con mucho cuidado en qué casos se podría hacer. De esta forma asumen que efectivamente no cuestionan en todos los casos ${ }^{326}$. Estas impresiones se verían ratificadas en los resultados arrojados por el estudio empírico de sentencias TOP de la Región Metropolitana que muestra que en un 53,7\% de los casos hubo cuestionamientos de los defensores a los reconocimientos en juicio y en un $46,3 \%$ no $^{327}$.

En este contexto, parece existir coincidencia entre los entrevistados en que los principales temas de cuestionamiento están en la sugestividad de los procedimientos y en apartamientos del Protocolo, como por ejemplo, la falta de una descripción física previa del sospechoso o la similitud de las fotografías empleadas en los set fotográficos. Tratándose de las exhibiciones, los cuestionamientos más comunes tienden a apuntar a la falta de espontaneidad de dichos procedimientos. Estas opiniones parecieran indicar que el Protocolo efectivamente está cumpliendo un cierto rol en ofrecer parámetros de análisis y control en juicio de las diligencias de reconocimiento aún cuando no se lo mencione explícitamente en las audiencias. Como señalaba en párrafos previos, esto encuentra correlato luego en algunos de los criterios judiciales para su valoración.

La investigación empírica sobre sentencias TOP también arroja información interesante acerca de los argumentos que son utilizados con mayor frecuencia por la defensa para cuestionar a los reconocimientos en juicio oral. Dentro de estos se señalan: el set fotográfico o rueda de imputados está mal confeccionada (25\%); existen inconsistencias en el relato de testigos (25\%); existen diferencias entre descripción previa y el imputado (22\%); transcurso del tiempo entre hecho y el reconocimiento (19\%); el estrés que tenía la víctima al momento de los hechos ( $19 \%$ ); la falta de una descripción previa de la persona reconocida (19\%); la caracterización muy general del imputado (19\%); el no uso de doble ciego (16\%); las malas condiciones de percepción (14\%); y, la inexistencia de datos sobre cómo fue llevado el reconocimiento en la carpeta investigativa $(11 \%)^{328}$.

Los policías entrevistados tienen una visión diferente a la revisada respecto al trabajo de los defensores. La mayoría de los funcionarios de la PDI afirman que "nunca" han sido cuestionados en juicio por la defensa a propósito de declarar sobre las diligencias de

\footnotetext{
${ }^{324}$ Entrevista Fiscal $n^{\circ} 2,9$ de junio de 2015; Entrevista Fiscal $n^{\circ} 3,10$ de julio de 2015; Entrevista Fiscal $n^{\circ}$ 4, 28 de julio de 2015; Entrevista Fiscal $n^{\circ} 8,28$ de diciembre de 2015; Entrevista Fiscal ${ }^{\circ} 11,7$ de enero de 2016; Entrevista Juez TOP $n^{\circ} 1$, 9 de junio de 2015; Entrevista Juez TOP $n^{\circ} 4$, 6 de julio de 2015; y, Entrevista Juez TOP $n^{\circ}$ 6, 14 de julio de 2015. Se suma a esto Entrevista Abogado ${ }^{\circ} 1,4$ de mayo de 2015.

${ }^{325}$ Entrevista Defensor $n^{\circ} 1,11$ de junio de 2015; Entrevista Defensor $n^{\circ} 3,2$ de julio de 2015; Entrevista Defensor $n^{\circ} 4,2$ de julio de 2015; Entrevista Defensor $n^{\circ}$ 5, 4 de septiembre de 2015; y, Entrevista Defensor $\mathrm{n}^{\circ} 6$.

${ }^{326}$ Entrevista Defensor $^{\circ}$ 2, 17 de junio de 2015; Entrevista Defensor n ${ }^{\circ} 8,11$ de mayo de 2016.

${ }^{327}$ CATALÁN, Aproximación Empírica, cit. nota n ${ }^{\circ}$ 17, p. 65.

${ }^{328}$ CATALÁN, Aproximación Empírica, cit. nota n ${ }^{\circ} 17$, p. 65, tabla ${ }^{\circ} 13$. La base se construye sobre las 36 sentencias en las que se identificó que los defensores presentaron cuestionamientos a la confiabilidad de los reconocimientos, que corresponde a un $53,7 \%$ del total de la muestra.
} 
Polít. crim. Vol. 12, No 23 (Julio 2017), Art. 9, pp. 291-379.

[http://www.politicacriminal.cl/Vol_12/n_23/Vol12N23A9.pdf]

reconocimiento que han practicado ${ }^{329}$. A ellos se suma otro funcionario que señala que han intentado cuestionarlo, pero que el nivel de preparación del defensor era de muy mala calidad $^{330}$. Sólo dos de los funcionarios reconocen un cierto nivel de cuestionamiento de los defensores. Uno señala lo siguiente:

"No me han cuestionado muchas veces, pero si se dirigen y atacan aquellos aspectos que el fiscal dejó volando, se toman de eso y preguntan. El defensor siempre hace preguntas relativas al porcentaje del reconocimiento, se cuestionan si las fotografías son similares, por ahí atacan."331.

En todas las categorías de entrevistados hay acuerdo que cuando se producen cuestionamientos, estos son fundamentalmente realizados a través de preguntas de contraexamen o como parte de alegatos de clausura. No es en cambio una práctica instalada el uso de otra evidencia, especialmente la prueba pericial, para atacar la credibilidad y confiabilidad de los reconocimientos. Me referiré a este tema con un poco más de detalle en el capítulo siguiente.

Las entrevistas a los funcionarios policiales también arrojaron información interesante sobre cómo ellos perciben la calidad del litigio de los fiscales en la materia. Su punto de vista es bastante crítico. Varios señalan que el problema central sería que los físcales llegan mal preparados a juicio y no conocen adecuadamente la investigación de manera que eso les impide sacarle completo provecho a la información que los policías podrían aportar sobre estas diligencias. Un funcionario relata de la siguiente forma su experiencia en la materia e intenta explicar sus causas al señalar:

"El fiscal pregunta qué hicimos y nosotros contamos que participamos en el reconocimiento y cómo fue, qué pasó, etc. A veces no hacen buenas preguntas, de hecho el fiscal nos dice 'cuente lo que hizo', no dirigen las preguntas. Además, generalmente no están preparados, los que más saben son los que vienen y participan de manera conjunta con nosotros en la investigación, pero eso es excepcional. Creo que los fiscales tienen muy mala capacitación." 332 .

Sobre este mismo tema otro funcionario encuentra una explicación algo distinta al sostener: "Yo no tengo dudas en la capacitación de los fiscales, sino del tiempo con que cuentan para prepararse y tener un conocimiento acabado de una carpeta o de la forma en que se plantea en juicio." 333 . Otro funcionario pone acento en la falta de trabajo conjunto previo como forma de preparar el juicio lo que se pagaría en el desaprovechamiento de la información disponible. Así, indica que

\footnotetext{
${ }^{329}$ Entrevista PDI n ${ }^{\circ} 2,20$ de enero de 2016; Entrevista PDI nº 3,20 de enero de 2016; Entrevista PDI ${ }^{\circ} 4,4$ de febrero de 2016; Entrevista PDI n ${ }^{\circ}$ 5, 4 de febrero de 2016; y, Entrevista PDI n 7, 4 de febrero de 2016.

${ }^{330}$ Entrevista PDI ${ }^{\circ} 8,4$ de febrero de 2016.

${ }^{331}$ Entrevista PDI n ${ }^{\circ}$ 6, 4 de febrero de 2016. También relata haber sido objeto de cuestionamientos Entrevista PDI $n^{\circ} 1,20$ de enero de 2016.

${ }^{332}$ Entrevista PDI $\mathrm{n}^{\circ}$ 6, 4 de febrero de 2016. Otro matiza esto señalando que hay diferencias importantes entre los fiscales en donde “...hay algunos muy bien preparados y otros que no." Entrevista PDI $n^{\circ} 4,4$ de febrero de 2016.

${ }^{333}$ Entrevista PDI n ${ }^{\circ} 1,20$ de enero de 2016.
} 
DUCE, Mauricio. "Reconocimientos oculares: una aproximación empírica a su funcionamiento y algunas recomendaciones para su mejora".

"Hay preparación pero es a medias....Te preguntan cuánto lleva en el área, si sabe por qué está aquí, cuénteme que fue lo que hizo y sería todo. Ahí sigo yo. No hay preparación, de todos los juicios que he ido, solamente en un juicio la preparación fue buena ya que me reuní con el fiscal." ${ }^{334}$.

Estas opiniones entregan una imagen bastante fuerte de cómo perciben el trabajo de los fiscales que debiera ser un objeto de una reflexión importante, especialmente considerando los hallazgos que analizaré en la sección siguiente.

Los datos del estudio empírico sobre sentencias tienden a ratificar en parte el cuadro descrito por los funcionarios policiales en materia del trabajo de los fiscales. El primer dato relevante obtenido es que los fiscales justificaron la confiabilidad del reconocimiento en juicio usando argumentos de diversa especie en un 55,2\% de los casos, en tanto que no realizaron tal labor en un $44,7 \%$ de ellos $^{335}$. Como se puede apreciar, este dato efectivamente reflejaría que, en cerca de la mitad de los casos, los fiscales no harían ejercicios de litigación o argumentación destinados a sustentar la confiabilidad de las diligencias de reconocimiento. En esa misma investigación se identificaron los argumentos más frecuentemente utilizados por los fiscales en los casos en que sí justifican o entregan razones para valorar a estas diligencias como confiables. Estos incluyeron: que el testigo o víctima hicieron una descripción previa (43\%); que tuvieron una buena percepción de los hechos (19\%); que hubo varios testigos o víctimas que pudieron reconocer (19\%); que el set fotográfico o la rueda de imputados estuvo bien confeccionada (16\%); la existencia de otras pruebas confirmatorias del reconocimiento (16\%); el reconocimiento producido en juicio (13\%); que se haya hecho conforme al Protocolo (13\%); entre otros con menor porcentaje $^{336}$.

Como se puede observar, se trata de argumentos bastante similares (claro que con distinta perspectiva) de los mencionados por los defensores y de los utilizados por los jueces al momento de fallar. Resulta interesante destacar que por primera vez aparece mencionado de manera explícita el cumplimiento del Protocolo (mencionado en un 13,5\% de las sentencias) como un argumento explícito para otorgarle confiabilidad a los resultados de las diligencias de reconocimiento. Sobre este punto cabe señalar que la misma investigación pudo determinar que en un $13,4 \%$ del total de casos estudiados alguno de los intervinientes (ya sea fiscal o defensa) invocó el Protocolo como parámetro para el análisis de los reconocimientos ${ }^{337}$. Esto daría cuenta de dos cuestiones relevantes. La primera es que el Protocolo todavía estaría teniendo un impacto limitado en su uso por parte de los litigantes. La segunda es que, al menos para un porcentaje limitado de casos, comienza a ser utilizado por el sistema.

\footnotetext{
${ }^{334}$ Entrevista PDI n ${ }^{\circ} 8,4$ de febrero de 2016.

${ }^{335}$ CATALÁN, Aproximación Empírica, cit. nota n ${ }^{\circ}$ 17, p. 57.

${ }^{336}$ Ellos incluyen el que una misma persona haya efectuado varios reconocimientos; la seguridad expresada al reconocer; y, la cercanía del lugar en que imputado fue detenido (todas con 1\%). CATALÁN, Aproximación Empírica, cit. nota $\mathrm{n}^{\circ} 17$, pp. 57-58, tabla $\mathrm{n}^{\circ} 15$. La base se construye sobre las 37 sentencias en las que se identificó que los fiscales argumentaron a favor de la confiabilidad del reconocimiento, que corresponde a un $55,2 \%$ del total de la muestra.

${ }^{337}$ CATALÁN, Aproximación Empírica, cit. nota n 17, p. 74.
} 
Polít. crim. Vol. 12, No 23 (Julio 2017), Art. 9, pp. 291-379.

[http://www.politicacriminal.cl/Vol_12/n_23/Vol12N23A9.pdf]

\subsubsection{Conocimiento y capacitación en materia de reconocimientos.}

Dejé para el final un último tema que me parece puede ser explicativo de varias de las prácticas y problemas que se han ido describiendo en las secciones anteriores de este capítulo. Durante la investigación se intentó indagar sobre los niveles de conocimiento y capacitación institucional que han recibido los distintos actores del sistema en materia de reconocimientos. Como tuve oportunidad de revisar, la evidencia científica disponible es clave para comprender la confiabilidad de estas diligencias por lo que un desconocimiento de la misma debiera tener un poder explicativo de las brechas significativas que he identificado entre las buenas prácticas recomendadas y la forma en que se ejecutan estas diligencias en el funcionamiento cotidiano del sistema. Por otra parte, también sería esperable que si se ha desarrollado un Protocolo interinstitucional que pretende modelar prácticas de los actores, éste debiera ser conocido por ellos y haber generado actividades de capacitación de algún tipo para asegurar su cumplimiento.

Los resultados obtenidos en todos estos temas son bastante desalentadores. El primer hallazgo es que en todas las categorías de entrevistados los niveles de conocimiento de la evidencia científica sobre la materia es escaso, salvo los defensores que en un $50 \%$ manifiestan tener algún conocimiento ${ }^{338}$. Esto se explica como consecuencia que la formación en estas materias a nivel institucional es prácticamente nula como señalaré más adelante, con la excepción de la Defensoría Penal Pública en donde se ha avanzado en algunos programas específicos sobre la materia, pero que no han tenido cobertura total a la fecha $^{339}$. En la contracara, los actores que manifiestan tener algún conocimiento sobre los hallazgos de la ciencia y las buenas prácticas obedecen a iniciativas de capacitación extra institucionales o de estudio individual que han realizado en algún momento específico de su carrera $^{340}$.

Tratándose de conocimiento del Protocolo la situación es distinta. La mayoría de los entrevistados en las diversas categorías reconoce tener un conocimiento medio a alto respecto al Protocolo ${ }^{341}$. Sin embargo, al indagar sobre las formas o procesos a través de los cuales han adquirido conocimiento del mismo se aprecia que se trata de actividades institucionales de difusión de muy poca intensidad o derechamente producto del conocimiento adquirido en la práctica. Como ya mencioné, salvo el trabajo realizado por la

\footnotetext{
338 Entrevista Defensor $\mathrm{n}^{\circ}$ 1, 11 de junio de 2015; Entrevista Defensor $\mathrm{n}^{\circ}$ 5, 4 de septiembre de 2015; Entrevista Defensor $n^{\circ}$ 6, 1 de abril de 2016; y, Entrevista Defensor n ${ }^{\circ}$, 19 de abril de 2016.

339 Estos programas se han efectuado a partir del desarrollo del Proyecto Inocentes por la propia institución que ha permitido sensibilizar la existencia de un problema con el uso de reconocimientos. De esta forma, varias defensorías regionales han organizado cursos en la materia utilizando los fondos regionales de capacitación disponibles, como por ejemplo de la IV, V, VII, X y XII regiones. También a nivel central se han organizado cursos especializados de litigación que incluyen la temática de los reconocimientos. Esta información ha sido obtenida por la experiencia personal del autor de este trabajo quien ha participado en dichas experiencias de capacitación.

${ }^{340}$ Por ejemplo, Entrevista Juez de Garantía n ${ }^{\circ} 5,15$ de julio de 2015 y Entrevista Juez TOP n 6, 14 de julio de 2015.

${ }^{341}$ Los abogados entrevistados sin embargo dan cuenta de una situación algo más crítica. Dos de ellos señalan desconocer por completo el Protocolo (Entrevista Abogado $\mathrm{n}^{\circ}$ 2, 4 de mayo de 2015 y Entrevista Abogado ${ }^{\circ}$ 4, 22 de julio de 2015) y otros dos afirman tener un conocimiento medio o medio bajo del mismo (Entrevista Abogado $\mathrm{n}^{\circ}$ 1, 4 de mayo de 2015 y Entrevista Abogado ${ }^{\circ}$ 3, 2 de julio de 2015).
} 
DUCE, Mauricio. "Reconocimientos oculares: una aproximación empírica a su funcionamiento y algunas recomendaciones para su mejora".

Defensoría Penal Pública, en ninguna de las instituciones que fueron entrevistadas se han desarrollado de manera sistemática programas o actividades de capacitación institucionales sobre los reconocimientos que incluyan tanto elementos de la ciencia como el conocimiento y uso del Protocolo.

Un buen ejemplo de esto son los fiscales. La mitad de los fiscales entrevistados señala explícitamente no haber recibido capacitación institucional en la materia ${ }^{342}$. Varios otros, sin pronunciarse explícitamente sobre el punto, dan a entender que no han tenido una formación "formal en la materia",343. Sólo un fiscal entrevistado relata una capacitación en la materia de la siguiente forma: "Si, creo que una inducción al Protocolo. Consistió en exponer el Protocolo, señalando que había sido instruido a nivel interinstitucional y que había que darle cumplimiento en caso de que hubiera reconocimiento. Hubo una charla., ${ }^{344}$. Como se puede apreciar, la situación no es muy auspiciadora. Aparentemente todos los fiscales recibieron el Protocolo por un canal institucional, pero su revisión y conocimiento ha dependido más de su esfuerzo personal y necesidades derivadas de la práctica que de un trabajo formal de la institución en la materia. Tal como lo concluye un fiscal, “...no basta que se establezca un Protocolo." 345.

Algo similar a lo descrito ocurre tratándose de los policías entrevistados. Casi todos los funcionarios entrevistados señalaron no haber tenido capacitación institucional en la materia. ${ }^{346}$ Uno de los pocos que recibió capacitación la describe sosteniendo que

"Se dieron instrucciones y capacitaciones para llevar adelante los protocolos en la mejor forma. Uno de los instructivos era relativo a las características de las fotografías y los set fotográficos, para que no se indujera a error a la persona que estaba reconociendo." 347 .

El otro señala que "La capacitación consistió en darnos a conocer el formato, cómo se debe hacer y cuáles son los parámetros." ${ }^{348}$. Como se puede apreciar, se trata de un tipo de capacitación bastante genérica que, en todo caso, no habría tenido una cobertura suficiente ya que sólo llegó a la minoría de los entrevistados. Como contrapartida, casi todos los entrevistados que señalaron no haber recibido capacitación indicaron conocer el Protocolo por medio de su lectura ya que éste habría sido enviado también por canales institucionales. Es decir, el método central para su difusión y uso sería su envío acompañado de algunas

\footnotetext{
${ }^{342}$ Entrevista Fiscal $n^{\circ} 1,7$ de mayo de 2015; Entrevista Fiscal $n^{\circ} 3,10$ de julio de 2015; Entrevista Fiscal $n^{\circ}$ 4, 28 de julio de 2015; Entrevista Fiscal $n^{\circ} 5,4$ de septiembre de 2015; Entrevista Fiscal $\mathrm{n}^{\circ} 6,11$ de $^{\circ}$ septiembre de 2015; y, Entrevista Fiscal n 8,28 de diciembre de 2015.

${ }^{343}$ Por ejemplo, Entrevista Fiscal n ${ }^{\circ}$ 9, 4 de enero de 2016 (quien relata que conoce el Protocolo ya que "nos dieron el libro") y Entrevista Fiscal n 1, 7 de enero de 2016 (quien señala que su conocimiento del Protocolo proviene de su lectura).

${ }_{344}$ Entrevista Fiscal $n^{\circ} 2,9$ de junio de 2015.

${ }^{345}$ Entrevista Fiscal n ${ }^{\circ} 12,12$ de enero de 2016.

${ }^{346}$ Entrevista Carabinero $\mathrm{n}^{\circ}$ 1, 10 de agosto de 2015; Entrevista Carabinero $\mathrm{n}^{\circ} 2,11$ de octubre de 2015; Entrevista PDI $n^{\circ}$ 1, 20 de enero de 2016; Entrevista PDI $n^{\circ}$ 2, 20 de enero de 2016, Entrevista PDI $n^{\circ} 4,4$ de febrero de 2016; Entrevista PDI n ${ }^{\circ}$ 5, 4 de febrero de 2016; Entrevista PDI $n^{\circ}$ 7, 4 de febrero de 2016; y, Entrevista PDI $n^{\circ} 8,4$ de febrero de 2016.

${ }^{347}$ Entrevista PDI $n^{\circ} 3,20$ de enero de 2016.

${ }^{348}$ Entrevista PDI n ${ }^{\circ}$ 6, 4 de febrero de 2016.
} 
Polít. crim. Vol. 12, No 23 (Julio 2017), Art. 9, pp. 291-379.

[http://www.politicacriminal.cl/Vol_12/n_23/Vol12N23A9.pdf]

instrucciones adicionales, pero sin formación específica. Un funcionario destaca que no obstante ello no se siente incapacitado para actuar debido a que "Las pautas son casi obvias y lógicas, no tienen nada contraintuitivo así que se entienden y siguen fácilmente.”, ${ }^{\text {, }}$. El problema de esto es que, como ya he visto, muchas de esas "pautas" contravienen el conocimiento científico afianzado en la materia y, por lo mismo, pueden ser fuente del desarrollo de procesos de identificación muy poco confiables o derechamente errados. Tampoco se hace cargo que la ejecución de esas "pautas" requiere de algunas destrezas y habilidades que no necesariamente poseen los funcionarios en actual ejercicio de sus cargos.

El caso de los jueces parece ser aún más grave que los anteriores. Todos los jueces entrevistados concordaron en que no han recibido ninguna capacitación institucional en la materia. Esto es consistente con la información que dispone la Academia Judicial sobre la oferta de cursos que ofrece ya que ninguno de ellos se refirió a este tema ${ }^{350}$. En este escenario, su conocimiento se ha producido por diversas vías no institucionales. Una de ellas es que las partes lo invocan en sus audiencias y ello los ha forzado a saber de su existencia $^{351}$. Otra es que ha sido enviado por algunas fiscalías a sus respectivos tribunales $^{352}$. También se relata que se accede a su contenido por el intercambio de información entre colegas ${ }^{353}$. Un juez entrevistado señala una opinión sobre el desarrollo de los procesos de capacitación judicial que explicaría el escenario descrito, señalando que "Las capacitaciones fuertes las hicimos al inicio. Ya después de la reforma las capacitaciones fueron en franca decadencia." 354 .

En definitiva, la imagen general que se puede construir sobre este punto es que el conocimiento promedio de los actores del sistema de justicia penal entrevistados está por debajo de lo que uno esperaría. Ello se debe a que los procesos de capacitación en la materia son extremadamente débiles, cuando no inexistentes. Esto es problemático ya que podría explicar muchos de los defectos y prácticas inadecuadas analizados a partir de la descripción de procedimientos que he hecho en secciones anteriores. También da cuenta que la estrategia de implementación del Protocolo ha sido bastante precaria. Como he señalado, hay evidencia que el Protocolo, aún con sus problemas, ha producido algún impacto positivo en el sistema. En este contexto, el desarrollo de procesos de capacitación más sistemáticos, especialmente de parte del Ministerio Público y las policías, podría haber sido un factor que jugara positivamente en incrementar tales impactos.

\footnotetext{
${ }^{349}$ Entrevista PDI ${ }^{\circ}$ 7, 4 de febrero de 2016.

${ }^{350}$ Ninguno de los cursos de perfeccionamiento asignados el año 2016 por la Academia Judicial se refiere al tema. Véase: http://intranet.academiajudicial.cl/Imagenes/Temp/Resoluci\%C3\%B3n\%203-2016_09022016.pdf [visitado el 01.07.2016]. Información del año 2014 apunta en la misma dirección. Véase: DUCE, “Algunas Lecciones A Partir de Cuatro Casos", cit. nota ${ }^{\circ} 9$, p. 180 (nota a pie de página $n^{\circ} 101$ ).

${ }^{351}$ Entrevista Juez de Garantía n ${ }^{\circ}$ 6, 3 de septiembre de 2015; Entrevista Juez de Garantía $n^{\circ} 7,14$ de septiembre de 2015; y Juez TOP n ${ }^{\circ} 8,22$ de diciembre de 2015.

${ }^{352}$ Entrevista Juez de Garantía n ${ }^{\circ} 4,8$ de julio de 2015 y Entrevista Juez TOP n ${ }^{\circ} 3,2$ de julio de 2015.

${ }^{353}$ Entrevista Juez TOP n ${ }^{\circ} 4,6$ de julio de 2015.

${ }^{354}$ Entrevista Juez de Garantía n ${ }^{\circ} 8,4$ de enero de 2016.
} 
DUCE, Mauricio. "Reconocimientos oculares: una aproximación empírica a su funcionamiento y algunas recomendaciones para su mejora".

\section{A modo de conclusión: algunas recomendaciones para avanzar.}

He dejado este capítulo final del trabajo para avanzar en algunas propuestas que puedan contribuir al mejoramiento de nuestro sistema de justicia criminal en relación a la realización de las diligencias de reconocimiento. No pretendo hacer un listado exhaustivo de todos los temas posibles sino focalizarme en las cuatro cuestiones que me parecen más estructurales y que podrían tener una mayor incidencia en la mejora de estos procedimientos $^{355}$. Por otra parte, no pretendo tampoco desarrollar el detalle de cada una de estas cuatro recomendaciones, sino plantearlas de manera general de forma de abrir un debate sobre este tema que me parece no ha estado instalado en nuestro país. Más que afinar propuestas, la idea es formular una invitación para debatir en áreas de trabajo en dónde creo urgente avanzar en una estrategia de cambio.

\subsection{Desarrollo de programas de capacitación y perfeccionamiento en la materia.}

Como quedó en evidencia en el capítulo anterior, una de las causas que puede explicar la existencia de prácticas policiales problemáticas para la ejecución de reconocimientos y su valoración posterior por parte de fiscales, defensores y jueces, ha sido la poca o nula formación recibida por ellos en la materia. Salvo excepciones, las instituciones del sistema no han asumido como un tema de importancia la necesidad de dotar a sus miembros de conocimientos y herramientas para actuar con eficacia en esta materia. Esto es incluso más grave si se considera que a partir del año 2013 se dictó un Protocolo interinstitucional destinado a regular las prácticas de fiscales y policías, con un enorme impacto potencial en el control que defensores y jueces podrían realizar de tales diligencias.

Me parece que el desarrollo de programas de capacitación y perfeccionamiento debiera cubrir al menos tres áreas para tener impacto en la mejora del sistema. Una primera tiene que ver con proveer de conocimientos sobre los principales hallazgos y consensos que existen desde la ciencia acerca de cómo funciona la memoria y cuáles son las prácticas que favorecen o perjudican la confiabilidad de los reconocimientos. Una segunda área debiera incorporar el conocimiento de las distintas reglas que rigen la materia en nuestro país, incluyendo una revisión crítica de las mismas a la luz de la evidencia científica y la experiencia comparada disponible. Finalmente, los programas debieran incorporar el desarrollo de destrezas y habilidades propias de la función que cumple cada actor del sistema. Por ejemplo, tratándose de las policías debiera incluir la realización de distintos tipos de procedimientos de reconocimiento, en el caso de los jueces la valoración y toma de decisiones basadas en la información proveniente de los reconocimientos, etc. ${ }^{356}$.

\footnotetext{
${ }^{355}$ A nivel comparado es posible identificar trabajos con listados bastante más extensos de recomendaciones que las que aquí incluiré. Con todo, recomiendo su revisión ya que se trata de aportes de mucho interés también para nuestra realidad. Dentro de ellos puede verse: FPT HEADS OF PROSECUTIONS COMMITTEE, The Path to Justice, cit. nota $\mathrm{n}^{\circ}$ 5, pp. 63-76; NATIONAL RESEARCH COUNCIL, Identifying the Culprit, cit. nota $\mathrm{n}^{\circ} 2$, pp. 71-81; SIMON, In Doubt, cit. nota $\mathrm{n}^{\circ} 29$, pp. 80-89.

${ }^{356}$ Algunas recomendaciones específicas para el desarrollo de programas de capacitación a la policía pueden verse en: NATIONAL RESEARCH COUNCIL, Identifying the Culprit, cit. nota ${ }^{\circ}$ 2, pp. 72-73.
} 
Polít. crim. Vol. 12, No 23 (Julio 2017), Art. 9, pp. 291-379.

[http://www.politicacriminal.cl/Vol_12/n_23/Vol12N23A9.pdf]

Estos programas debieran también desarrollarse en dos niveles. En un primer término, algunos componentes de ellos debieran formar parte del "paquete de formación básica" que se recibe al ingresar a las respectivas instituciones. Además, debiera luego formar parte de programas especializados de perfeccionamiento continúo que permitan acceder a un conocimiento que en la materia se ha ido incrementando y evolucionando.

Una de las ventajas de identificar la capacitación y perfeccionamiento como un área clave de trabajo tiene que ver con que todas las instituciones del sistema tienen hoy día un enorme espacio en el que dichos programas pudieran ser desarrollados. En efecto, instituciones como el Poder Judicial y las policías ofrecen un programa de capacitación inicial a sus integrantes antes de que asuman sus funciones y todas cuentan luego con una oferta de perfeccionamiento en el tiempo. En ambos ámbitos los recursos destinados son significativos, independiente que siempre pueda haber algunas necesidades insatisfechas. Lo que ocurre con el Poder Judicial es un ejemplo claro de lo que he dicho. Hoy día cualquier persona que quiera ser un juez de la república debe ser aceptado y aprobar el programa de formación que ofrece la Academia Judicial de cerca de diez meses de duración en el cual se entregarían las herramientas necesarias para cumplir su labor frente a "... las insuficiencias que presenta la formación universitaria para el ejercicio de la función judicial."357. Una vez en posesión de sus cargos, los jueces tendrán la posibilidad de tomar cursos de perfeccionamiento destinados a "...promover la adquisición de nuevos conocimientos y desarrollar habilidades para desempeñar de mejor forma su función.”358. En definitiva, los jueces cuentan con un sistema que ofrece enormes espacios para el perfeccionamiento en materias como las que planteo.

Algo similar ocurre tratándose de fiscales y defensores. En el caso de los fiscales, desde el Plan Estratégico de 2009 se inició un proceso de capacitación más sistemático de sus funcionarios a partir de un diagnóstico acerca de perfiles de competencia y necesidades específicas. Así, en el período 2009-2015 se ejecutaron 113 cursos por parte de la Unidad Nacional de Capacitación (cursos centralizados) destinados a fiscales. A ello se suma la realización de 2.191 actividades de capacitación ejecutadas a nivel regional destinados a todo tipo de funcionarios ${ }^{359}$. La Defensoría Penal Pública, por su parte, registra sólo el 2015 la ejecución de 151 actividades de capacitación en la que el 94\% de los funcionarios de su dotación intervinieron ${ }^{360}$.

\footnotetext{
${ }^{357}$ Información obtenida del sitio web de la Academia Judicial en: http://www.academiajudicial.cl/Programas.aspx?id_menu=24 [visitado el 01.07.2016].

${ }_{358}$ Información obtenida del sitio web de la Academia Judicial en: http://www.academiajudicial.cl/Programas.aspx?id_menu=23 [visitado el 01.07.2016]. Según describe la propia página "Anualmente la Academia presenta una variada oferta de cursos de perfeccionamiento, abordando contenidos de diversa índole, que van tanto desde temas propios de la teoría del derecho, como otros relativos al derecho vigente, hasta tópicos dirigidos a mejorar los aspectos cotidianos de las tareas en tribunales."

${ }^{359}$ Datos obtenidos de: MINISTERIO PÚBLICO, Memoria Institucional 2007-2015, Santiago: Ministerio Público, 2016, pp. 144-149. Disponible en: https://issuu.com/ministeriopublico3/docs/fiscal a de chile 2007-2015 - memo [visitado el 01.07.2016].

${ }^{360}$ DEFENSORÍA PENAL PÚBLICA, Memoria 2015, Santiago: Defensoría Penal Pública, 2015, p. 229 Disponible en: http://www.dpp.cl/resources/upload/files/documento/c3b8389eb0ae9ec02148e4225368f58b.pdf [visitado el 01.07.2016].
} 
DUCE, Mauricio. "Reconocimientos oculares: una aproximación empírica a su funcionamiento y algunas recomendaciones para su mejora".

Como se puede apreciar en esta somera revisión, las instituciones ofrecen un espacio importante de capacitación que podría aprovecharse para mejorar la situación en materia de reconocimientos. Si como he visto en secciones previas se trata de una diligencia de uso común, de suma importancia en la decisión de casos y, además, que produce un riesgo importante de tomar decisiones equivocadas, debiera claramente formar parte de las prioridades de capacitación de todas las instituciones del sistema.

\subsection{La introducción de tecnología en los procedimientos de reconocimiento.}

Una parte importante de las prácticas problemáticas identificadas en este trabajo podrían superarse con la introducción de algunos medios tecnológicos en las diligencias de reconocimientos. Se trata de herramientas que en la actualidad son de fácil disponibilidad y bajo costo en comparación con los daños que genera el sistema al producir identificaciones de dudosa confiabilidad. Me interesa detenerme en dos que creo son las de mayor impacto: sistema de registro y sistemas automatizados para los reconocimientos en set fotográfico.

La primera innovación es la introducción de un sistema de registro de mayor calidad que las actas actualmente utilizadas. Como he tenido posibilidad de revisar en varias secciones, la carencia de un sistema de registro de calidad constituye un problema muy significativo en la operativa del sistema desde varios puntos de vista. En primer lugar, permite la subsistencia de prácticas asociadas a las diligencias de reconocimiento que se apartan del Protocolo y de las buenas prácticas recomendadas por la literatura especializada. En segundo término, impide que fiscales y defensores puedan hacer control de la calidad del trabajo realizado en esas diligencias en las etapas previas a juicio. Finalmente, dificulta la valoración de confiabilidad que se pueda hacer de las mismas en sede judicial.

Las actas escritas actuales no están recogiendo aspectos cruciales de cómo son llevados adelantes estos procedimientos. Esto incluye, por ejemplo, el lenguaje detallado utilizado por los funcionarios o los testigos y víctimas que reconocen, el que puede arrojar pistas claves para evaluar su calidad, el tipo de interacciones que se produjeron durante y con posterioridad a la diligencia que permitan identificar si existió algún tipo de inducción o reforzamiento a una elección realizada con dudas. Este formato no permite tampoco, por otra parte, registrar los tiempos de respuestas del testigo o víctima que son fundamentales para evaluar la confiabilidad del reconocimiento. Así, se podrían seguir agregando varios otros elementos de igual importancia.

En opinión de la literatura especializada, como he mencionado previamente, este problema se resuelve implementando un sistema de registro audiovisual de las diligencias. De hecho, la implementación de sistemas de este tipo es una de las recomendaciones más persistentes que se pueden encontrar en la literatura especializada ${ }^{361}$. Esto por cuanto se trata de un

\footnotetext{
361 Además de las referencias que ya he hecho en esta material puede verse también: NATIONAL RESEARCH COUNCIL, Identifying the Culprit, cit. nota $\mathrm{n}^{\circ} 2$, p. 74. En el informe elaborado por las agencias de persecución penal de Canadá se reconoce que este es el sistema de registro más completo y óptimo, pero se entiende las dificultades de implementarlo con la misma intensidad en un país del tamaño y las diferencias como el suyo. Para el caso de imposibilidad en algunas regiones se recomienda registrar en
} 
Polít. crim. Vol. 12, No 23 (Julio 2017), Art. 9, pp. 291-379.

[http://www.politicacriminal.cl/Vol_12/n_23/Vol12N23A9.pdf]

formato de registro que podría recoger de manera fidedigna la cantidad y tipo de información requerida para permitir un adecuado control y valoración. Se trata, además, de una propuesta que ya se ha formulado en nuestro país de parte de la autoridad. En efecto, en el Plan de Seguridad Pública formulado el año 2014 por el gobierno se incluyó de manera específica una propuesta en esta dirección al señalarse, luego de reconocer la importancia de los reconocimientos y su falta de regulación legal, que "Atendido lo anterior, se impulsará la incorporación de una norma que fije parámetros específicos tales como: ...el registro en video de la diligencia..." ${ }^{362}$.

Lamentablemente, hasta la fecha no se conoce avance alguno sobre la presentación de un proyecto de ley en la materia y menos sobre la implementación de un sistema de este tipo a nivel de las policías. En parte, esto podría explicarse por resistencias institucionales a la implementación de mecanismos de registro de este tipo que constituyeran un obstáculo para avanzar en la materia. Para verificar la posición de los distintos actores del sistema en este tema incluí una pregunta sobre este punto en las entrevistas realizadas. Los resultados muestran que, al menos a nivel de opinión personal, existe un acuerdo bastante sólido en que se trataría de una medida positiva. En esta dirección, nueve de los diez funcionarios policiales dieron su opinión sobre esta materia y todos señalaron estar de acuerdo con que se avance en este sentido, incluso algunos destacando su conveniencia. Por ejemplo un carabinero entrevistado señaló "Sería mucho más transparente para nosotros...No lo veo como un aspecto problemático, sería un beneficio tanto para carabineros como la PDI, como así también un medio probatorio directo para la fiscalía." ${ }^{, 363}$. Un funcionario PDI manifiesta: "Sería bueno, lo mismo con las declaraciones que se toman, pues se dejaría constancia en el mismo video de las expresiones del testigo y de diferentes aspectos que dejan en evidencia si el testigo está siendo veraz."364. Las únicas preocupaciones detectadas están asociadas a la disponibilidad de recursos técnicos para poder implementar esto ${ }^{365}$ y a la necesidad de capacitar adecuadamente en su uso ${ }^{366}$.

Los fiscales que se pronunciaron sobre este punto también expresan su acuerdo con avanzar en la dirección sugerida, pero se manifiestan un poco más escépticos a los avances que efectivamente puedan hacerse en la materia. Por una parte, algunos creen que habría importantes resistencias institucionales a nivel de las policías ${ }^{367}$. Otro fiscal apunta más bien a la posibilidad que, aún introducido el registro audiovisual, se podrían desarrollar prácticas "tras bambalinas" que limitaran su impacto 368 .

audio o al menos en un acta que tenga transcripción detallada y textual de los procedimientos de reconocimiento. Véase: FPT HEADS OF PROSECUTIONS COMMITTEE, The Path to Justice, cit. nota ${ }^{\circ}$ 5 , p. 67.

362 MINISTERIO DEL INTERIOR Y SEGURIDAD PÚBLICA, Plan Nacional de Seguridad Pública, cit. nota $\mathrm{n}^{\circ} 15$, p. 67.

${ }^{363}$ Entrevista Carabinero ${ }^{\circ} 2,11$ de octubre de 2015.

${ }^{364}$ Entrevista PDI n³, 20 de enero de 2016. También manifiestan ventajas Entrevista PDI $n^{\circ} 1,20$ de enero de 2016; y, Entrevista PDI $n^{\circ} 2,20$ de enero de 2016 (quien también postula extender este sistema a las declaraciones que toman a imputados).

${ }^{365}$ En esta línea Entrevista PDI n ${ }^{\circ}$ 6, 4 de febrero de 2016 y Entrevista PDI n ${ }^{\circ}$ 7, 4 de febrero de 2016.

${ }^{366}$ Entrevista PDI ${ }^{\circ} 4,4$ de febrero de 2016.

${ }^{367}$ Entrevista Fiscal n ${ }^{\circ}$ 5, 4 de septiembre de 2015 y Entrevista Fiscal n ${ }^{\circ} 6,11$ de septiembre de 2015.

${ }^{368}$ Entrevista Fiscal $n^{\circ} 2,9$ de junio de 2015. 
DUCE, Mauricio. "Reconocimientos oculares: una aproximación empírica a su funcionamiento y algunas recomendaciones para su mejora".

Los jueces de garantía y juicio oral también se manifiestan favorables a la introducción de esta medida. Varios destacan las ventajas que tendría implementar este sistema de registro. Una de ellas tendría que ver con la mejora en la calidad de la información. Así, un Juez de Garantía señala

“...entonces cualquier medio idóneo que produzca información de calidad bienvenido sea, un video me parece consustancial a esta calidad de información. De hecho, los modestos hurtos de supermercado se resuelven mucho más fácil cuando llega el video del supermercado. El problema se acaba de hecho."369.

Otro juez destaca el papel que este sistema de registro podría tener en el control de la actuación policial al señalar "Sería útil porque frenaría ciertos procedimientos un poco irregulares o truchos de la policía en orden a presionar a la víctima..." 370 . A pesar de esta posición también hay jueces que piensan que en la práctica existirían reticencias institucionales de la policía para implementar una propuesta de este tipo ${ }^{371}$. Dichas reticencias son minimizadas por otros jueces que estiman que las policías ya han comenzado a ocupar cámaras en forma intensa en diversos tipos de procedimientos dando una señal que están avanzando en esta misma dirección ${ }^{372}$.

Como puede apreciarse, al menos desde el punto de vista de los actores del sistema, la posibilidad de introducir un registro videograbado de los reconocimientos es percibido como un avance positivo desde distintos puntos de vista. Sólo existen algunas dudas sobre la voluntad institucional de hacerlo. Eso es lo que lleva a un juez a plantear que sólo podría efectivamente implementarse por ley $^{373}$ lo que, en todo caso, va en la dirección de la propuesta contenida en el Plan de Seguridad Pública. Sobre el rol de la regulación legal de los reconocimientos volveré en una propuesta que desarrollaré más adelante.

Un problema o límite para esta propuesta se produce con las exhibiciones. Estas, se generan en contextos de instantaneidad que podrían dificultar la elaboración de registros más sofisticados que la constancia actual en los partes policiales. Me parece que, a pesar de lo anterior, el registro audiovisual también debiera óptimamente incluir a esta forma de reconocimiento, al menos para un número importante de $\operatorname{casos}^{374}$. La experiencia relatada unos párrafos antes por jueces que indican que en la actualidad las policías ya han introducido el uso de cámaras y registros de este tipo en la ejecución de otras diligencias de

\footnotetext{
${ }^{369}$ Entrevista Juez de Garantía n ${ }^{\circ} 2,25$ de junio de 2015. En una línea similar véase también Entrevista Juez de Garantía n ${ }^{\circ}$ 6, 3 de septiembre de 2015; Juez TOP n 3, 2 de julio de 2015; y, Juez TOP n ${ }^{\circ} 5$, 8 de julio de 2015.

${ }^{370}$ Entrevista Juez de Garantía n ${ }^{\circ} 4,8$ de julio de 2015. En una línea similar Entrevista Juez de Garantía n ${ }^{\circ} 8$, 4 de enero de 2016.

${ }^{371}$ Entrevista Juez de Garantía n ${ }^{\circ}$ 7, 14 de septiembre de 2015 y Entrevista Juez TOP n ${ }^{\circ} 8,22$ de diciembre de 2015 .

${ }^{372}$ Entrevista Juez TOP n ${ }^{\circ} 1,9$ de junio de 2015 y Entrevista Juez TOP n 4, 6 de julio de 2015.

${ }^{373}$ Entrevista Juez de Garantía n ${ }^{\circ}$ 7, 14 de septiembre de 2015.

${ }^{374}$ En la encuesta del Police Executive Research Forum en los Estados Unidos el año 2013, un 31,9\% de las agencias declaró registrar por vía de este método los "Show-ups", otro 34\% en registro de audio. Como se puede apreciar, existe un enorme espacio para avanzar en el uso de sistemas de registros más sofisticas aún en contextos como las exhibiciones. Véase: POLICE EXECUTIVE RESEARCH FORUM, A National Survey, cit. nota $n^{\circ} 21$, p. 54 .
} 
Polít. crim. Vol. 12, № 23 (Julio 2017), Art. 9, pp. 291-379.

[http://www.politicacriminal.cl/Vol_12/n_23/Vol12N23A9.pdf]

investigación (por ejemplo allanamientos y detenciones), lo que da cuenta que esto no debiera ser un obstáculo mayor, aunque sí agrega dificultades operativas a examinar con cuidado sobre la base de conocer mejor la experiencia actual en este punto, lo que no fue objeto de esta investigación.

Una segunda área en donde el uso de la tecnología podría producir un impacto importante en la mejora de la calidad y confiabilidad de estas diligencias es en el uso de sistemas computacionales automatizados para la realización de los reconocimientos en reemplazo de los procedimientos actuales. Hay quienes extienden esta recomendación incluyendo tanto los reconocimientos en rueda de sospechosos como a los en set de fotografías ${ }^{375}$. Hemos visto que en Chile el reconocimiento en rueda es más bien marginal en la práctica, por lo que me parece que incluso avanzado sólo en la introducción de estos sistemas en materia de reconocimientos fotográficos la ganancia ya sería mayor ${ }^{376}$.

Una primera ventaja de estos sistemas es que permitiría tener una base de datos de fotografías más estandarizadas y de mejor calidad para la construcción de los set a exhibir (incluyendo en ellos a cebos o distractores que satisfagan los estándares que he mencionado), allí en donde hemos visto esto hoy es una debilidad importante de nuestro sistema, según lo señalan los entrevistados. En segundo lugar, este tipo de procedimientos permiten limitar las interacciones entre los administradores del procedimiento y la víctima o testigo, ya que en general permiten que se puedan realizar sentados frente a un computador y así llevar adelante los pasos requeridos para practicar la diligencia. De esta forma se evitan o minimizan riesgos de inducción o contaminación. En tercer término, este tipo de herramientas genera sistemas de registros de alta calidad y completos ya que no sólo permite la videograbación de la diligencia sino también guardar el historial completo de toda la información utilizada. Además, se señala que permiten aumentar las posibilidades de realización del procedimiento al poder puede ser realizado a distancia a través de una conexión en internet, lo que podría redundar en reducción de costos que supone instalar el sistema en una etapa inicial ${ }^{377}$. Finalmente, se trata de un formato que no perjudica la calidad y precisión de los reconocimientos según demuestra la investigación en la materia $^{378}$.

Este trabajo no es la oportunidad para revisar los detalles de estos sistemas computarizados, sino más bien para plantear la necesidad de avanzar en la dirección de implementarlos en nuestro país y generar debate sobre lo mismo. No se trata, tampoco de una cuestión en

375 SIMON, In Doubt, cit. nota $\mathrm{n}^{\circ} 29$, pp. 86-89, NATIONAL RESEARCH COUNCIL, Identifying the Culprit, cit. nota ${ }^{\circ} 2$, p. 73 el que pone especial énfasis en el uso de esta tecnología para asegurar el doble ciego.

${ }^{376}$ En esta dirección, el National Institute of Justice de los Estados Unidos incluyó en un informe del año 1999 esta recomendación a las agencias policiales de dicho país. En la encuesta realizada por Police Executive Research Forum, el año 2013 sólo un porcentaje menor (12,4\%) de las agencias entrevistadas indicaron que lo habían implementado. POLICE EXECUTIVE RESEARCH FORUM, A National Survey, cit. nota $\mathrm{n}^{\circ} 21$, p. 85 .

${ }^{377}$ Sobre estas ventajas: SIMON, In Doubt, cit. nota ${ }^{\circ} 29$, pp. 86-89.

${ }^{378}$ MACLIN, Otto H.; ZIMMERMAN, Laura A.; MALPASS, Roy S., "PC Eyewitness and the Sequential Superiority Effect: Computer-Based Lineup Administration", Law and Human Behaviour, Vol. $29 \mathrm{n}^{\circ} 3$ (2005), pp. 303-321. 
DUCE, Mauricio. "Reconocimientos oculares: una aproximación empírica a su funcionamiento y algunas recomendaciones para su mejora".

donde no exista algún tipo de experiencia y desarrollo de buenas prácticas. Cito a modo ejemplar la experiencia del KADAC desarrollada por la PDI en la que con pocos recursos y uso de tecnología bastante simple se ha permitido mejorar de manera sustantiva la calidad del trabajo en las exhibiciones de kardex sin sospechosos ${ }^{379}$.

\subsection{Necesidad de mejorar la regulación normativa sobre los reconocimientos.}

He mencionado que nuestra actual legislación no contempla reglas que de manera explícita regulen la práctica de las diligencias de reconocimiento. En abstracto esto no es un problema per se ya que sería concebible un sistema que funcionara correctamente sólo a partir de regulaciones reglamentarias o protocolos de actuación bien desarrollados y con capacidad de ordenar la práctica cotidiana del sistema. La evidencia recogida en esta investigación da cuenta que no es el caso en nuestro país. Por el contrario, al parecer nos encontramos en un escenario que podría ser descrito como en el peor de los mundos: no tenemos regulación legal y sólo contamos con un Protocolo que, si bien es un avance, no ha sido capaz de disciplinar la actividad. Aún más, ese Protocolo tiene regulaciones problemáticas a la luz de la evidencia científica disponible y presenta algunos vacíos importantes, como por ejemplo, la falta de reglamentación de las exhibiciones que constituyen el procedimiento más utilizado en la práctica.

Este escenario me hace pensar en la conveniencia de introducir alguna regla al Código Procesal Penal que pudiera contribuir a la mejora de prácticas. No hay que engañarse, una norma legal por sí misma no tiene la capacidad de cambiar la realidad y las prácticas si no va acompañada de otros elementos, como por ejemplo, una implementación adecuada que incluya medios y capacitación. Con todo, en el estado actual que ha sido descrito en esta investigación, una reforma legislativa podría constituir una señal política fuerte para que las distintas instituciones del sistema de justicia penal se hagan cargo de manera más intensa de los problemas que se enfrentan en la materia ${ }^{380}$. Un buen diseño legal, además, debiera permitir generar espacios de litigación sobre los reconocimientos que no se han desarrollado en la actualidad por la inexistencia de regulación y que podrían servir de control de la calidad y confiabilidad de los mismos. Eso daría mayor espacio al desarrollo de jurisprudencia con mayor peso normativo. En definitiva, todo esto podría traducirse en una depuración y mejora de las prácticas. Finalmente, una regulación legal podría fijar el piso o parámetros básicos a los que debieran ajustarse los protocolos de actuación institucionales de una manera que fuera más consistente con la evidencia científica disponible. Además, le daría a estos un mayor peso normativo al estar respaldados por una exigencia legal y no simplemente una voluntad institucional.

Como señalé en la introducción, la idea de legislar en la materia ha venido rondando en nuestro país desde hace algunos años. Se planteó por primera vez el año 2013 con la proposición de un nuevo artículo 196 bis al CPP en un proyecto presentado por el Poder Ejecutivo al Senado, sin que hasta la fecha haya tenido un avance importante en su

\footnotetext{
${ }^{379}$ LLANQUIMÁN, “Kardex Antidelincuencial ”, cit. nota n²26, pp. 136-156.

${ }^{380}$ En esta dirección se pronuncia también Alcaíno quien señala que "Esta nueva normativa pareciera ser un incentivo importante para generar preocupación en el cumplimiento de los estándares." ALCAÍNO, "La Confiabilidad como Estándar", cit. nota n 11, p. 594.
} 
Polít. crim. Vol. 12, № 23 (Julio 2017), Art. 9, pp. 291-379.

[http://www.politicacriminal.cl/Vol_12/n_23/Vol12N23A9.pdf]

tramitación legislativa ${ }^{381}$. A esto se ha sumó la propuesta contenida en el Plan de Seguridad Pública del año 2014 que planteó dictar una ley que pudiera perfeccionar los procedimientos de reconocimientos, la que tampoco se ha transformado a la fecha en un proyecto específico. En este escenario no parece muy descabellado en avanzar en una propuesta de reforma legal.

Un tema central a dilucidar son los contenidos que debiera incluir una legislación en la materia. Se trata de una cuestión compleja, ya que se debe equilibrar, por una parte, una regulación que reconozca los principales hallazgos de la evidencia científica, pero que, por la otra, no cierre a futuro el desarrollo de prácticas que mejoren dichos estándares o que recojan la evolución que en el tiempo se va produciendo en la propia ciencia. Por lo mismo, no pretendo hacer una propuesta detallada sino más bien referirme a los contenidos básicos que debiera contener una regla de este tipo. Sus alcances precisos debieran ser objeto de otros análisis que no puedo incluir en este ya extenso trabajo.

Como definición general, me parece que debiera tratarse de una regla relativamente sencilla que contenga aspectos gruesos y no detalles demasiados específicos, los que me parece necesariamente deben ser objeto de regulación reglamentaria o a nivel de protocolos. En este contexto, un primer tema es que la regla debiera incorporar no sólo a los reconocimientos fotográficos y en ruedas, sino también las exhibiciones. Para poder hacer ello sin entrar en los detalles de cada forma de reconocimiento, la norma legal debiera poner más bien el foco en fijar un estándar general de calidad en la realización de los mismos $^{382}$. Ese estándar debiera fijar exigencias mínimas de confiabilidad en la realización de las diligencias para otorgarles algún reconocimiento en el sistema. Por ejemplo, se podrían poner una prohibición a que los procedimientos incluyan aspectos indebidamente sugestivos o inductivos o, desde otro punto de vista, que todo procedimiento llevado adelante para la realización de estas diligencias deba favorecer que sea la memoria de la víctima o del testigo la que haga el trabajo de identificación, entre otras opciones.

Un segundo tema clave que debiera regular la regla propuesta es el sistema de registro de las diligencias de reconocimiento. Como ya he señalado, en el óptimo éste debiera ser de carácter audiovisual u otro equivalente de manera de tener la información más completa posible. La regla podría contener una excepción en casos justificados en que un registro de esa naturaleza no sea posible de efectuar, estableciendo igualmente deberes fuertes de registro de información en los sucedáneos que los reemplacen.

\footnotetext{
${ }^{381}$ De acuerdo a la información oficial el proyecto se encuentra sin movimiento desde el 11 de marzo de 2015 y desde septiembre del 2013 sin actividades de avance relevantes. El estado de tramitación puede verse en: https://www.camara.cl/pley/pley_detalle.aspx?prmID=9216\&prmBoletin=8810-07 [visitado el 01.07.2016]. Como ya señalé, este proyecto de ley fue presentado por medio del Mensaje $\mathrm{N}^{\circ}$ 502-360, Mensaje de S.E El Presidente de la República, con el que Inicia un Proyecto de Ley que Perfecciona el Sistema de Justicia Penal, 29 de enero de 2013. Dicha propuesta fue luego modificada por un conjunto de indicaciones presentadas por el propio Poder Ejecutivo al Senado el día 4 de septiembre de 2013. Véase: Mensaje n ${ }^{\circ}$ 200-361, Formula Indicación al Proyecto de Ley que Perfecciona al Sistema de Justicia Penal, 04 de septiembre de 2013.

${ }^{382}$ En esta línea, pero refiriéndose a un tema más específico, se inscribe la propuesta de Alcaíno. Véase: ALCAÍNO, "La Confiabilidad como Estándar”, cit. nota n 11, pp. 582-594.
} 
DUCE, Mauricio. "Reconocimientos oculares: una aproximación empírica a su funcionamiento y algunas recomendaciones para su mejora".

En tercer término, la norma propuesta debiera regular las consecuencias del incumplimiento, tanto del estándar general de confiabilidad como de las exigencias de registro. En mi opinión, esa sanción debiera ser la inadmisibilidad de la diligencia o una parte de ella como prueba a juicio. Como adelanté en una sección previa ${ }^{383}$, el tema de la admisión o exclusión a juicio de la prueba que da cuenta de las diligencias de reconocimientos es una cuestión compleja, aún en países que tienen mayor desarrollo en la materia que Chile, como por ejemplo, los Estados Unidos ${ }^{384}$. Con todo, precisamente sobre la base de dicha experiencia, se podría pensar una regla que equilibrara adecuadamente las necesidades de contar con información para resolver los casos y asegurar que la calidad de la misma cumpla con algunos mínimos que evite la probabilidad de error. En esta dirección, Wells ha propuesto recientemente en los Estados Unidos abandonar la dicotomía de admisión total versus exclusión completa que se utiliza habitualmente en los debates de admisibilidad de las pruebas referidas a los reconocimientos a pesar que ello no viene impuesto ni por las leyes existentes ni por la jurisprudencia vigente de dicho país en la materia. Plantea, en cambio, avanzar a un sistema de admisiones limitadas (por ejemplo con prohibiendo al testigo abordar un punto específico de su reconocimiento, como podría ser, entre otros, el nivel de confianza con el cual reconoce al imputado si es que se considera que éste ha sido "inflado" por retroalimentación del sistema) ${ }^{385}$ y exclusiones parciales (por

${ }^{383}$ Supra 4.3.4.

${ }^{384}$ En el sistema federal de los Estados Unidos se permite la exclusión de la prueba vinculada a los reconocimientos desde la década de los '70 del siglo pasado producto de un interesante desarrollo jurisprudencial de la Corte Suprema. El estándar actual se encuentra fijado desde el caso Manson v. Brathwaite resuelto el año 1977 y permite, a grandes rasgos, excluir prueba de reconocimiento en casos en que exista un "riesgo sustancial de identificación errónea". Para ello debe seguirse un análisis en dos pasos. En primer lugar, se debe analizar si los procedimientos de identificación fueron "impermisiblemente sugestivos". En ese evento, como segundo paso se debe determinar, sobre la base de considerar la totalidad de las circunstancias, si a pesar del procedimiento inadecuado el reconocimiento igualmente es confiable. Para determinar la confiabilidad la Corte ha establecido un conjunto de factores (conocidos como factores Biggers por el caso Neil v. Biggers en que se originaron del año 1972) que incluyen: la oportunidad que tuvo la víctima o testigo para observar a la persona; el nivel de atención que prestó; la precisión de la primera descripción; el grado de certeza manifestado al reconocer; y, el tiempo transcurrido. Se trata de una jurisprudencia fuertemente criticada en la actualidad tanto desde la doctrina legal como desde la comunidad científica ya que los factores no recogerían adecuadamente o más bien contrarían el conocimiento disponible. Esto ha llevado a que varias cortes supremas de estados, como por ejemplo del Estado de New Jersey (Caso State v. Henderson de 2011), hayan elevando y mejorado el estándar federal. En otros, como por ejemplo Wisconsin y New York han adoptado reglas legales en la misma dirección. La literatura sobre esta evolución jurisprudencial y legal, el análisis del caso Manson y su crítica y sobre los desarrollos más recientes es inabarcable para un trabajo de esta naturaleza. Además de textos ya citados previamente en esta materia recomiendo revisar: WELLS/QUINLIVAN, "Suggestive Eyewitness Identification", cit. nota $\mathrm{n}^{\circ} 88$; TRENARY, Amy D., "State v. Henderson: A Model for Admitting Eyewitness Identification Testimony", University of Colorado Law Review, Vol. 84 N 4 (2013), pp. 1256-1303; JONES, Carla, “A New Age of Eyewitness Identification Evidence in Light of Modern Scientific Research: Why State v. Henderson Does Not Significantly Alter the Management of Eyewitness Identification Evidence", Rutgers Law Journal, Vol. $44 \mathrm{~N}^{\circ} 3$ (2014), pp. 511-545; LEONETTI, Carrie, "Showing Up: Eyewitness-Identification Requirements in Bosnia and Herzegovina: A Comparative Case Study", Penn State Law Review, Vol. 119 (2014), pp. $439-483$. Una explicación en la literatura nacional CASTILLO, "Enjuiciando al Proceso Penal Chileno desde el Inocentrismo", cit. nota n 8, pp. 274-275; ALCAÍNO, "La Confiabilidad como Estándar", cit. nota n 11, pp. 584-585.

${ }^{385}$ En nuestro país existe también una práctica que podría asociarse a esta propuesta de admisiones limitadas. Se trata de las denominadas "exclusiones temáticas de prueba" en virtud de la cual los jueces de garantía en la APJO permiten el ingreso de una prueba, típicamente un testigo, pero impidiéndole referirse a algún punto 
Polít. crim. Vol. 12, № 23 (Julio 2017), Art. 9, pp. 291-379.

[http://www.politicacriminal.cl/Vol_12/n_23/Vol12N23A9.pdf]

ejemplo no permitiendo que el testigo mencione un punto del procedimiento de reconocimiento, pero que sí pueda ser abordado por la defensa si desea incluirlo como elemento para su valoración). Se señala que un sistema como éste podría resguardar mucho mejor los intereses en juego ${ }^{386}$. Además, se propone complementar una regla de este tipo con otros remedios o paliativos diferentes a la exclusión como, por ejemplo, el uso de peritos en materia de la investigación científica existente sobre reconocimientos oculares ${ }^{387}$.

En Chile ya existen algunas propuestas desde la doctrina en el ámbito de la admisibilidad y exclusión de las pruebas que se refieren a los reconocimientos, pero creo que todavía ancladas en parte en la lógica que Wells llama a abandonar y que me parece lo más adecuado $^{388}$.

Finalmente, la regla debiera contener una remisión al desarrollo de protocolos destinados a regular los detalles específicos de realización de las diligencias. En mi opinión, lo ideal sería trabajar con un protocolo de corte interinstitucional como el vigente en la actualidad. Junto con hacer esta remisión general, la norma podría establecer exigencias en términos de su revisión periódica a la luz del desarrollo de la ciencia o la jurisprudencia local, como también la necesidad que los equipos de elaboración incluyan no solo miembros de las agencias de persecución penal sino que también expertos independientes y a otros actores del sistema (por ejemplo jueces).

Vale la pena explicitar que la propuesta de introducción de una reforma legal que regule a los reconocimientos en el CPP asume que el actual Protocolo debiera ser objeto de perfeccionamiento en las mismas líneas señaladas en forma precedente $\mathrm{y}$, especialmente, considerando las críticas y problemas de la práctica que he identificado en secciones previas de este trabajo.

específico. Por ejemplo, la admisión como testigo de un funcionario policial que llevó adelante la investigación, pero con exclusión de hacer referencias a una confesión del imputado que el mismo juez estimó fue obtenida con vulneración de garantías fundamentales.

${ }^{386}$ WELLS/GREATHOUSE/SMALARZ, Why do motions, cit. nota $\mathrm{n}^{\circ} 28$, pp. 178-181. Un punto interesante que lleva a justificar esta propuesta se basa en el diagnóstico según el cual para un juez es difícil excluir por completo un reconocimiento, aún cuando tenga vicios, si es que es posible a la vez que presente algunos elementos rescatables que podrían servir para resolver un caso. Esto lleva a que en la práctica de los Estados Unidos la tendencia haya sido a la de interpretar muy restrictivamente los estándares de exclusión en esta materia si es que la lógica es de todo o nada. Me parece que este razonamiento es muy pertinente para el caso nacional.

${ }^{387}$ WELLS/GREATHOUSE/SMALARZ, Why do motions, cit. nota ${ }^{\circ}$ 28. p. 179. Volveré a algo sobre el uso de prueba pericial en el punto siguiente.

388 Alcaíno ha propuesto un criterio de admisión o exclusión de la prueba basado en la confiabilidad del reconocimiento. Si se está en presencia de reconocimientos cuya confiabilidad son claramente cuestionables, él es partidario de la exclusión de la prueba que se refiera a ellos. Tratándose de reconocimientos de confiabilidad poco cuestionable o dudosa es en cambio partidario de su admisión a juicio. ALCAÍNO, "La Confiabilidad como Estándar", cit. nota n 11, pp. 583-594. 
DUCE, Mauricio. "Reconocimientos oculares: una aproximación empírica a su funcionamiento y algunas recomendaciones para su mejora”.

\subsection{Investigación $y$ desarrollo de una comunidad de expertos en materia de reconocimientos.}

Como se ha señalado a lo largo de este trabajo, los aportes provenientes de la investigación científica desarrollada en el ámbito comparado en materia de funcionamiento de la memoria y procedimientos de reconocimiento ocular entregan una información clave para mejorar el funcionamiento del sistema de justicia penal en esta área. Lamentablemente, es posible apreciar en nuestro país no existe un desarrollo científico que haya expandido esto a la realidad local, ni una comunidad de expertos en el área que investigue, haga docencia, apoye el perfeccionamiento de prácticas y desarrollo de políticas públicas en estas materias. Me parece que este fenómeno explica, al menos en parte, los hallazgos de esta investigación.

Por lo mismo es clave buscar fórmulas y mecanismos que permitan a corto plazo aumentar la investigación nacional en la materia y a mediano y largo constituir una comunidad académica de especialistas que se transformen en actores relevantes en el diseño, uso y debate de los procedimientos de reconocimiento. En esta línea me parece que el Estado dispone de varias herramientas que podrían incentivar este desarrollo sin grandes cambios a políticas públicas que hoy se encuentran vigentes. Para la formación de capital humano avanzado, por ejemplo, se dispone del programa conocido como Becas Chile que tiene por propósito explícito la formación de "investigadores y profesionales de excelencia con alta preparación en todas las áreas del conocimiento para el desarrollo de Chile. ${ }^{, 389}$. A nivel de investigación y formación de equipos académicos una fórmula que permitiría avanzar en esta dirección es la de orientar una porción de los fondos concursables que entrega la Comisión Nacional de Investigación Científica y Tecnológica (Conicyt) en sus diversos tipos de proyectos de investigación (Fondecyt, Anillos en Ciencias, etc.) ${ }^{390}$. En el contexto actual de discusión del nuevo estatuto y financiamiento de la educación superior en Chile, podría también parte de los fondos basales de investigación que se discuten en la actualidad a instituciones de educación superior que desarrollen líneas de trabajo o constituyan de equipos en la materia. En fin, me parece que en el actual esquema de promoción de capital humano, investigación científica y fortalecimiento institucional de las universidades que promueve el Estado existen espacios importantes para el desarrollo de una comunidad especializada en materia de reconocimientos oculares.

¿Qué es lo que podría aportar esta comunidad? Para ofrecer una respuesta distinguiría dos niveles. En un nivel "macro" me parece que sería posible esperar cuatro cuestiones principales. Un aumento significativo de la investigación científica nacional para determinar con mayor precisión la efectiva concurrencia en nuestra realidad de los factores y aspectos que han sido identificados en el ámbito comparados como claves para otorgarle confiabilidad a los reconocimientos ${ }^{391}$. Una segunda cuestión es, a partir del conocimiento

\footnotetext{
${ }^{389}$ Mayores antecedentes en: http://www.conicyt.cl/becas-conicyt/sobre-becas-conicyt/que-es-becas-conicyt/ [visitado el 01.07.2016].

${ }^{390}$ Mayores antecedentes en: http://www.conicyt.cl/ [visitado el 01.07.2016].

${ }^{391}$ Para ver aspectos del tipo de investigación a desarrollar recomiendo ver las recomendaciones del National Research Council de los Estados Unidos del año 2014. NATIONAL RESEARCH COUNCIL, Identifying the Culprit, cit. nota $\mathrm{n}^{\circ} 2$, pp. 77-79.
} 
Polít. crim. Vol. 12, No 23 (Julio 2017), Art. 9, pp. 291-379.

[http://www.politicacriminal.cl/Vol_12/n_23/Vol12N23A9.pdf]

y experticia acumulada, contribuir al desarrollo de protocolos y prácticas institucionales más virtuosas en la materia ${ }^{392}$. En tercer término, debieran aportar en el desarrollo y ejecución de programas de capacitación a los distintos actores del sistema de justicia penal. Finalmente, uno esperaría de esta comunidad un aporte en el conocimiento general y sensibilización de la sociedad sobre los problemas y desafíos en el área.

En un segundo nivel, que llamaría "micro", me parece que el aporte de una comunidad de expertos podría ser de mucha importancia en el funcionamiento cotidiano del sistema de justicia penal a través de su apoyo en la investigación y juzgamiento de los casos. Por ejemplo, en los Estados Unidos existen experiencias en las cuáles los expertos apoyan el trabajo de policías y fiscales con evaluaciones de la calidad de los reconocimientos durante la etapa de investigación con el propósito de permitirles tener mayor claridad de las fortalezas y debilidades de su caso y orientar mejor las investigaciones posteriores ${ }^{393}$. Algo similar podría ocurrir tratándose de defensores públicos de manera de que su litigación en esta etapa sea de mayor calidad. Para esto, por ejemplo, podrían aprovecharse parte de los recursos destinados a pericias que cuenta la Defensoría Penal Pública ${ }^{394}$.

También es posible identificar potenciales aportes en etapas posteriores del proceso. Por ejemplo, las discusiones sobre admisibilidad o exclusión (ya sean totales o parciales como he planteado en secciones previas) podría enriquecerse enormemente con el apoyo de opiniones expertas que ilustren al juez de garantía sobre los criterios científicos que debiera utilizar para determinar el grado de confiabilidad de un reconocimiento ocular que se intenta ingresar a juicio ${ }^{395}$. Además, otra posibilidad sería utilizar prueba pericial en los juicios orales de manera de ilustrar a los tribunales del estado de la ciencia y los criterios consensuados para valorar reconocimientos. Me interesa destacar que éste uso no debiera tener por propósito sustituir la función judicial de valorar la credibilidad de los reconocimientos, sino sólo aportar elementos relevantes asentados en la respectiva ciencia para que el tribunal pueda realizar dicha tarea. En consecuencia, me parece que el aporte de los expertos no es el sacar conclusiones sobre los reconocimientos en concreto, sino más bien brindar información general sobre el estado del arte en la ciencia y sobre los procedimientos llevados en efecto en el caso. Eventualmente, también podrían incluir el análisis de concurrencia de factores específicos en un caso concreto. Se trata de un tema que no es pacífico en el derecho comparado. Por ejemplo, se trata de un tema ampliamente discutido en la jurisprudencia de los Estados Unidos. La tendencia inicial en dicho país fue bastante reacia a la admisión de esta prueba entendiendo que ella podía usurpar la función

\footnotetext{
${ }^{392}$ Un ejemplo de este tipo de aportes está constituido por el trabajo realizado en los Estados Unidos por la American Psychology-Law Asociation (Asociación Americana de Psicología y Derecho) en la producción de un trabajo de revisión científica sobre la materia el año 1998 conocido como "white paper". Este trabajo constituyó una de las bases sobre la cual se dictó con posterioridad una guía elaborada por el Departamento de Justicia para las agencias de persecución penal en materia de reconocimientos oculares de testigos. SIMON, In Doubt, cit. nota ${ }^{\circ}$ 29, p.82. La guía puede encontrarse en https://www.ncjrs.gov/pdffiles1/nij/178240.pdf [visitado el 01.07.2016].

${ }^{393}$ SIMON, In Doubt, cit. nota n ${ }^{\circ} 29$, p. 81.

${ }^{394}$ La Defensoría Penal Pública reporta en su memoria anual de 2015 que dicho año fueron encargados 11.319 informes periciales con un gasto superior a los 1.200 millos de pesos. DEFENSORÍA PENAL PÚBLICA, Memoria 2015, cit. nota $\mathrm{n}^{\circ} 360$.

${ }^{395}$ En esta dirección: WELLS/GREATHOUSE/SMALARZ, Why do motions, cit. nota nº 28, p. 181.
} 
DUCE, Mauricio. "Reconocimientos oculares: una aproximación empírica a su funcionamiento y algunas recomendaciones para su mejora".

del juzgador. El desarrollo posterior, basado en la evidencia disponible acerca de los riegos de error, ha venido produciendo un cambio relevante tanto en materia de regulación normativa como jurisprudencial en varios estados, consolidando una clara tendencia su admisibilidad en la actualidad ${ }^{396}$.

Finalmente, me parece que otro espacio en donde el aporte de expertos en reconocimientos sería extremadamente útil para el funcionamiento del sistema es en su uso tratándose de los recursos de revisión. Por ejemplo, la tramitación de los casos ante la Corte Suprema de Pedro Lobos y Julio Robles podría haberse visto muy beneficiada si es que en dicha sede pudiera haberse recurrido a esta evidencia como forma de acreditar su condena errónea.

Como se pude apreciar, el desarrollo de mayor investigación científica en la materia y el surgimiento de una comunidad experta podrían aportar en niveles muy importantes a la mejora de la situación actual. Parece ser un área en donde hay una necesidad muy clara y en donde nuestras políticas públicas y sistema legal ofrecen enormes espacios de mejora.

\footnotetext{
${ }^{396}$ Una de las decisiones más recientes en esta materia por la que se admitió el uso de prueba pericial en estos casos fue la adoptada por la Corte Suprema del Estado de Illinois en People of the State of Illinois v. Eduardo Lerma (Docket No. 118496), 22 de enero de 2016 en: http://www.news-gazette.com/sites/all/files/pdf/2016/02/10/118496.pdf [visitado el 01.07.2016]. Una visión panorámica del debate en dicho país antes del desarrollo de esta jurisprudencia más reciente puede verse en la siguiente nota: "The Province of the Jurist: Judicial Resistance to Expert Testimony on Eyewitnesses as Institutional Rivalry", Harvard Law Review, Vol. 126 (2013), pp. 2381-2402. Un relato que da cuenta del período previo en donde hubo más dificultades puede verse en LAMPINEN, The Psychology of Eyewitness Identification cit. nota $n^{\circ} 94$, pp. 244-248. En el caso chileno, algunos jueces orales manifiestan en sus entrevistas que sería positivo la introducción de prueba pericial en esta materia. Véase: Entrevista Juez TOP $\mathrm{n}^{\circ}$ 3, 2 de julio de 2015 y Entrevista Juez TOP n 4, 6 de julio de 2015.
} 
Polít. crim. Vol. 12, No 23 (Julio 2017), Art. 9, pp. 291-379.

[http://www.politicacriminal.cl/Vol_12/n_23/Vol12N23A9.pdf]

\section{BIBLIOGRAFÍA}

1.- Libros:

CISTERNA, Adolfo, La Detención por Flagrancia en el Nuevo Código Procesal Penal, Santiago: Librotecnia, 2004.

DUCE, Mauricio; RIEGO, Cristián, Proceso Penal, Santiago: Editorial Jurídica de Chile, 2007.

DURÁN, Rodrigo, Medidas Cautelares Personales en el Proceso Penal, 3era Edición, Santiago: Librotecnia, 2011.

EPSTEIN, Jules, "Eyewitness and Erroneous Convictions: An American Conundrum”, en: LUCY, Sarah, Controversies in Innocence Cases in America, England: Ashgate, 2014.

GARRETT, Brandon L., Convicting the Innocent: Where Criminal Prosecutions Go Wrong, United States: Harvard University Press, 2011.

HARRIS, David, Failed Evidence, New York: New York University Press, 2012.

HIRSCHBERG, Max, La Sentencia Errónea en el Proceso Penal, Trad. BANZHAF, Tomas A., Buenos Aires: Ediciones Jurídicas Europa-América, 1969.

HORVITZ, María Inés; LÓPEZ, Julián, Derecho Procesal Penal Chileno. Tomo II, Santiago: Editorial Jurídica de Chile, 2004.

LAMPINEN, James et al., The Psychology of Eyewitness Identification (Essays in Cognitive Psychology), New York: Taylor and Francis Group, 2012.

LOFTUS, Elizabeth F.; DOYLE, James M.; DYSART, Jennifer E., Eyewitness Testimony: Civil and Criminal, United States: LexisNexis, 2013.

MANZANERO, Antonio; GONZÁLEZ, José Luis, Avances en psicología del testimonio, Santiago: Ediciones Jurídicas de Santiago, 2013.

MAZZONI, Giuliana, ¿Se Puede Creer a un Testigo? El Testimonio y las Trampas de la Memoria, Madrid: Editorial Trotta, 2010.

MORALES, Ana María; WELSCH, Gherman, El Reconocimiento de Imputados en Chile y a Nivel Comparado, Santiago: Fundación Paz Ciudadana, 2011.

NAUGHTON, Michael, The Innocent and the Criminal Justice System. A Sociological Analysis of Miscarriages of Justice, United Kingdom: Palgrave Macmillan, 2013.

SIGMAN, Mariano, La Vida Secreta de la Mente, Buenos Aires: Debate, 2016.

SIMON, Dan, In Doubt: The Psychology of the Criminal Justice Process, United States: Harvard University Press, 2012.

SOLETO, Helena, La Identificación del Imputado, Valencia: Tirant lo Blanch, 2009.

2.- Capítulos de libros:

AUSTIN, Jacqueline et al., "Double-blind Lineup Administration: Effects of Administrator Knowledge on Eyewitness Decisions en: CUTLER, Brian L. (Ed.), Reform of Eyewitness Identification Procedures, Washington D.C.: American Psychological Association, 2013, pp. 139-160.

BRADFIELD, Amy; PAVLETIC, Afton, "Eyewitness Confidence Malleability", en: CUTLER, Brian L. (Ed.), Conviction of the Innocent: Lessons from Psychological Research, Washington D.C.: American Psychological Association, 2012, pp. 149-165. 
DUCE, Mauricio. "Reconocimientos oculares: una aproximación empírica a su funcionamiento y algunas recomendaciones para su mejora".

CLARK, Steven, RUSH, Ryan A.; MORELAND, Molly B., "Constructing the Lineup: Law, Reform, Theory and Data, en: CUTLER, Brian L. (Ed.), Reform of Eyewitness Identification Procedures, Washington D.C.: American Psychological Association, 2013, pp. 87-112.

DIGES, Margarita; PÉREZ-MATA, Nieves, "La Prueba de Identificación desde la Psicología del Testimonio", en: DIGES, Margarita et al., Identificaciones fotográficas y en rueda de reconocimientos, Madrid: Marcial Pons, 2014, pp. 33-85.

FORST, Brian, "Wrongful Convictions in a World of Miscarriages of Justice", en: HUFF, Ronald; KILLIAS, Martin (Eds.), Wrongful Conviction and Miscarriages of Justice: Causes and Remedies in North American and European Criminal Justice Systems, New York: Routledge, 2013, pp. 15-43.

GOODSELL, Charles A.; WETMORE, Stacy A.; NEUSCHATZ, Jeffrey S.; GRONLUND, Scott D., "Showups", en: CUTLER, Brian L. (Ed.), Reform of Eyewitness Identification Procedures, Washington D.C.: American Psychological Association, 2013, pp. 45-63.

LLANQUIMÁN, Alex, et al:: "Kardex Antidelincuencial Clasificado (KADAC)”, en: FUNDACIÓN PAZ CIUDADANA, Buenas prácticas para el análisis delictual en América Latina 2015, Santiago: Fundación Paz Ciudadana, 2016, pp. 136-156.

MORENO, Leonardo, "Algunas Consideraciones Sobre el Funcionamiento de la Reforma Procesal Penal”, en: DECAP, Mauricio; DUCE, Mauricio; MORENO, Leonardo; SÁEZ, Jorge, El Modelo Adversarial en Chile. Ponencias Sobre su Implementación en la Reforma Procesal Penal, Santiago: Thomson Reuters, 2013, pp. 67-218

OBACH, Jorge; GARCÍA, María Carmen, "Praxis Judicial sobre los Reconocimientos de Identidad", en: DIGES, Margarita et al., Identificaciones Fotográficas y en Rueda de Reconocimientos, Buenos Aires: Marcial Pons, 2014, pp. 87-115.

SMALARZ, Laura; WELLS, Gary L., "Eyewitness Certainty as System Variable”, en: CUTLER, Brian L. (Ed.), Reform of Eyewitness Identification Procedures, Washington D.C.: American Psychological Association, 2013, pp. 161-177.

STEBLAY, Nancy K., "Lineup Instructions", en: CUTLER, Brian L. (Ed.), Reform of Eyewitness Identification Procedures, Washington D.C.: American Psychological Association, 2013, pp. 65-86.

WELLS, Gary L.; GREATHOUSE, Sarah M.; SMALARZ, Laura, Why do motions to suppress suggestive eyewitness identifications fail?, Washington D.C.: American Psychological Association, 2012.

ZIMMERMAN, David M.; AUSTIN, Jacqueline L.; KOVERA, Margaret Bull, "Suggestive Eyewitness Identification Procedures, en: CUTLER, Brian L. (Ed.), Conviction of the Innocent: Lessons from Psychological Research, Washington D.C.: American Psychological Association, 2012, pp. 125-148.

3.- Artículos Académicos:

ALCAIÍNO, Eduardo, "La confiabilidad como estándar para evaluar la calidad de los reconocimientos de imputados", Polít. crim. Vol. 9, № 18 (2014), pp. 564-613.

CASTILlO, Ignacio, "Enjuiciando al Proceso Penal Chileno desde el Inocentrismo (algunos apuntes sobre la necesidad de tomarse en serio a los inocentes)", Polít. crim. Vol. 8, No 15 (2013), pp. 249-313. 
Polít. crim. Vol. 12, No 23 (Julio 2017), Art. 9, pp. 291-379.

[http://www.politicacriminal.cl/Vol_12/n_23/Vol12N23A9.pdf]

DUCE, Mauricio, "Algunas Lecciones A Partir de Cuatro Casos de Condena de Inocentes en Chile", Revista de Derecho Universidad Católica del Norte, Año $22 n^{\circ} 1$ (2015), pp. 149208.

“¿Debiéramos Preocuparnos de la Condena de Inocentes en Chile? Antecedentes Comparados y Locales para el Debate", Revista Ius et Praxis, Año 19 n 1 (2013), pp. 77 138.

"La Condena de Inocentes en Chile: Una Aproximación Empírica a partir de los Resultados de los Recursos de Revisión Acogidos por la Corte Suprema en el período 20072013”. Polít. crim. Vol. 10, No 19 (2015), pp. 159-191.

FINDLEY, Keith, "Adversarial Inquisitions: Rethinking the Search for the Truth", New York Law School Law Review, Vol. 56 (2011-2012), pp. 912-941.

GARRETT, Brandon, "Eyewitness and Exclusion", Vanderbilt Law Review, Vol. 66 (2012), pp. 451-506.

GOULD, Jon, et al., "Predicting Erroneous Convictions", Iowa Law Review, Vol. 99 (2014), pp.471-522.

JONES, Carla, "A New Age of Eyewitness Identification Evidence in Light of Modern Scientific Research: Why State v. Henderson Does Not Significantly Alter the Management of Eyewitness Identification Evidence”, Rutgers Law Journal, Vol. 44 № 3 (2014), pp. 511545.

LEONETTI, Carrie, "Showing Up: Eyewitness-Identification Requirements in Bosnia and Herzegovina: A Comparative Case Study”, Penn State Law Review, Vol. 119 (2014), pp. 439-483.

LIBEDINSKY, Sofía, "Exigencias para un Adecuado Reconocimiento de Imputados”, Revista 93, $\mathrm{N}^{\mathrm{o}} 6$ año 2 (2001), pp. 30-35.

MACLIN, Otto H.; ZIMMERMAN, Laura A.; MALPASS, Roy S., "PC Eyewitness and the Sequential Superiority Effect: Computer-Based Lineup Administration", Law and Human Behaviour, Vol. 29 n 3 (2005), pp. 303-321.

MERINO, Alberto; REUSE, Marcelo, "Testigos presenciales y reconocimiento de imputados en Chile. Aproximación a los procedimientos utilizados y propuestas para una mejora de prácticas", Revista de Derecho y Ciencias Penales, ${ }^{\circ} 15$ (2010), pp. 55-83.

SEPÚLVEDA, Verónica, "Identificación de Imputados. Condiciones de Legitimidad", Revista Razonamiento Penal, $\mathrm{N}^{\circ} 1$ (2012), pp. 9-18.

TRENARY, Amy D., "State v. Henderson: A Model for Admitting Eyewitness Identification Testimony”, University of Colorado Law Review, Vol. 84 N 4 (2013), pp. 1256-1303.

WELLS, Gary; QUINLIVAN, Deah, "Suggestive Eyewitness Identification Procedures and the Supreme Court's Reliability Test in Light of Eyewitness Science: 30 Years Later", Law and Human Behavior, Vol. 33, $\mathrm{N}^{\circ} 1$ (2009), pp 1-24.

4.- Jurisprudencia nacional:

Corte Suprema de Chile, Recurso de Revisión, Sentencia del 22 de febrero de 2012, Causa Rol no 12.018-2011.

Corte Suprema de Chile, Recurso de Revisión, Sentencia del 14 de enero de 2014, Causa Rol no 11.109-2013. 
DUCE, Mauricio. "Reconocimientos oculares: una aproximación empírica a su funcionamiento y algunas recomendaciones para su mejora".

Corte de Apelaciones de Copiapó, Recurso de Nulidad, Sentencia del 10 de septiembre de 2010, Causa Rol n $130-2012$.

5.- Otros:

CARABINEROS DE CHILE, Manual sobre Normas Básicas para la Identificación de Imputados de Delitos a través del Reconocimiento Fotográfico y la Rueda de Personas, Santiago: Carabineros de Chile, 2009.

CATALÁN, Mario, Aproximación Empírica sobre la Realización y Valoración de la Prueba del Reconocimiento Ocular en Chile, Santiago: Trabajo final para titulación del Magíster en Derecho Penal y Procesal Penal, Universidad Diego Portales, septiembre 2016, 124 pp., no publicado (documento electrónico en poder del autor).

DEFENSORÍA PENAL PÚBLICA, Memoria 2015, Santiago: Defensoría Penal Pública, 2015. Disponible en:

http://www.dpp.cl/resources/upload/files/documento/c3b8389eb0ae9ec02148e4225368f58b.pdf [visitado el 01.07.2016].

DOMEYKO, Antonia, "Los Dibujantes Detrás de los Más Buscados”, Revista El Sábado, n854, 31 de enero de 2015, pp. 10-14, en:

http://diario.elmercurio.com/detalle/index.asp?id=\%7b04c66d3e-b168-49d5-95e88692938c68c4\%7d\# [visitado el 01.07.2016].

FISCALIA REGIONAL METROPOLITANA ORIENTE, Oficio 098-2010 del Fiscal Regional Xavier Armendáriz, Procedimiento de Reconocimiento de Imputados, Santiago: Fiscalía Regional Metropolitana Oriente, 2010.

FPT HEADS OF PROSECUTIONS COMMITTEE, The Path to Justice: Preventing Wrongful Convictions, Canadá: FPT HEADS OF PROSECUTIONS COMMITTEE, 2011.

FPT HEADS OF PROSECUTIONS COMMITTEE WORKING GROUP, Report on the Prevention of Miscarriages of Justice, Canadá: Department of Justice, 2004.

LIPTAK, Adam, "34 Years Later Supreme Court Will Revisit Eyewitnesses IDs”, New York Times, 22 de agosto de 2011, en:

http://www.nytimes.com/2011/08/23/us/23bar.html?scp=1\&sq=\%22Perry\%20v.\%20New\%20Ham pshire\%22\&st=cse [visitado el 01.07.2016].

MINISTERIO DEL INTERIOR Y SEGURIDAD PÚBLICA, Plan Nacional de Seguridad Pública y Prevención de la Violencia y el Delito: Seguridad para Todos, Santiago: Gobierno de Chile, p. 67. Disponible en:

http://www.seguridadpublica.gov.cl/filesapp/Libro\%20final\%20final.pdf [visitado el 01.07.2016].

MINISTERIO PÚBLICO, Protocolo Interinstitucional de Reconocimiento de Imputados, Santiago: Ministerio Público, 2013.

, Boletín Estadístico Anual 2015, Santiago: Ministerio Público, 2016. Disponible en: http://www.fiscaliadechile.cl/Fiscalia/estadisticas/index.do [visitado el 01.07.2016].

, Memoria Institucional 2007-2015, Santiago: Ministerio Público, 2016. Disponible en: https://issuu.com/ministeriopublico3/docs/fiscal_a_de_chile_2007-2015_-_memo [visitado el 01.07.2016].

NATIONAL RESEARCH COUNCIL, Identifying the Culprit: Assessing Eyewitness Identification, Washington D.C.: The National Academies of Sciences, Engineering, and Medicine, 2014. 
Polít. crim. Vol. 12, No 23 (Julio 2017), Art. 9, pp. 291-379.

[http://www.politicacriminal.cl/Vol_12/n_23/Vol12N23A9.pdf]

POLICE EXECUTIVE RESEARCH FORUM, A National Survey Eyewitness Identification Procedures in Law Enforcement Agencies, Washington D.C.: National Institute of Justice, 2013.

POLICIA DE INVESTIGACIONES DE CHILE, Orden General $n^{\circ} 2287$ del Director General de la Policía de Investigaciones de Chile, Aprueba Cartilla Instructiva para el Reconocimiento de Personas, Santiago, Policía de Investigaciones de Chile, 2010.

ROMÁN, Francisco, "Ricardi, Tras 13 Años en Prisión, Ya es Inocente", El País, 24 de julio de 2009, en: http://elpais.com/diario/2009/07/24/sociedad/1248386406 850215.html [visitado el 01.07.2016].

UNIVERSIDAD DE CONCEPCIÓN, Estudio reconocimiento visual errado en el proceso penal oral, Concepción: Programa de Responsabilidad Social de la Universidad de Concepción, 2005.

URTUBIA, Eduardo, "Cristián López en la más dura: 'El Estado destruyó mi vida", La Cuarta, 3 de agosto de 2015, en: http://www.lacuarta.com/noticias/cronica/2015/08/63-186960-9cristian-lopez-en-la-mas-dura-el-estado-destruyo-mi-vida.shtml [visitado el 01.07.2016]. 
DUCE, Mauricio. "Reconocimientos oculares: una aproximación empírica a su funcionamiento y algunas recomendaciones para su mejora".

\section{ANEXO METODOLÓGICO}

Este anexo tiene por objeto proveer información más detallada sobre la metodología de esta investigación y, en particular, sobre su componente de entrevistas. Se trató de entrevistas semi-estructuradas elaboradas sobre una matriz común de preguntas, pero que incluyeron componentes diferenciados por rol. Todas ellas cubrieron cuatro áreas temáticas principales: aspectos generales; cuantificación; descripción de procedimientos; y, litigio y valoración. Las pautas utilizadas por cada categoría de entrevistados están disponible en los archivos del proyecto que guarda el investigador responsable.

Las entrevistas fueron ejecutadas en el período del mes de mayo de 2015 y mayo de 2016. $\mathrm{Su}$ duración fue en promedio de una hora, pero ellas incorporaron otros aspectos de esta investigación que serán objeto de futuros trabajos. La extensión dependió de los roles. En caso de los funcionarios policiales ellas duraron en promedio 30 minutos, pero los actores del sistema legal en general un poco más de una hora y hasta una hora y veinte minutos en los casos de mayor duración. En cada una de ellas, los entrevistaron fueron informados de sus derechos y prestaron su consentimiento. Copia de dichos consentimientos informados se encuentran en poder del autor de este trabajo de acuerdo a las pautas que exige Fondecyt.

Las entrevistas fueron grabadas digitalmente y transcritas en forma completa por un equipo de colaboradores técnicos del proyecto, todos estudiantes de derecho. Como se ha señalado en la introducción, se trató de 51 entrevistas que incluyeron a 13 fiscales, 8 defensores, 8 jueces de garantía, 8 jueces de tribunales de juicio oral, 4 abogados particulares y 10 funcionarios policiales. En el caso de los jueces se tomaron los listados disponibles en la página web del Poder Judicial y se escogieron nombres de jueces de tribunales diversos que fueron contactados luego por correo electrónico programándose la entrevista de acuerdo a las respuestas recibidas. En el caso de fiscales y defensores se recurrió, en primer lugar, a personas conocidas por el investigador responsable en las distintas oficinas regionales y luego se pudo acceder a otros por medio de referencias. En el caso de los abogados, se buscó identificar abogados de distintos perfiles de ejercicio profesional conocidos por el investigador principal. El acceso más problemático se dio con los funcionarios policiales. Tratándose de Carabineros se pudo acceder por contactos personales a los entrevistados. En el caso de la PDI se dirigió una carta a las autoridades institucionales y no se recibió una respuesta formal, sino el contacto desde una unidad especializada de investigación.

Las entrevistas fueron realizadas individualmente por el investigador responsable (26 entrevistas, $51 \%$ del total) o los ayudantes del proyecto $(25,49 \%$ del total). Los actores involucrados son todos funcionarios de sus respectivas instituciones que se desempeñaban a la fecha de la entrevista en la Región Metropolitana, aún cuando varios tenían experiencia previa en otras regiones del país.

La selección de los entrevistados se hizo intentando buscar diversidad de experiencias en atención a las diferenciase en las prácticas que se pueden observar en distintas zonas de la Región Metropolitana. Para ello entonces se intentó cubrir distintas jurisdicciones en cada rol y diversidad de género. Tratándose de los fiscales, los entrevistados pertenecen a tres de las cuatro fiscalías regionales metropolitanas (cuatro de la Centro Norte, seis de la Oriente 
Polít. crim. Vol. 12, № 23 (Julio 2017), Art. 9, pp. 291-379.

[http://www.politicacriminal.cl/Vol_12/n_23/Vol12N23A9.pdf]

y tres de la Sur). En el caso de los defensores ellos forman parte de las dos unidades regionales de la Región Metropolitana (cinco de la Norte y tres de la Sur). Los jueces de garantía y de juicio oral corresponden a ocho juzgados diferentes de la Región Metropolitana en cada categoría. Respecto a los abogados entrevistados, dos llevan adelante ejercicio libre en el área penal y dos trabajan en una institución privada que presta asesorías en la materia. Sólo tratándose de funcionarios policiales existieron dificultades para realizar entrevistas y poder asegurar diversidad. Tratándose de la Policía de Investigaciones, sólo pudimos entrevistar a ocho funcionarios pertenecientes a una misma unidad investigativa especializada. Esto, como he adelantado en el texto principal, podría arrojar un tipo de sesgo. En el caso de Carabineros se logró contar con dos entrevistas solamente, por debajo de lo que originalmente se planteaba en la investigación.

En cuanto a las características de género de los entrevistados, 17 de ellos, es decir, un $33,3 \%$ correspondió a mujeres y $34(66,6 \%)$ hombres. Por categorías, la menor presencia de mujeres se dio en los funcionarios policiales en donde ellas fueron un $20 \%$ de la muestra. En cambio, tratándose de jueces de juicio oral, ellas representaron el $50 \%$ de los entrevistados. 